\title{
Umbilical artery blood flow velocity waveforms and placental vascular resistance : a study in fetal lambs
}

Citation for published version (APA):

van Huisseling, J. C. M. (1990). Umbilical artery blood flow velocity waveforms and placental vascular resistance : a study in fetal lambs. [Doctoral Thesis, Maastricht University]. Datawyse. https://doi.org/10.26481/dis.19901207jh

Document status and date:

Published: 01/01/1990

DOI:

10.26481/dis.19901207jh

Document Version:

Publisher's PDF, also known as Version of record

\section{Please check the document version of this publication:}

- A submitted manuscript is the version of the article upon submission and before peer-review. There can be important differences between the submitted version and the official published version of record. People interested in the research are advised to contact the author for the final version of the publication, or visit the DOI to the publisher's website.

- The final author version and the galley proof are versions of the publication after peer review.

- The final published version features the final layout of the paper including the volume, issue and page numbers.

Link to publication

\footnotetext{
General rights rights.

- You may freely distribute the URL identifying the publication in the public portal. please follow below link for the End User Agreement:

www.umlib.nl/taverne-license

Take down policy

If you believe that this document breaches copyright please contact us at:

repository@maastrichtuniversity.nl

providing details and we will investigate your claim.
}

Copyright and moral rights for the publications made accessible in the public portal are retained by the authors and/or other copyright owners and it is a condition of accessing publications that users recognise and abide by the legal requirements associated with these

- Users may download and print one copy of any publication from the public portal for the purpose of private study or research.

- You may not further distribute the material or use it for any profit-making activity or commercial gain

If the publication is distributed under the terms of Article $25 \mathrm{fa}$ of the Dutch Copyright Act, indicated by the "Taverne" license above, 


\section{Umbilical artery blood flow velocity waveforms and placental vascular resistance}

\section{A study in fetal lambs}

PROEFSCHRIFT

ter verkrijging van de graad van doctor aan de Rijksuniversiteil Limburg te Maastricht op gezag van de Rector Magnificus, Prof. Dr. F.I.M. Bonke, volgens het besluit van het College van Dekanen, in het openbaar te verdedigen op vrijdag, 7 december 1990 om 14.00 uur

door

Johannes Caspar Maria van Huisseling 


\section{Promotor:}

Prof. Dr J. de Haan

\section{Copromotor:}

Dr T.H.M. Hasaart

\section{Beoordelingscormmissie:}

Proff; Dr R.S. Reneman, (voorzitter)

Prof. Dr C.E. Blanco,

Prof. Dr P.W. Nathanielsz, Cornell University, Ithaca, NY, USA

Prof. Dr H.J.J. Wellens,

Prof. Dr J.W. Wladimiroff, EUR

CIP-DATA KONINKLIJKE BIBLIOTHEEK, DEN HAAG

Huisseling, Johannes Caspar Maria van

Umbilical artery blood flow velocity waveforms and placental vascular resistance: a study in fetal lambs / Johannes Caspar Mariat van Huisseling. - Maastricht : Datawyse. - III.

Thesis Maastricht. - With ref. - With summary in Dutch. ISBN 90-5291-041-3

SISO 605.5 UDC 618.2+612.64(043.3) NUGI 743

Subject Headings: Doppler velocimetry / placental vascular resistance / umbilical blood flow.

Produktie en layout: Datawyse Maastricht, Ruud Leliveld Druk: Krips Repro Meppel 
Aan Catrien 
"Doppler is the answer, but to what question?

Beattie R.B.and Dornan J.C.,

British Medical Journal 1989;298:631-635 


\section{Voorwoord}

Dit proefschrift kwam tot stand binnen de vakgroep Obstetrie en Gynaecologie van het Academisch Ziekenhuis Maastricht onder leiding van Dr T.H.M. Hasaart en Prof. Dr J. de Haan.

Het onderzoek werd uitgevoerd in het Biomedisch Centrum van de Rijksuniversiteit Limburg te Maastricht.

$V$ an al diegenen die hebben bijgedragen aan het tot stand komen van clit proefschrift wil ik met name bedanken:

Prof. Dr J. de Haan, promotor en opleider, die mij op geheel eigen wijze tot het doen van onderzoek wist aan te zetten en hiertoe alle gelegenheid bood.

Tom Hasaart, copromotor, beste Tom, van jou heb ik veel geleerd, wan het opereren van de schapen tot het schrijven van een proefschrift en al wat daar tussen zit.

De leden van de beoordellingscommissie, Prof.Dr R.S. Reneman, Prof. Dr C.E. Blanco, Prof.Dr P. Nathanielsz, Prof.Dr H.J.J. Wellens en Prof.Dr J.W. Wladimiroff voor het beoordelen van het manuscript.

De medewerkers van de Centrale Proefdier Voorziening van het Biomedisch Centrum, met name May Bost, Joyce Suyk, Frans Slangen en Huib Fransen.

Guido Muijsers, medepromovendus, voor het met raad en daad bijstaan bij de operaties, de experimenten en het schrijven.

Cees Ruissen, voor zijn technische hulp en adviezen.

Louis Peeters, voor zijn kritieken en stimulerende invloed.

Mijn mede-assistenten en ex-mede-assistenten, voor hun daadwerkelijke hulp bij operaties en experimenten, met name "schapenarls' Paul Janssen.

Tenslotte Catrien, voor haar hulp en steun op alle andere fronten. 



\section{Contents}

CHAPTER I Introduction

1.1 Doppler ultrasound

1.2 Flow velocity waveform description

1.3 Blood flow in the fetus

1.4 Vascularization of the placenta

1.5 Placental vascular resistance

1.5.1 Measurement of placental vascular resistance

1.6 The umbilical artery blood velocity waveform and placental vascular resistance

1.7 Potential of umbilical artery velocimetry

1.8 Experimental data on blood velocity waveforms in fetal sheep

1.9 Purpose and outline of the present study

1.10 References

CHAPTER II Umbilical artery flow velocity waveforms during acute hypoxemia and the relationship with hemodynamic changes in the fetal lamb

CHAPTER III Umbilical artery flow velocity waveforms and placental vascular resistance during maternal placental outflow obstruction in sheep

CHAPTER IV Fetal hypertension induced by norepinephrine infusion and umbilical artery flow velocity waveforms in fetal sheep

CHAPTER V Umbilical artery pulsatility index and placental vascular resistance during acute hypoxemia in fetal Jumbs

CHAPTER VI The acute response of the umbilical artery pulsatility index to changes in blood volume in fetal sheep

CHAPTER VII Umbilicoplacental vasculatory responses to norepinephrine and angiotensin II in relation to blood velocity waveforms in the placental circulation in fetal sheep

CHAPTER VIII Summary and conclusions

Samenvatting en conclusies

Curriculum Vitae 


\section{Introduction}

\subsection{Doppler ultrasound}

Doppler ultrasound technology appears to be a promising tool, by which possibly information can be obtained regarding the fetal cardiovascular system. The application of Doppler ultrasound to measure volume blood flow in the fetus was first reported by Gill et al.(1979) for the umbilical vein and by Eik-Nes et al.(1980) for the fetal descending aorta. Since then numerous reports have been published on quantitative blood flow per kg estimated fetal body weight in the intra-abdominal part of the umbilical vein and thoracic descending aorta in normal and complicated pregnancies in the third trimester. However, measurement of volume blood flow in a pulsatile vessel is subject to various problems. The estimation of fetal body weight in utero is subject to potential error (Hill et al.,1986). The angle of insonation of the Doppler ultrasound beam has to be known and the diameter of the vessel under study has to be measured (Eik-Nes et al., 1981). Estimation of mean and maximum blood velocities is a potential source of error depending on the technical set-up. Moreover, a wide distribution in individual volume flow data is reported for the lower part of the fetal descending aorta (Pijpers, 1985). Measurement of volume blood flow in the fetus is thus of little clinical value because of the inherent measurement inaccuracies, comprising a potential error of $35 \%$ for fetal descending aorta volume flow measurements and up to $50 \%$ for the umbilical artery (Erskine and Ritchie, 1985).

In order to avoid the aforementioned problems spectral analysis of the blood flow velocity waveform was introduced, together with the development of ratios extracting information from the velocity signal. The calculation of these ratios is independent from the angle of insonation of the ultrasound beam. These ratios however, provide qualitative information regarding blood velocities in the vessel under study.

FitzGerald and Drumm (1977) first described Doppler frequency shift analysis of blood velocities in the umbilical artery using continuous wave Doppler technology. Audio frequency analysis of the Doppler signals is performed with a spectrum 
analyzer. The spectrum analyzer displays a spectrum of frequencies corresponding with the different red blood cell velocities within the artery, as a function of time. The intensity of the grey scale of the spectrum represents signal amplitude, which corresponds with the number of cells passing at a particular velocity. The maximum frequency outline of the spectrum (envelope) is used to calculate indices, which are supposed to yield information on fetal circulatory dynamics. The forward pressure gradient, produced by the cardiac contraction force, causes a rapid acceleration of the blood cells (McDonald, 1974), which produces the rising slope of the flow velocity waveform (Stuart et al., 1980). The degree of acceleration is also dependent on the viscosity of the blood and the elasticity of the vessel wall (McDonald, 1974). The maximum systolic velocity is reached when the acceleration force switches to deceleration, caused by reversal of the pressure gradient and resulting in the descending slope of the waveform. The end-diastolic velocity and the rate of deceleration are supposed to reflect downstream peripheral vascular resistance (Stuart et al., 1980).

\subsection{Flow velocity waveform description}

It is stressed that with the aforementioned Doppler ultrasound techniques one measures blood velocity. The indices that have been developed to describe the velocity waveform are based on observations rather than theory (Thompson, 1987).

Commonly used indices for description of the umbilical blood velocity waveform are the $A / B$ ratio (or $S / D$ ratio), defined as the maximum systolic value divided by the end-diastolic value (FitzGerald and Drumm, 1977; Stuart et al., 1980), the resistance index (RI), defined as 1 minus end-diastolic value divided by the systolic value (Planiol and Pourcelot, 1974), and the pulsatility index (PI), defined as the maximum systolic frequency minus the minimum diastolic frequency divided by the mean over the cardiac cycle (Gosling and King, 1974). The PI was originally developed to quantitate the arterial pathway capabilities in patients with occlusive peripheral arterial disease (Gosling et al., 1971). The use of the resistance index and the $A / B$ ratio is restricted in case of zero or negative 
end-diastolic flow velocities, since the respective values may become meaningless. The PI, however, can adequately describe these conditions (Ruissen et al, 1987).

In this thesis the pulsatility index will be used as a description of the umbilical artery blood velocity waveform. The methodology of parameter calculation and technical description of the instrumental set-up has been reported earlier by Ruissen et al. (1987), while reliability assessment of Doppler blood velocity waveform measurements in fetal sheep was studied by Muijsers et al. (submitted).

\subsection{Blood flow in the fetus}

In the fetus the systemic, pulmonary and umbilical circulation are connected by several shunts. The umbilical placental circulation is an extra-corporal circulatory system essential for fetal survival and growth, which is discarded at birth. Quantitative information on the fetal circulation is almost entirely obtained in the last trimester of the fetal lamb. The right and left ventricles of the fetal heart work in parallel, because of the existence of the foramen ovale and the ductus arteriosus. Well-oxygenated blood returns from the placenta through the umbilical vein. About $50-55 \%$ of the umbilical venous blood bypasses the liver through the ductus venosus into the inferior vena cava, the rest enters the hepatic vasculature and is partially mixed with portal vein blood in the right liver lobe. The well oxygenated blood from the ductus venosus and left liver lobe streams preferentially across the foramen ovale to the upper body, whereas the less-oxygenated blood is directed through the tricuspid valve to the lower body and the placenta (Edelstone and Rudolph, 1979). During fetal hypoxemia the proportion of blood through the ductus venosus increases, with a concomitant fall in liver flow (Reuss and Rudolph, 1980).

Another unique aspect of the fetal circulation, in contrast to the adult situation, is the relatively high cardiac output, high fetal heart rate and low arterial pressure. Fetal cardiac output is almost exclusively altered by changes in heart rate, since the fetus has little capacity to alter its stroke volume (Rudolph and Heymann, 1974). The fetal heart has been shown to work close to the top of its Frank-Starling curve (Gilbert, 1980). Apart from the high heart rate, blood flow to the fetal tissues 
and placenta will also be dependent on alterations in perfusion pressure and resistance in the various vascular beds (Dawes, 1962; Berman et al., 1976).

\subsection{Vascularization of the placenta}

In the human the two umbilical arteries enter the surface of the chorionic plate and ramify to the placental cotyledons. The arteries perforate the chorionic plate into major stem villi with vessel diameters of $1.5 \mathrm{~mm}$. These vessels ramify into cotyledonary vessels of the second order with a diameter of 1 $\mathrm{mm}$. The cotyledonary vessels curve in the direction of the basal plate, frequently dividing to form the villous branches of the third order. After the definitive architecture of the human placenta is reached at the end of the first trimester, placental growth is characterized by a continuous proliferation of the terminal capillary bed. The placental villous tree, bearing leaf-like chorionic villi, differentiates and grows. The diameters of the vessels increase as does the volume of the chorionic tissue. The surface of the placental villi is surrounded by maternal blood in the intervillous space. Here the exchange of metabolites and oxygen takes place. The proliferation process continues until term, although it is slowed down in the third trimester. A considerable placental reserve capacity is present, since even a $30 \%$ obstruction of the placental vasculature is not necessarily associated with fetal morbidity (Fox, 1986). The venous blood is collected in the umbilical vein (one in the human, two in the sheep), enters the abdomen at the umbilical ring and runs towards the liver to form the ductus venosus and portal sinus.

The macroscopic aspect of the ovine placenta differs considerably from the human placenta. The ovine placenta is composed of 80-100 cotyledons, situated at caruncles, which are distributed all over the endometrial surface. The umbilical arteries branch into major cotyledonary arteries, which in turn divide into minor cotyledonary arteries. Two or three of these smaller vessels supply a cotyledon. Finally, terminal branches are sent off into the villi to supply an extensive capillary plexus. The microvascular anatomy of the sheep fetus is thus grossly similar to the human. At the level of maternal-fetal gas and nutrient exchange however, the sheep has additional layers like maternal capillary endothelium, connective tissue and epithelium (Ramsey and Donner, 1980). 


\subsection{Placental vascular resistance}

Pressure measurements in the vessels of the umbilical circulation in fetal lambs from the distal aorta to the inferior vena cava indicate that the major pressure gradient is constituted in the placental microvasculature which is considered a low resistance pool (Dawes, 1962). Placental vascular resistance decreases from 90 to 115 days of gestation in the fetal lamb, while umbilical blood flow per $\mathrm{kg}$. fetal weight increases. From 115 days onwards placental vascular resistance does not significantly alter. The increase in umbilical blood flow, in order to match fetal growth, is subsequently caused by a gradual rise in blood pressure (Dawes, 1962). A sharp fall in umbilical artery $A / B$ ratio, measured with continuous wave Doppler ultrasound, from 66 days to 109 days of gestation, with no alterations in $\mathrm{A} / \mathrm{B}$ ratio from 109 to 136 days has been reported for the fetal lamb (Newnham et al., 1987). These observations suggest an association between placental resistance and Doppler flow velocity waveform indices.

Since the umbilical arteries are not innervated (Roach, 1973), and not under feedback control (Anderson and Faber, 1984), it is likely that the umbilical circulation is passive and that umbilical blood flow is primarely determined by the arterial-venous pressure difference and placental vascular resistance at a given heart rate. Fetal heart rate has a linear relationship with umbilical blood flow (Rudolph, 1976).

The umbilical circulation however, is sensitive to various vasoactive substances which are important during fetal stress. Catecholamines, angiotensin II and vasopressin do not seem to play an important role in the undisturbed fetus (Rankin and Phernetton, 1978; Edelstone et al., 1980). On the other hand, these substances have been shown to be substantially elevated in cases of fetal stress as hypoxemia (Jones and Robinson, 1975; Lewis et al., 1982; Rurak et al., 1978), hemorrhage (Iwamoto and Rudolph, 1981; Jones et al., 1985), and parturition (Broughton-Pipkin et al., 1977). With respect to placenta] vascular resistance it has been shown that angiotensin II constricts the umbilical artery (Adamson et al., 1989), and that vasopressin increases placental vascular resistance (Irion and Clark, 1990). Adamson et al. showed that the increase in placental vascular resistance upon norepinephrine is situated in the umbilical vein (Adamson et al., 1989).

Some prostaglandins have also been shown to alter umbilical blood flow and increase placental vascular resistance, 
when infused into the fetal circulation (Novy et al., 1974; Berman et al., 1978). On the other hand, prostaglandin synthetase inhibitors do not result in significant changes in placental vascular resistance and umbilical blood flow (Rudolph and Heymann, 1978) suggesting that prostaglandins do not play a significant role in basal umbilical vasomotor tone. Prostaglandins are local hormones with very shortlasting activity and infusion of large quantities may therefore not reflect their physiological significance. Evidence exists that prostaglandins exert their effects on the fetal placental circulation by modulating the action of angiotensin II (Glance et al., 1986). Thromboxane is a potent constrictor of the umbilical circulation and it is suggested that thromboxane is responsible for the obliterative process in the placental microvasculature observed in patients with intra-uterine growth restriction (Trudinger et $a l ., 1988$ ), which is associated with high placental vascular resistance (Giles et al., 1985).

The interactions and interdependencies of the various vasoactive substances with regard to the regulation of the fetal placental circulation, remains to be elucidated. Furthermore it is questionable if the umbilical placental circulation is only passive to pressure changes.

Whether changes in maternal arterial placental inflow and venous outflow pressure would alter umbilical blood flow, according to the "sluice flow" concept (Power and Longo, 1973), is controversial (Thornburg et al., 1976; Berman et al., 1976). On the other hand, Hasaart et al. $(1985,1986,1989)$ have shown the existence of a "sluice flow" concept on the fetal side of the system. Recently Stock et al. (1989) found evidence for matching of maternal and fetal placental blood flow ratios in the sheep and suggested the existence of (a) locally acting regulatory mechanism(s).

Fetal hypoxic stress does not alter umbilical blood flow (Peeters et al., 1979; Rudolph, 1976), as long as heart rate is maintained. Whether or not fetal hypoxemia can alter placental vascular resistance is controversial (Parer et al., 1980; Reuss et al., 1982; Cohn et al., 1985; Yaffe et al., 1987) and appears to depend on the way fetal hypoxemia is imposed and how placental vascular resistance is measured.

In summary, various factors can influence umbilical blood flow, most likely as a result of changes in arterial blood pressure and fetal heart rate. Although several vasoactive sub- 
stances have been proven to increase placental vascular resistance, their exact function in fetal homeostasis and adaptation to stress has not yet been established.

\subsubsection{Measurement of placental vascular resistance}

Calculation of placental vascular resistance is based on the Poisseuille equation: placental vascular resistance $=$ mean arterial pressure minus mean umbilical venous pressure divided by umbilical blood flow.

Some remarks can be made regarding the application of the Poisseuille equation for the fetal placental circulation.

Rudolph made a strong case that the formula is not applicable in case of variations in heart rate. A decrease in umbilical blood flow as a result of a decrease in fetal heart rate, with unaltered blood pressure, does not merely have to reflect an increased placental vascular resistance (Rudolph, 1976). The Poisseuille equation is applied for steady-flow resistance calculations and may be unreliable in a pulsatile flow system (Milnor, 1972). Pulsatile flow and pressure are generated by cardiac contraction and the pulsatility at a given point in the vascular bed is determined by the elasticity of the vessel walls, the distribution of physical properties (length and diameters of the vessels) troughout the vascular bed and the degree of wave reflection. Wave reflections are created by the non-uniform elasticity of the vessels and by the change of vessel diameter and the total cross-section of the bed at each point of branching (McDonald, 1974). Thus, apart from resistance, the reactance of the vascular bed has to be taken into account, which is enclosed in the calculation of vascular impedance. Vascular impedance is the ratio of pulsatile pressure and pulsatile flow and does not have to be the same for all pulse frequencies (Milnor, 1972).

Increased vascular resistance indicates increased dissipation of the energy of blood flow within the vascular bed, although it does not identify the nature, cause or exact site of this increase, since it omits the energy entailed in pulsations (Milnor, 1972). Vascular resistance, in terms of energy dissipation, can only be interpreted if the gravitational and kinetic energies are the same at the outlet as at the inlet of the bed and all the blood that enters the bed leaves it through a single vessel (Milnor, 1982). 
The placental vascular bed meets these conditions and in general obeys the Poisseuille equation (Rudolph, 1976).

Another point of concern with regard to placental vascular resistance calculation is the site of measurement of the arterial and venous pressures in the fetal lamb. Mean arterial pressure is commonly measured in the distal abdominal aorta, which is representative of umbilical arterial pressure (Dawes, 1962). Venous pressure can be measured at various sites in the fetus, i.e. in the inferior vena cava, in the umbilical vein close to the umbilical ring and in the umbilical vein close to the placenta. Differences in umbilical venous pressure and inferior vena cava pressure under various conditions may give rise to different outcomes of placental vascular resistance calculations: The hepatic and part of the systemic venous system is added furthermore to the vascular pathway if inferior vena cava pressure is used in this formula. On the other hand, pressure measured in the umbilical vein close to the placenta lacks information on the rest of the umbilical vein, the umbillical sinus and ductus venosus.

In this thesis umbilical venous pressure was measured in a major cotyledonary vein cannulated from the placental site.

\subsection{The umbilical artery blood flow velocity waveform and placental vascular resistance}

Since the first publication of FitzGerald and Drumm (1977), many centres have published their reference values of the applied blood velocity indices (Reuwer et al., 1984,1986; Schulman et al., 1984; van Vugt et al., 1987).

As pregnancy advances the umbillical artery blood velocity indices show a progressive decline, caused by a relative increase in diastolic velocities, in analogy with the decrease in placental vascular resistance throughout gestation in fetal sheep (Dawes, 1962).

It was also observed that low-resistance vascular beds as the umbilical, pregnant uterine and internal carotid are characterized by relatively high diastolic forward velocities, in contrast to the high-resistance vascular bed of for example the femoral artery, in which a period of reversed blood velocity in diastole is observed. The developed indices for describing the blood velocity wavefor, are based on empirical data and statistically elaborated using existing parameters (Thompson, 1987). For example, the pulsatility index was developed by 
analyzing the velocity waveform in such a way that it was sensitive to changes in peripheral vascular resistance (Gosling and King, 1974).

Umbilical artery blood velocity indices have been demonstrated to be elevated in high risk pregnancies complicated by pre-eclampsia and growth-retardation (Reuwer et al., 1987; Trudinger et al., 1985, 1987; Erskine and Ritchie, 1985; Schulman et al., 1984). The increase in the respective indices is attributed to an increase in placental vascular resistance as demonstrated by the reduced end-diastolic velocities. Support for these observations in human pregnancy has been provided by Brosens et al. (1967) who demonstrated that trophoblast invasion of the spiral arteries results in transformation of the spiral arteries into distended, tortuous utero-placental arteries. Absence of the second phase of trophoblast invasion, between 14 to 20 weeks of gestation, has been demonstrated to be associated with development of intra-uterine growth retardation and pre-eclampsia (Brosens et al., 1977; Khong et al., 1986). The effect of utero-placental insufficiency on umbilical blood flow and increased fetal placental vascular resistance with subsequent intra-uterine growth restriction was demonstrated by Clapp et al. (1980), who embolized the uterine circulation with microspheres.

Indirect evidence for a relationship between elevated Doppler velocity indices of the umbilical artery and placental vascular resistance was provided by Giles et al. (1985), McCowan et al. (1987), Bracero et al. (1989) and Fok et al. (1990), who reported a significant reduction or obliteration of the arteries in the tertiary stem villi in placentae of growth-retarded fetuses compared to normal controls. Placental vascular resistance was, for obvious reasons, not measured in these studies and the relationship with elevated velocity indices was assumed. These pathological changes in placentae of growth retarded fetuses have not been reported before in literature and the pathogenesis has not yet been elucidated. Hanretty et al. (1988) and Brar and Platt (1989) described patients in whom previously established absent end-diastolic umbilical artery velocities showed improvement in the course of pregnancy. The thump filter was turned off during the examination and the umbilical cord was examined at five different sites (Brar and Platt, 1989). This suggests that, in contrast to the described placental pathology, other factors may play a role. 


\subsection{Potential of umbilical artery velocimetry}

Longitudinal prospective studies showed no potential in identifying intra-uterine growth retardation by umbilical artery velocimetry, but merely identified fetuses with adverse outcome (van Vugt et al., 1988; Dempster et al., 1989; Chambers et al., 1989; Hastie et al., 1990).

Numerous studies on the use of Doppler ultrasound as a screening test to detect intra-uterine growth retardation failed to prove its value and end with the remark that the proper role of Doppler ultrasound has not yet been assessed and that it should not be rushed into clinical practice (Beattie et al. 1989; Bruinse et al., 1989; Newnham et al., 1990; Hanretty et al., 1989).

The absence of end-diastolic blood velocities in the umbilical artery is generally considered to be a potential hazardous condition to the fetus, which is associated with high morbidity and mortality and according to Woo et al. (1987) and Brar and Platt (1988) immediate intervention is needed. In contrast Rochelson et al. (1987) and Divon et al. (1989) showed that immediate delivery may not be mandatory, but intensive surveillance is justified. Woo suggested that impaired fetal cardiac function also might contribute to absent end-diastolic velocities (Woo et al., 1987).

Screening in low risk populations should be confined to detection of absent diastolic velocities in the umbilical artery and would be beneficial in identifying those fetuses who need more intensive monitoring (Redman, 1989). On the basis of a randomized controlled trial in high-risk pregnancies, it is advocated that umbilical artery velocimetry improves antenatal decision making by recognition of fetal compromise (Trudinger et al., 1987). On the basis of a large randomized controlled trial Omtzigt (1990) advocated intensified fetal monitoring rather than immediate intervention in case of abnormal velocimetry results.

\subsection{Experimental data on blood flow velocity waveforms in fetal sheep}

Umbilical artery waveform indices have been longitudinally assessed by Newnham et al. (1987) and Irion and Clark (1990) in the chronically instrumented fetal sheep. It was 
shown that umbilical artery blood velocity indices decrease with advancing gestation at approximately the same rate as in the human fetus.

Various authors provided evidence that increased velocity indices in the fetus are related to increased vascular resistance downstream at the site of measurement by embolization of the peripheral circulation (Noordam et al., 1987) and umbilical circulation (Trudinger et al., 1987; Morrow et al., 1989; Nimrod et al., 1989; Adamson et al., 1990), although considerable methodological differences were present and some observed alterations were difficult to explain. For example, Trudinger et al. (1987) noted that umbilical artery velocity indices were elevated before placental vascular resistance increased. Adamson et al. (1990) observed no change in the shape of the umbilical artery velocity waveform, when placental vascular resistance was increased 16 -fold by infusion with angiotensin II.

\subsection{Purpose and outline of the present study}

In contrast to the numerous reports on blood flow velocity waveforms in the human fetus, very few studies have been performed in experimental animals under controlled conditions. Experimental evidence for several conclusions and assumptions from human Doppler studies with respect to the fetal umbilical and placental circulation is for the greater part absent.

In this thesis, some aspects of the relationship between fetal and placental hemodynamic variables on the one hand and the umbilical artery blood velocity waveform on the other hand are presented.

The contributions of certain changes in the regulation of the fetal circulation to changes in the PI of the umbilical artery have not been assessed. To evaluate the relationship between the PI of the umbilical artery on one hand and placental vascular resistance and hemodynamic variables such as arterial inflow pressure, venous outflow pressure, umbilical blood flow and fetal heart rate on the other hand, short lasting changes in the fetal circulation were induced by means of artificially produced late decelerations in the fetal heart rate.

Also a study was designed in which acute fetal hypoxemia was induced by occlusion of the maternal common internal 
iliac artery. The fetal hemodynamic response, with regard to placental vascular resistance and the umbilical artery PI, was evaluated.

Supine position in late human pregnancy causes compression of the maternal inferior vena cava and a decrease in intervillous blood flow (Kauppila et al., 1980) and was reported to be associated with elevated umbilical artery $S / D$ ratios, compared to S/D ratios in lateral position (Marx et al., 1986). The hypothesis was tested that compression of the maternal inferior vena cava increased the umbilical artery PI on the basis of increments in placental vascular resistance.

Fetal catecholamine levels are elevated in cases of hypoxic stress (Jones and Robinson, 1975) and are known to cause hypertension (Rankin et al., 1980; Oakes et al., 1980). No data are available on the effect of fetal hypertension on the umbilical artery blood velocity waveform. Whether norepinephrine increases placental vascular resistance is somewhat controversial (Rankin and Phernetton, 1976, Berman et al., 1978, Adamson et al., 1989). The effects of norepinephrine infusion on placental vascular resistance and the umbilical artery PI were studied.

A negative correlation has been reported between the degree of fetal hypoxemia in the human fetus, established in blood samples obtained by cordocentesis and elevated umbilical artery blood velocity indices (Nicolaides et al., 1988; Weiner, 1990). The fetus responds to hypoxemia with a series of cardiovascular changes, based on regional changes in organ vascular resistance. It is presumed that the umbilical circulation is moderately favoured during hypoxemia (Battaglia and Meschia, 1986), although controversy exists if and to what extent fetal hypoxemia may alter placental vascular resistance (Parer et al., 1980; Reuss et al., 1982; Cohn et al., 1985; Yaffe et al., 1987).

In this context the effect of fetal hypoxemia, induced by maternal breathing of a low oxygen gas mixture, on umbilical artery PI and placental vascular resistance was studied.

Changes in blood volume have been shown to affect cardiac output (Gilbert, 1980). Especially hemorrhage of the fetus causes a reduction in cardiac output and hypotension (Schröder et al., 1984). Either increases or no changes in umbilical 
blood velocity indices have been shown to occur in the human fetus upon intravascular transfusion for hemolytic disease (Weiner and Anderson, 1989; Copel et al, 1988). The effects of acute changes in fetal blood volume on the umbilical artery PI were examined. Fetal blood volume was altered by either infusion of $50 \mathrm{ml}$. maternal blood (hypervolemia) or withdrawal of $50 \mathrm{ml}$. fetal blood (hypovolemia).

Angiotensin II and norepinephrine have been shown to play an important role in controlling umbilical vasomotor tone, by constricting the umbilical artery and umbilical vein respectively. (Adamson et al., 1989). The effects of resistance changes in different umbilical placental beds on proximal and distal umbilical artery blood velocity waveforms were assessed. To this end Doppler transducers were placed on the common umbilical artery and a cotyledonary artery. Resistances were changed by intravenous bolus injections of norepinephrine and angiotensin II in the anesthesized fetal lamb.

\section{References}

Adlamson SL, Morrow RJ, Bull SB, Langille BL. Vasomotor responses of the umbilical circulation in fetal sheep. Am J Physiol 1989;256:R105662.

Adamson SL, Morrow RJ, Langille BL, Bull SB, Ritchie JWK. Site-dependent effects of increases in placental vascular resistance on the umbilical artery velocity waveform in fetal sheep. Ultrasound Med Biol 1990; 16:19-27.

Anderson DF, Faber JJ. Regulation of fetal placental blood flow in the lamb. Am J Physiol 1984;247:R567.

Battaglia FC, Meschia G. An introduction to fetal physiology. Academic Press, Orlando, Florida, 1986.

Beattie RB, Dornan JC. Antenatal screening for intrauterine growth retardation with umbilical artery Doppler ultrasonography. Br Med J 1989;298:631-35.

Berman W, Goodlin RC, Heymann MA, Rudolph AM. Relationships between pressure and flow in the umbilical and utorine circulations in sheep. Circ Res 1976;38:262.

Berman jr W, Goodlin RC, Heymann MA, Rudolph AM. Effect of pharmacologic agents on umbilical blood flow in fetal lambs in utero. Biol Neonate 1978;33:225-35.

Bracero LA, Beneck D, Kirshenbaum N, Peiffer M, Stalter P, Schulman H. Doppler velocimetry and placental disease. Am J Obstet Gynecol 1989;161:388-93.

Brar HS, Platt LD Reverse end-diastolic flow velocity on umbilical artery velocimetry in high-risk pregnancies: An ominous finding with adverse pregnancy outcome. Am J Obstet Gymecol 1988;159:559-61. 
Brar HS, Platt LD. Antepartum improvement of abnormal umbilical artery welocimetry: Does it accur? Am ot Obstet Gynecol 1989;160:36-9.

Brosens 1 . Robertson WB, Dixon $H G$. The physiological response of the wessels of the placental bed to normal pregnancy. J Pathol Bacteriol 1967;93:569-79.

Brosens I. Dixon $\mathrm{HG}$, Robertson WB. Fetal growth retardation and the arteries of the placental bed. Br J Obstet Gynaecol 1977,84:656-63.

Broughton-Pipkin F, Symonds EM. Factors affecting angiotensin II concentrations in the human infant at birth. Clin Sci Mol Med 1977;52"44956.

Bruinse HW, Sumons EA, Reuwer PJHM. Clinical value of screening for growth retardation by Doppler ultrasound. J Ultrasound Med 1989; 8.207.9.

Chambers SE, Hoskins PR, Haddad NG, Johnstone FD, McDicken WN, Muir BB. A comparison of fetal abdominal circumference measurements and Doppler ultrasound in the prediction of small-for-dates babies and fetal compromise. Br J Obstet Gynaecol 1989;96:803-8.

Clapp JF, Szeto HH, Larrow $R$, Hewitt J, Mann LI. Umbilical blood flow response ta embolization of the uterine circulation. Am J Obstet Gynecol $1980 ; 138: 60-7$.

Cohn NE, Jackson BT, Piaseckï GJ, Cohen WR, Nowy MJ. Fetal cardiovascular responses to asphyxia induced by decreased uterine perfusion. J Dev Physiol 1985;7:289-97.

Copel JA, Grannum PA, Belanger K, Green JJ, Hobbins JC. Pulsed Doppler flow-velocity waveforms before and after intrauterine intravascular transfusion for severe erythroblastosis fetalis. Am. J Obstet Gynecol 1988;158:768-74.

Dawes GS. The umbilical circulation. Am J Obstet Gynecol 1962;84:163448.

Dempster J, Mires GJ, Patel N, Taylor DJ. Umbilical artery velocity waveforms: poor association with small-for-gestational-age babies. $\mathrm{Br}$ J Obstet Gynaecol 1989;96:692-6.

Divon $M Y_{*}$ Girz BA, Lieblich R, Langer O. Clinical management of the fetus with markedly diminished umbilical artery end-diastolic flow. Am J Obstet Gynecol 1989;161:1523-7.

Edelstone DI, Rudolph AM. Preferential streaming of ductus venosus blood to the brain and heart in fetal lamb. Am J Physiol 1979;237:H724.

Edelstone DI, Merick RE, Caritis SN, Mueller-Heubach E. Umbilical venous blood flow and its distribution before and during autonomic blockade in fetal lambs. Am J Obstet Gynecol 1980;138:703-7.

Eik-Nes SH, Brubakk AO, Ulstein MK. Measurement of human fetal blood flow. Br. Med J 1980;1:283-4.

Eik-Nes $\mathrm{SH}_{i}$ Marsal K, Kristofferson $\mathrm{K}$, Vernersson E. Transcuteneous measurement of human fetal blood flow. Methodological studies. In: Recent advances in ultrasound diagnosis III. Eds. Kurjak A, Kratochwil A. Excerpta Medica Amsterdam 1981,pp 209-19.

Frskine RLA, Ritchie JWK. Quantitative measurement of fetal blood flow using Doppler ultrasound. Br J Obstet Gynaecol 1985;92:600-4.

Erskine RLA, Ritchie JWK. Umbilical artery blood flow characteristics in normal and growth-retarded fetuses. Br JObstet Gynaecol 1985;92:605 610. 
FitzGerald DE, Drumm JE. Non-invasive measurement of human fotal circulation using ultrasound: a new method Br Med J 1977,2:1450-1.

Fok RY, Pavlova Z, Benirschke $K$, Paril RH, Platt LA. The correlation of arterial lesions with umbilical artery Doppler velocimetry im placentas of small-for-dates pregnancies. Obstet Gynecol 1990;75:578-83.

Fox H. Pathology of the placenta. Clin Obstet Gynecol 1986;13:501-19.

Gilbert RD. Control of the cardiac output during changes in blood volume. Am J Physiol 1980;238:H80-6.

Giles WB, Trudinger $\mathrm{B}$ J, Baird $\mathrm{PJ}$. Fetal umbilical artery flow velocity waveforms and placental resistance: pathological correlation. $\mathrm{Br} J$ Obstet Gynaecol 1985;92:31-8.

Gill RW. Pulsed Doppler with B-mode imaging for quantitative blood flow measurement. Ultrasound Med Biol 1979;5:222-35.

Glance $\mathrm{DG}_{3}$ Elder MG, Myatt L. The actions of prostaglandins and their interactions with angiotensin II in the isolated perfused human placental cotyledon. Br J Obstet Gynaecol 1986;93:488-94.

Gosling $\mathrm{RG}$, Dunbar $\mathrm{G}$, King $\mathrm{DH}$, et al. The quantitative analysis of occlusive peripheral arterial disease by a non-intrusive ultrasonic technique. Angiology 1971;22:52-5.

Gosling RG, King DH. Continuous wave ultrasound as an alternative and complement to X-rays in vascular examinations. In: Cardiovascular applications of ultrasound. Ed. Reneman RS, North-Holland/American Elsevier, New York 1974, pp 266-82.

Hanretty KP, Whittle MJ, Rubin PC. Reappearance of end diastolic velocity in a pregnancy complicated by severe pregnancy induced hyperten. sion. Am J Obstet Gynecoll 1988;158:1123-4.

Hanretty KP, Primrose MH, Neilson JP, Whittle MJ Pregnancy screening by Doppler uteroplacental and umbilical artery waveforms. Br f Obstet Gynaecol 1989;96:1163-67.

Hasaart THM, de Haan J. Depression of uterine blood flow during total umbilical cord occlusion in sheep: Eur J Obstet Gynecol Reprod Biol $1985 ; 19: 125-31$.

Hasaart THM, de Haan J, Horiguchi T. Effect of selective occlusion of the umbilical arteries and/or veins on umbilical blood flow in sheep. Eur d Obstet Gynecol Reprod Biol 1986;21:53-60.

Hasaart THM, de Haan w, Horiguchi. Uterine vascular resistance during compression of the umbilical arterial and/or venous circulation in sheep. Eur J Obstet Gynecol Reprod Biol 1989;33:39-47.

Hastie SJ, Howie CA, Whittle MJ, Flemming JEE, Rubin PC. Umbilical artery blood velocity waveform analysis in predicting the small-fordates fetus. Eur J Obstet Gynecol Reprod Biol 1990;35:35-39.

Hill LM, Breckie R, Wolfgram KR, O'Brien PC. Evaluation of three methods for estimating fetal weight. o Clin Ultrasound 1986;14:171. 176.

Irion $\mathrm{GL}$, Clark KE. Direct determination of the ovine fetal unbilical artery blood flow waveform. Am J Obstet Gynecoll 1990;162:541-9.

Iwamoto $\mathrm{HS}$, Rudolph $\mathrm{AM}$. Role of renin-angiotensin system in response to hemorrhage in fetal sheep. Am J Physiol 1981;240:H848-54.

Jones CM, Rose JC, Randall KT, Hargrave BY. Catecholamine responses in fetal lambs subjected to hemorrhage. Am ol Obstet Gynecol 1985; 151.475-78. 
Wones CT, Robirison RO. Plasma catecholamines in fetal and adult sheep. J Physiol 1975;248:15-33.

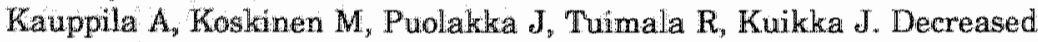
intervillous and unchanged myometrial blood flow in supine recumbeney. Obstetrics and Gynecology 1980;55:203-5.

Khong TY, de Wolf $\mathrm{F}$, Robertson WB, Brosens I. Inadequate maternal vascular response to placentation in pregnancies complicated by preedampsia and by small-for-gestational infants. Br J Obstet Gynaecol $1986 ; 93 \times 1049-59$.

Lewis $A B$, Evans WN, Sischo W. Plasma catecholamine responses to hypoxemia in fetal lambs. Biol Neonate 1982;41:115-22.

Marx GF, Patel S, Berman JA, Farmakides G, Schulman H. Umbilical blood flow velocity waveforms in different maternal positions and with epidural analgesia. Obstetrics and Gynecology 1986;68:61-4.

McCowan LM, Mullen BM, Ritchie $K$. Umbilical artery flow velocity waveforms and the placental vascular bed. Am J Obstset Gynecol $1987 ; 157: 900 \times 2$.

MeDonald DA. Blood flow in arteries. 2nd edition. Ed. Edward Arnold Publishers Ltd, London, 1974.

Milnor WR. Pulsatile blood flow. N Engl J Med 1972;287:27-34.

Milnor WR. (1982) Hemodynamics. Williams and Wilkins, Baltimore, USA pp. 30-31.

Morrow RJ, Adamson SL, Bull SB, Knox Ritchie JW. Effect of placental ermbolization on the umbilical arterial velocity waveform in sheep. Am J Obstet Gymecol 1989;161:1055-60.

Muijsers GJJM, Ruissen CJ, Kaesemann $\mathrm{H}$, Jager WA, van Huisseling $\mathrm{H}$, Hasaart WHM. Methodology and reliability assessment of Doppler blood velocity waveform measurements in fetal sheep. (submitted for publication)

Newnham JP, Kelly RW, Roberts RV, Macintyre M, Speijers J, Johnson $\mathrm{T}$, Reid SE. Fetal and maternal flow velocity waveforms in normal sheep pregnancy. Placenta 1987;8:125-36.

Newnham JP, Patterson LL, James IR, Diepeveen DA, Reid SE. An evaluation of the efficacy of Doppler velocity waveform analysis as a screening test in pregnancy. Am J Obstet Gymecol 1990;162:403-10.

Nicolaides KH, Bilardo CM, Soothill PW, Campbell S. Absence of end diastolic frequencies in umbilical artery: a sign of fetal hypoxia and acidosis. Br Med J 1988;297:1026-7.

Nimrod C, Clapp III J, Larrow R, D'Alton M, Persaud D. Simultaneous use of Doppler ultrasound and electromagnetic flow probes in fetal flow assessment. J Ultrasound Med 1989;8:201-5.

Noordam MJ, Wladimiroff $J W$, Lotgering FK, Struijk PC, Tonge HM. Fetal blood flow velocity waveforms in relation to changing peripheral vascular resistance. Early Human Development 1987;15:119-27.

Novy MJ, Piasecki $G$, Jackson BT. The effect of PGE2 and PGF2alpha on the umbilical circulation. Prostaglandins 1974;5:543-55.

Oakes GK, Ehrenkranz RA, Walker AM, McLaughlin MK, Brennan SC, Chez RA. Effect of alpha-adrenergic agonist and antagonist infusion on the umbilical and uterine circulations of pregnant sheep. Biol Neonate $1980 ; 38: 229-37$.

Omtzigt AWJ. Clinical value of umbilical Doppler velocimetry. A randomized controlled trial. Thesis, Utrecht, 1990. 
Parer JT, Krueger TR, Harris JL. Fetal oxygen consumption and mecham nisms of heart rate response during artificially produced late decelerations of fetal heart rate n sheep Am J Obstet Gymeol 1980;136:478-82.

Peeters LiLH, Sheldon RE, Jones dr MD, Makowski ISI, Mescha G. Blood flow to fetal organs as a function of arterial oxygen content. Am a ODst. Gynecol $1979 ; 135: 637-46$.

Pijpens L. Blood flow in the human fetal descending aorta. A pulsed Doppler study. Thesis, Rotterdam, 1985.

Power GG, Longo LD. Sluice flow in the placenta: maternal vascular pressure effects on fetal circulation. Am I Physiol 1973;225(6):1490-6.

Planial TH, Pourcelot $L$. Doppler effect study of the carotid circulation. In: Vlieger M, White DN, McCready VR (eds); Ultrasonics in medecine. Excerpta Medica, Amsterdam, 1974.

Ramsey EM, Donner MW. Placental vasculature and circulation. Georg Thieme Publishers, Stuttgart, 1980.

Rankin JHG, Phernetton TM. Alpha and angiotensin receptor tone in the near-term sheep fetus. Proc Soc Exp Biol Med 1978;185:166-9.

Rankin JHG, Stock MK, Anderson DF. Fetal heart rate and umbilical blood flow. J Dev Physiol 1980;2:11-6.

Redman CWG. Examination of the placental circulation by Doppler ultrasound. Br Med J 1989;298:621-2.

Reuss ML, Parer JT, Harris JL, Krueger TR. Hemodynamic effects of alpha-adrenergic blockade during hypoxia in fetal sheep. Am J Obstet Gynecol 1982;142:410-15.

Reuwer PJHM, Bruinse HW, Stoutenbeek P, Haspels AA. Doppler assesment of the fetoplacental circulation in normal and growth-retarded fetuses. Eur J Obstet Gynaecol Reprod Biol 1984;18:199-205.

Reuwer PJHM. Doppler assessment of feto-placental circulatory competence. Thesis, Utrecht, 1986.

Reuwer PJHM, Rietman GW, Sijmons EA et al. Intra-uterine grow th retardation: Prediction of perinatall distress by Doppler ultrasound. Lancet $1987 ;$ ii:415-18.

Roach MJ. (1973) A biophysical look at the relationship of structure and function in the umbilical artery. In: Foetal and Neonatal Physiology: Proc. Barcroft Centenary Symp. Eds: RS Comline, KW Cross, Dawes GS, Nathanielsz PW. Cambr. Univ. Press, London, pp $141-163$.

Rochelson B, Schulman H, Farmakides G, Bracero L, Ducey J, Fleischer A. Penny B, Winter D. The significance of absent end diastolic velocity in umbilicl artery velocity waveforms. Am J Obstet Gymecol 1987; 156:1213-8.

Rudolph AM, Heymann MA. Hemodynamic changes induced by blockers of prostaglandin synthesis in the fetal lamb in utero. In: Advances in prostaglandin and thromboxane research. Vol.4. Eds: F. Coceani, P.M. Olley. Raven Press NY, 1987, pp 231-37.

Rudolph AM, Heymann MA. Fetal and neonatal circulation and respiration. Ann Rev Physiol 1974;36:187.

Rudolph AM. Factors affecting umbilical blood flow in the lamb in utero. In: Proceedings of the 5 th European congress of Perinatal Medicine, Uppsala, Sweden, 1976:159-72.

Ruissen CJ, van Vugt JMG, Hoogland HJ, Hoeks APG, de Haan J. Technical aspects of fetal Doppler measurements. Gynecol Obstet Invest $1987 ; 24: 1-13$. 
Murak DW. Plasma vasopressin levels during hypoxemia and the cardiovascular effects of exogenous vasopressin in foetal and adult sheep. if Physiol (London) 1978:277:341-57.

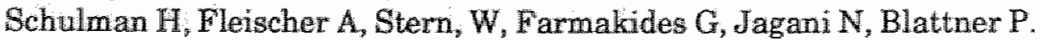
Umbilical velocity wave ratios in human pregnancy. Am J Obstet Gynaecol 1984;148:985-90.

Schioder H, Gibert RD, Power GG: Urinary and hemodynamic responses to blood volume changes in fetal sheep. I Dev Physiol 1984;6:131-41.

Stock MK, Reid DL, Phernetton TM, Rankin JHG. Matching of maternall and fetal flow ratios in the sheep placenta. J Dev Physiol 1989;11:29-35.

Stuart B, Drumm J, FitzGerald DE, Duignan NM. Fetal blood velocity waveforms in normal pregnancy. Br J Obstet Gymaecol 1980;87:780-5.

Thompson RS. Blood velocity waveforms. Seminars in perinatology 1987; 11:300-10.

Thornburg KL, Bissonnette JM, Faber JJ. Absence of placental waterfall phenomenon in chronically prepared fetal lambs. Am. J Physiol 1976; $230(4): 886$.

Trudinger BJ, Giles WB, Cook CM, Bombardieri J, Collins L. Fetal umbilical artery flow vellocity waveforms and placental resistance: clinical significance. Br J Obstet Gynaecol 1985;92:23-30.

Trudinger BJ, Cook CM, Giles WB, Connelly A, Thompson RS. Umbilical artery flow velocity waveforms in high-risk pregnancy. Randomized controlled trial. Lancet 1987; i:188-90.

Trudinger BJ, Stevens D, Connelly A, Hales JRS, Alexander G, Bradley $\mathrm{L}$, Fawcett A, Thompson RS. Umbilical artery flow velocity waveforms and placental resistance: The effects of embolization of the umbilical circulation. Am J Obstet Gynecol 1987;157:1443-48.

Trudinger BJ, Cook CM, Thompson RS, Giles WB, Connelly A. Low-dose aspirin therapy improwes fetal weight in umbilical placental insufficiency. Am J Obstet Gynecol 1988;159:681-5.

van Vugt JMG, Ruissen CJ, Hoogland HJ, de Haan J. A prospective study of the umbilical artery waveform in appropriate-for-date and growthretarded fetuses. Gynecol Obstet Invest 1987;23:217-25.

van Vugt JMG, Ruissen CJ, Schouten HJA, Theunissen M, Hoogland $\mathrm{H}_{\text {, }}$ de Haan $\mathrm{J}$. Umbilical artery velocimetry: a prospective longitudinal study in search of the intrauterine growth-retarded fetus. Early Hum Dew 1988;18:59-71.

Weiner CP, Anderson TL. The acute effect of cordocentesis with or without fetal curarization and of intravascular transfusion upon umbilical artery waveform indices. Obstet Gynecol 1989;73:219-24.

Weiner CP. The relationship between the umbilical artery systolic/diastolic ratio and umbilical blood gas measurements in specimens obtained by cordocentesis. Am. J Obstet Gynecol 1990;162:1198-1202.

Woo JSK, Liang ST, Lo RLS. Significance of an absent or reversed diastolic flow in Doppler umbilical artery waveforms. I Ultrasound Med 1987; $6: 291-7$.

Yaffe H, Parer JT, Bllock BS, Llanos A.J. Cardiorespiratory responses to graded reductions of uterine bloodflow in the sheep fetus. J Dev Physiol $1987 ; 9: 325-36$. 


\section{Umbilical artery flow velocity waveforms during acute hypoxemia and the relationship with hemodynamic changes in the fetal lamb}

Hans van Huisseling, Tom H.M. Hasaart, Cees $J$. Ruissen, Guido J.J.M. Muijsers and Jelte de Haan

American Journal of Obstetrics and Gynecology $1.989 ; 161: 1061-4$

\section{Abstract}

The contribution of the various variables of the fetal circulation to changes in the Pulsatility Index (PI) of the umbilical artery flow velocity wave form has not yet been assessed. Acute fetal hypoxemia was induced by 60 to 90 seconds of total occlusion of the maternal common internal iliac artery in 6 sheep. Mean fetal pO2 decreased from 26.0 to $18.3 \mathrm{mmHg}$ $(p<0.01)$ after occlusion of uterine blood flow. Fetal heart rate decreased from 188 to 121 beats per minute at the end of occlusion $(\mathrm{p}<0.05)$. Placental vascular resistance did not change during the heart rate deceleration. The PI increased from 0.86 during control period to 1.27 at the end of occlusion $(p<0.05)$. After fetal parasympathetic blockade with atropine fetal heart rate and placental vascular resistance did not change during occlusion. The PI did not change during occlusion after parasympathetic blockade. It is concluded that the changes in the umbilical artery PI during late decelerations in the fetal heart rate pattern appear to be primarily associated with changes in fetal heart rate and bear no relationship with placental vascular resistance. 


\section{Introduction}

The use of Doppler ultrasound technology for the description of umbilical artery flow velocity waveforms is becoming a routine measurement in obstetrical practice. For the description of the flow velocity waveform of the umbilical artery indices are used, which, according to some authors $(1,2,3)$, reflect changes in placental vascular resistance. These indices, e.g. the $\mathrm{A} / \mathrm{B}$ ratio, (maximum frequency/minimum frequency), or the P(ulsatility) I(ndex) ((maximum frequency minimum frequency)/mean frequency), are slope-independent arithmetical descriptions of the blood velocity spectra (4). The PI is considered to be the most practical of these indices, since the $\mathrm{A} / \mathrm{B}$ ratio becomes infinite with end-diastolic zero- or backflow. These factors have little influence on the PI (5).

The aim of the clinical application of Doppler measurements is to detect fetal compromise and/or intra-uterine growth retardation as early as possible. There is evidence that placental vascular resistance is increased in intrauterine growth retardation (3). Increased blood velocity waveform indices of the umbilical artery have also been reported in cases of fetal growth retardation $(6,7)$. However, in a recent prospective longitudinal study umbilical artery velocimetry proved to have little predictive value with regard to intrauterine growth retardation (8). At present, information with respect to those fetal hemodynamic variables which covary with the PI in the umbilical artery is still scarce. In recent reports animal studies are recommended in order to fill the gaps in our knowledge of the physiological and pathophysiological background of the flow velocity waveform in fetal vessels $(9,10)$.

The aim of this study was to evaluate the relationship between the pulsatility index of the umbilical artery on the one hand and placental vascular resistance and hemodynamic variables such as arterial inflow pressure $(\mathrm{Pa})$, venous outflow pressure (Puv), umbilical venous blood flow (QUV) and fetal heart rate (FHR) on the other. To this end we induced changes in the fetal circulation by means of artificially produced late decelerations in the fetal heart rate $(11,12)$. 


\section{Material and methods}

\section{Surgery}

The experiments were carried out in 6 ewes of the Dutch Texel breed, between 100 days and 130 days of gestation (term 147 days). Surgical instrumentation was carried out under aseptic conditions and general anesthesia, induced with pentobarbital and maintained with $5 \%$ halothane in $2: 1$ mixture of nitrous oxide and oxygen. The ewe received 1 gram of ampicillin $i . v$. before operation. The abdomen was opened through a paramedian incision.

An inflatable balloon occluder was placed around the maternal common internal iliac artery. The fetal lambs were approached by hysterotomy in the uterine wall lying over the fetal pelvis. An electromagnetic flow transducer was placed around the intra-abdominal common part of the umbilical veins (13). An inflatable balloon occluder was placed around the umbilical cord for in vivo zero blood flow calibration. Fetal instrumentation involved the insertion of a catheter in the femoral artery advanced into the distal aorta at the level of the umbilical arteries for registration of fetal arterial pressure, which is representative of umbilical arterial pressure (14). Electrodes for recording of fetal heart rate were placed. A catheter was inserted into a major umbilical vein through a cotyledonary vein for the measurement of umbilical venous pressure. Finally, an intra-amniotic catheter was left in the uterine cavity to allow intra-uterine pressure measurement. All catheters and electrodes were exteriorized through a skin incision in the ewe's flank. The guidelines for the care and use of the animals approved by the local institution, were followed.

\section{Measurements}

Blood flow in the common umbilical vein was measured with a Skalar transflow 601 flowmeter system (Skalar Delft, Holland). Fetal arterial blood pressure, umbilical venous pressure and intraamniotic fluid pressure were determined with the zero point at the level of the ewe's spine. All signals were led to amplifiers (Hewlett Packard 8800 series), displayed on a monitor and an eight-channel strip chart recorder, stored on magnetic tape, digitised and analysed with a computer. In the first three fetal lambs the umbilical artery flow velocity waveforms were obtained externally with a $4 \mathrm{MHz}$ continuous wave Doppler transducer (Delalande, $250 \mathrm{~Hz}$ high pass filter) placed on the ewe's abdomen with the ewe in a semirecumbent posi- 
tion. Optimal beam position in the continuous wave Doppler measurements was achieved by ear, aided by the display of the frequency profile on the monitor of a spectrum analyzer (Doptek). In the next three fetal lambs a $5 \mathrm{MHz}$ implantable pulsed wave Doppler device with a diameter of 3 millimeters was used, which was positioned in a polyvinyl cuff under a $45^{\circ}$ angle and placed around one of the umbilical arteries of the fetal lamb. The umbilical arteries were dissected free at the abdominal entry of the cord. The polyvinyl cuff was fixed around one of the arteries and the device was covered again with the dissected layer of Wharton's jelly. The Doppler shift signals were stored in quadrature on analog tape, synchronously with the electromagnetic flow measurements, fetal arterial pressure, umbilical venous pressure and fetal heart rate for off-line analysis.

\section{Experiments}

The animals were allowed to recover for at least three days after surgery. Gestational age at the time of the experiments was between 103 and 133 days. Total maternal common internal iliac artery occlusions of 60-90 seconds duration were performed by inflating the balloon occluder with saline. Immediately before and after the occlusion a fetal arterial blood sample was withdrawn for analysis of fetal acid-base balance. In 6 anima $]_{\mathrm{s}}$, a total of 5 occlusions in each animal was performed with intact autonomic nervous system ( $n=6$, group 1), whereas in 5 animals belonging to the same group of animals with intact autonomic nervous system, a total of 4 occlusions in each animal was performed after cholinergic blockade with atropine $(n=5$, group II). Cholinergic blockade was established before the control measurement by injecting $1 \mathrm{mg}$. atropine per kilogram estimated fetal weight intra-arterially, in order to prevent decelerations of the FHR during occlusion. The atropine treatment was repeated every 20 minutes to ensure complete parasympathetic blockade throughout the experimental period.

\section{Calculations and data analysis}

The mean values for the hemodynamic variables were assessed during a 10 second period, 40 seconds before occlusion (control period), a 10 second period at the end of occlusion and a 10 second period 60 seconds after occlusion. Mean umbilical artery PI was calculated for 5 consecutive heart cycles which occurred during these intervals of 10 seconds. A period of at 
least 5 minutes was taken prior to the next occlusion in order to allow the fetus to recover. Placental vascular resistance was defined as the ratio of the difference in fetal arterial inflow pressure and venous umbilical outflow pressure and the umbilical blood flow (Resistance $=(\mathrm{Pa}-\mathrm{Puv}) / \mathrm{QUV})$.

Mean values, standard deviations and standard errors of the mean were computed for each variable from the control measurements 40 seconds before occlusion, at the end of occlusion and 60 seconds after occlusion for each series of occlusions per animal. The mean values of the occlusions per animal were grouped for each variable $(n=6$ animals in group $I$ and $n=5$ animals in group II). Statistical analysis was then performed on the pooled mean values from each animal by comparing the control values before occlusion with the values at the end of occlusion and with the values during the post-occlusion respectively, by means of Wilcoxon's matched-pairs signedranks test. A p-value of less than 0.05 was taken to represent statistical significance. Throughout the text mean values are given with the SEM. The blood gas values before and after occlusion were tested by a paired Student's t-test. The blood gas values are expressed as mean $\pm \mathrm{SD}$.

\section{Results}

Uterine blood flow obstruction resulted in a decrease in fetal $\mathrm{pO}_{2}$ from $26.0 \pm 6.3 \mathrm{mmHg}$ to $18.3 \pm 5.7 \mathrm{mmHg}$ after occlusion $(\mathrm{p}<0.01)$, while $\mathrm{pCO}_{2}$ increased from $42.2 \pm 4.5$ $\mathrm{mmHg}$ to $45.8 \pm 4.5 \mathrm{mmHg}(\mathrm{p}<0.01)$.

Fetal $\mathrm{pH}$ did not change before and after occlusion, $7.33 \pm$ 0.07 and $7.31 \pm 0.06$ respectively.

\section{A. Intact autonomic nerve system}

Table I summarizes the mean values \pm SEM of the measured parameters, sampled during the 10 second periods before, during and after occlusion of the maternal common iliac artery in group I. The mean FHR in the steady state period before occlusion was $188 \pm 6.1$ beats per minute (bpm), decreased to $121 \pm 10.0 \mathrm{bpm}$ at the end of occlusion $(\mathrm{p}<0.05)$ and increased to $164 \pm 10.6 \mathrm{bpm}$ one minute after occlusion. Fetal placental perfusion pressure (fetal arterial pressure minus 
Table l: Fetal hemodynamic variables in relation to occlusion of the maternal combnon interval iliac artery.

\begin{tabular}{|c|c|c|c|}
\hline $\begin{array}{l}\text { Mean } \pm S E M \\
(n=6)\end{array}$ & Control & Occlusion & Posti-acclusion \\
\hline Fetal heart rate (bpm) & $188 \pm 6.1$ & $121 \pm 10.0 *$ & $164 \pm 10.6$ \\
\hline Placental perfusion pressure $(\mathrm{mmHg})$ & $35.8 \pm 5.1$ & $36.3 \pm 6.0$ & $41.5 \pm 6.8^{*}$ \\
\hline Umbilical blood flow (mi min $\left.{ }^{-1}\right)$ & $425 \pm 42.4$ & $445 \pm 44.9$ & $448 \pm 46.9$ \\
\hline $\begin{array}{l}\text { Placental wascular resistance } \\
\qquad\left(\mathrm{mmHg} \cdot \mathrm{ml}^{-1}, \mathrm{~min}\right)\end{array}$ & $0.083 \pm 0.01$ & $0.078 \pm 0.01$ & $0.090 \pm 0.01$ \\
\hline Pulsatility Index & $0.86 \pm 0.04$ & $1.27 \pm 0.02 *$ & $0.87 \pm 0.03$ \\
\hline
\end{tabular}

$* p<0.05$ compared with control value (Wilcoxon's matched pairs signed-ranks test)

umbilical venous pressure) did not change during occlusion but increased from $35.8 \pm 5.1 \mathrm{mmHg}$ to $41.5 \pm 6.8 \mathrm{mmHg}$ after occlusion $(\mathrm{p}<0.05)$.

The increase in umbilical venous blood flow from $425 \pm 42.2$ ml.min ${ }^{-1}$ to $445 \pm 44.9 \mathrm{ml} . \mathrm{min}^{-1}$ during occlusion was not significant. One minute after occlusion blood flow was $448 \pm$ $46.9 \mathrm{ml} . \mathrm{min}^{-1}$. Placental vascular resistance did not change during occlusion as compared to control value, $0.083 \pm 0.01$ $\mathrm{mmHg} \cdot \mathrm{ml}^{-1} \cdot \mathrm{min}$ and $0.078 \pm 0.01 \mathrm{mmHg} \cdot \mathrm{ml}^{-1}$. $\min$ respectively. Umbilical artery PI increased from $0.86 \pm 0.04$ to $1.27 \pm$ 0.02 during occlusion $(\mathrm{p}<0.05)$ and returned to control value after occlusion $(0.87 \pm 0.03)$.

\section{B. Parasympathetic blockade}

Table II summarizes the results after cholinergic blockade. FHR was $215 \pm 15.9 \mathrm{bpm}$ before occlusion and $211 \pm 8.4 \mathrm{bpm}$ during occlusion. After occlusion FHR increased to $240 \pm 14.5$ bpm $(\mathrm{p}<0.05)$. Fetal placental perfusion pressure did not change during occlusion but increased from $42.1 \pm 6.2 \mathrm{mmHg}$ during control to $48.2 \pm 6.9$ after occlusion ( $p<0.05$ ). Umbilical venous blood flow increased from $495 \pm 51.6 \mathrm{ml}^{-1} \mathrm{~min}^{-1}$ to 534 $\pm 58.5 \mathrm{ml} \cdot \mathrm{min}^{-1}$ during occlusion $(\mathrm{p}<0.05)$ and was still elevated one minute after occlusion at $528 \pm 53.2 \mathrm{ml} . \mathrm{min}^{-1}(\mathrm{p}$ $<0.05$ ). Placental vascular resistance did not change: $0.093 \pm$ $0.01 \mathrm{mmHg} \cdot \mathrm{min} \cdot \mathrm{ml}^{-1}$ before occlusion, $0.091 \pm 0.01 \mathrm{mmHg}$. $\min . \mathrm{ml}^{-1}$ during occlusion and $0.098 \pm 0.01 \mathrm{mmHg} \cdot \mathrm{min} . \mathrm{ml}^{-1}$ in 
Table H: Fetal hemodynamic variables in relation to occhusion of the maternal common internal iliac artery after atropine administration to the fews

\begin{tabular}{|c|c|c|c|}
\hline $\begin{array}{l}\text { Mean }+S E M \\
(n=5)\end{array}$ & Control & Occlusion & Post-octlusion \\
\hline Fetal heart rate (bpm) & $215 \pm 15.9$ & $211 \pm 8.4$ & $240 \pm 14.5 *$ \\
\hline Placental pertiusion pressure ( $\mathrm{mmH}$ (g) & $42.1 \pm 6.2$ & $44.8 \pm 6.4$ & $48.2 \pm 6.9 *$ \\
\hline Umbilical blood flow (ml.min $\left.{ }^{-1}\right)$ & $495 \pm 51.6$ & $534 \pm 58.5^{*}$ & $528 \pm 532^{*}$ \\
\hline $\begin{array}{l}\text { Placental vascular resistance } \\
\qquad\left(\mathrm{mmHg} \cdot \mathrm{mi}^{-1} \cdot \mathrm{min}\right)\end{array}$ & $0.093 \pm 0.01$ & $0.091 \pm 0.01$ & $0.098 \pm 0.01$ \\
\hline Pulsatility Index & $0.92 \pm 0.11$ & $0.84 \pm 0.11$ & $0.86 \pm 0.09$ \\
\hline
\end{tabular}

${ }^{*} p<0.05$ compared with control value (Wilcoxon's matched pairs sigmed-ranks test)

the post-occlusion period. The umbilical artery PI showed no significant changes: $0.92 \pm 0.11$ before occlusion, $0.84 \pm 0.11$ during occlusion and $0.86 \pm 0.09$ one minute after occlusion.

During none of the experiments end-diastolic zero flow or backflow was observed in the flow velocity waveform pattern.

\section{Comment}

The aim of this study was to investigate the relationship between the umbilical artery pulsatility index (PI) and various hemodynamic variables and placental vascular resistance of the fetal circulation, during acute short-lasting fetal hypoxemia. This was achieved by 60-90 seconds of obstruction of utero-placental blood flow.

Occlusion of the common internal iliac artery caused a vagal-mediated late deceleration in the fetal heart rate in all of the thirty occlusions with an intact fetal autonomic nervous system.

The fetal heart rate deceleration was accompanied by a significant delayed rise in fetal placental perfusion pressure after occlusion and an insignificant change in umbilical venous blood flow during and after occlusion in the group with intact autonomic nervous system. These findings are in accordance with previous reports $(11,12,15)$. Placental vascular resistance did not change during occlusion nor in the post-occlusion period (Table I). Based on these observations, we con- 
clude that in the group with intact autonomic nervous system, the increase in umbilical artery PI during occlusion is caused by the deceleration of the fetal heart rate.

The vagal-mediated fetal heart rate deceleration during occlusion was blunted by atropine administration to the fetus. The slight increase in umbilical blood flow without a change in heart rate or perfusion pressure during occlusion is probably the result of a statistical aberration produced by the small number of cases $(n=5)$. The subsequent delayed acceleration after occlusion is due to sympathetic activity (11).

The difference in reaction in PI in both groups can be explained by changes in fetal heart rate.

A prolonged cardiac cycle during slower heart rates results in a lower value of end-diastolic frequencies and therefore, in an increase in the PI provided that no major changes in umbilical blood flow occur as was the case in both groups. In the human fetus it has been shown that fetal heart rate and umbilical artery PI are inversely correlated (16).

Whether or not fetal hypoxemia can alter placental vascular resistance remains controversial. Various studies were conducted in which placental vascular resistance was measured using radionuclide labelled microspheres and/or electromagnetic flow meters. Reuss et al. found an increase in placental vascular resistance during fetal hypoxemia, induced by giving a low $\mathrm{O}_{2}$ gasmixture to the ewe (15). No significant changes in placental vascular resistance during late decelerations, produced by short lasting maternal aortic occlusions of 20 seconds, were found by Parer et al. in normoxemic fetal lambs (12). An increase in placental vascular resistance was reported after prolonged uterine flow obstruction (17). A reduction in uterine flow by $50 \%$ during 15 to 20 minutes did not alter placental vascular resistance whereas uterine flow reductions by $75 \%$ caused an increase in placental vascular resistance (18).

It is inferred from the studies mentioned that only prolonged uterine flow obstruction which is associated with severe fetal hypoxemia can trigger an increase in placental vascular resistance. In the present study late decelerations were mimicked by inducing transient fetal hypoxemia by imposing brief uterine flow obstructions.

The experimental data obtained in this study indicate that placental vascular resistance does not change during brief acute transient fetal hypoxemia. Therefore, the observed 
changes in umbilical artery PI in this experimental set-up are not rellated to changes in placental vascular resistance, but to changes in fetal heart rate.

\section{References}

1 Schulman H, Fleischer A, Stern W, Farmakides G, Jagani N, Blattner $P$. Umbilical velocity wave ratios in human pregnancy. Am J Obstet Gynecol 1984;148:985-90.

2 Trudinger BJ, Giles WB, Cook CM, Bombardieri J, Collins L. Fetal umbilical artery flow velocity waveforms and placental resistance: clinical significance. Br J Obstet Gynaecol 1985;92:23-30.

3 Giles WB, Trudinger BJ, Baird PJ. Fetal umbilical artery flow velocity waveforms and placental resistance: pathological correlation. $\mathrm{Br} \mathrm{J}$ Obstet Gynaecol 1985;92:31-38.

4. Gosling RG, Dunbar G, King DH et al. The quantitative analysis of occlusive peripheral arterial disease by a non-intrusive ultrasonic technique. Angiology 1971;22:52-55

5 Ruissen CJ, van Vugt JMG, Hoogland HJ, Hoeks APG, de Haan J. Technical aspects of fetal Doppler measurements. Gynec Obstet Invest 1987;24:1-13.

6 Erskine RLA, Ritchie JWK. Umbilical artery blood flow characteristics in normal and growth-retarded fetuses. Br J Obstet Gynaecol 1985; 92:605-10.

7 Fleischer A, Schulman H, Farmakides G, Bracero L, Blattner P, Randolph $\mathrm{G}$. Umbilical artery velocity waveforms and intrauterine growth retardation. Am J Obstet Gynecol 1985;151:502-5.

8 van Vugt JMG, Ruissen CJ, Hoogland HJ, de Haan J. A prospective study of the umbilical artery waveform in appropriate-for-date and growth-retarded fetuses. Gynaecol Obstet Invest 1987;23:217-25.

9 Nathanielsz PW, Maulik D, Yarlagadda P, Figueroa J. Animal models for the study of maternal-fetal physiology and pathophysiology. In: Maulik D, McNellis D, eds. Doppler ultrasound measurement of maternal-fetal hemodynamics. Perinatology Press, 1987:283-99.

10 Neilson JP. Doppler ultrasound. Br J Obstet Gynaecol 1987;94:929-32.

11 Martin CB Jr, de Haan J, van der Wildt B, Jongsma HW, Dieleman A, Arts THM. Mechanisms of late decelerations in the fetal heart rate. $A$ study with autonomic blocking agents in fetal lambs. Eur J Obstet Gynecol Reprod Biol 1979;9:361-73.

12 Parer JT, Krueger TR, Harris JL. Fetal oxyger consumption and mechanisms of heart rate response during artificially produced late decelerations of fetal heart rate in sheep. Am J Obstet Gynecol 1980; 136:478-82. 


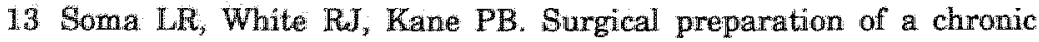
maternal fetal model in pregnant sheep. A technique for the measurement of middle uterine blood flow umbilical blood flow ${ }_{3}$ and fetal ampling in the awake sheep. J Surgical Res $1971 ; 11: 85-94$

14 Dawes GS. The umbilical circulation. Am J Obstet Gynecol 1962; $84: 1634-48$

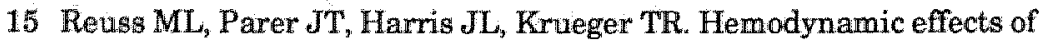
alpha-adrenergic blockade during hypoxia in fetal sheep. Am J Obstet Gynecol 1982;142:410-15.

16 Mulders LGM, Muysers GJJM, Jongsma HW, Nijhuis JG, Hein PR. The umbilical artery blood flow velocity waveform in relation to fetal breathing movements, fetal heart rate and fetal behavioural states in normal pregnancy at 37 to 39 weeks. Early Hum Dev 1986;14:283-93.

17 Cohn NE, Jackson BT, Piasecki GJ, Cohen WR, Novy MJ. Fetal cardiovascular responses to asphyxia induced by decreased uterine perfusion. J Dev Physiol 1985;7:289-97.

18 Yaffe H, Parer JT, Block BS, Llanos AJ. Cardiorespiratory responses to graded reductions of uterine bloodflow in the sheep fetus. J Dev Physiol 1987:9:325-36. 


\section{Umbilical artery flow velocity waveforms and placental vascular resistance during maternal placental outflow obstruction in sheep}

Hans van Huisseling, Tom H.M. Hasaart, Guido *.J.M. Muijsers and Jelte de Haan

Journal of Developmental Physiology 1990;13:93-7

\section{Summary}

This fetal sheep study was designed to test the hypothesis that the Pulsatility Index (PI) of the umbilical artery flow velocity waveform varies as a function of placental vascular resistance. Placental vascular resistance was raised by a one minute occlusion of the maternal inferior vena cava. Occlusion of the maternal inferior vena cava resulted in a decrease in fetal heart rate from $183 \pm 7.8$ beats per minute to $142 \pm 8.6$ beats per minute at the end of occlusion $(p<0.05)$. Placental vascular resistance increased from $0.113 \pm 0.021 \mathrm{mmHg}^{-1}$. min during control to $0.151 \pm 0.033 \mathrm{mmHg}^{-1}{ }^{-1} \cdot \min (\mathrm{p}<0.05)$ during occlusion. The PI increased from $1.05 \pm 0.05$ to $1.85 \pm$ $0.4(p<0.05)$ during occlusion. After parasympathetic blockade with atropine fetal heart rate did not change during occlusion. Placental vascular resistance increased from $0.091 \pm 0.014$ before to $0.121 \pm 0.021 \mathrm{mmHg} \cdot \mathrm{ml}^{-1}$.min during occlusion $(\mathrm{p}<$ 0.05 ). The PI increased from $0.98 \pm 0.1$. before to $1.12 \pm 0.12$ during acclusion $(p<0.05$ ). These results support the hypothesis that, in the fetal sheep, placental vascular resistance is one of the determinants of the PI of the umbilical artery. 


\section{Introduction}

Prewiously published studies of umbilical artery flow velocity waveforms in normal human pregnancy have shown a pattern of high end-diastolic flow velocity relative to the peak systolic velocity $(1,2)$. For the description of the flow velocity waveform several indices are used: 1) the $S / D$ ratio (peak systolic velocity/end-diastolic velocity) and 2) the Pulsatility Index: $\mathrm{PI}$ (peak systolic velocity-least diastolic velocity)/mean velocity $(3,4)$. These indices are believed to reflect downstream vascular resistance of the placental vascular bed $(5,6)$. The umbilical circulation in ovine pregnancy is of low impedance and there is a decrease in resistance of the umbilical circulation with advancing gestation (7). Both human and ovine studies (8) have demonstrated that the PI and the S/D ratio of umbilical artery flow velocities decrease with advancing gestation, possibly indicative of a decrease in placental resistance to flow. Different characteristics of this umbilical artery flow velocity waveform pattern, e.g. decreased or absent enddiastolic flow velocity, may be seen in situations in which the fetus is compromised, as e.g. in severe intrauterine growth retardation due to placental insufficiency $(9,10)$. Experimental evidence in animal models with regard to the relationship between placental vascular resistance and the pattern of the umbilical artery flow velocity waveform has not been well established $(11,12)$. The supine position in late human pregnancy causes compression of the maternal inferior vena cava and a decrease in intervillous blood flow (13). The umbilical artery $\mathrm{S} / \mathrm{D}$ ratio has been reported to be higher with the mother in a supine rather than in lateral position (14).

The purpose of this study was to perform short lasting occlusions of the maternal inferior vena cava to test the hypothesis that the umbilical artery Pulsatility Index varies as a function of placental vascular resistance.

\section{Material and methods}

\section{Surgery}

The experiments were carried out in 6 ewes of the Dutch Texel breed, between 101 and 117 days of gestation (term 147 days). Surgical instrumentation was carried out under aseptic conditions and general anesthesia, induced with pentobarbital and maintained with $1 \%$ halothane in $2: 1$ mixture of nitrous 
oxide and oxygen. The ewe received 1 gram of ampicillin i.v. before surgery. The abdomen was opened through a paramedian incision.

An inflatable balloon occluder was placed around the maternal inferior vena cava below the level of the renal veins. The fetal lambs were approached by hysterotomy in the uterine wall lying over the fetal pelvis. An electromagnetic flow trans ducer was placed around the intra-abdominal common part of the umbilical veins (15). An inflatable balloon occluder was placed around the umbilical cord at the site of the abdominal insertion for in vivo zero blood flow calibration. A femoral artery catheter was inserted and advanced into the distal aorta at the level of the umbilical arteries for registration of fetal arterial pressure, which is representative of umbilical arterial pressure (7). Electrodes for recording of fetal heart rate were sewn in place. The umbilical arteries were dissected free at the abdominal entry of the cord. A $5 \mathrm{MHz}$ implantable pulsed wave Doppler device with a diameter of 3 millimeters was positioned in a polyvinyl cuff under a $45^{\circ}$ angle and was placed and fixed around one of the umbilical arteries of the fetal lamb. The device was covered again with the dissected layer of Wharton's jelly.

A catheter was advanced into a major umbilical vein through a cotyledonary vein for the measurement of umbilical venous pressure. Finally, an intra-amniotic catheter was left in the uterine cavity to allow intra-uterine pressure measurement. All catheters and electrodes were exteriorized through a skin incision in the ewe's flank. Catheter placement was confirmed at autopsy. The guidelines for the care and use of the animals approved by the local institution, were followed.

\section{Measurements}

Blood flow in the common umbilical vein was measured with a Skalar transflow 601 flowmeter system (Skalar, Delft,Holland). Fetal arterial blood pressure, umbilical venous pressure and intra-amniotic fluid pressure were determined with the zero point at the level of the ewe's spine. All signals were led to amplifiers (Hewlett Packard 8800 series), displayed on a monitor and an eight-channel strip chart recorder, stored on magnetic tape, digitized and analyzed with a computer. The Doppler shift signals were stored in quadrature on analog tape, synchronously with the other signals for off-line analysis. 


\section{Experiments}

The animals were allowed to recover for at least three days after surgery. Total occlusions of the maternal inferior vena cava of 60 seconds duration were performed by inflating the balloon occluder with saline.

In each animal, one occlusion of the maternal vena cava was performed with intact autonomic nervous system $(n=6$, group I), as well as after cholinergic blockade with atropine $(\mathrm{n}=6$, group II). Cholinergic blockade was established $30 \mathrm{~min}-$ utes before the control measurement by injecting $1 \mathrm{mg}$. atropine per kilogram estimated fetal weight intra-arterially, in order to prevent decreases in the FHR during occlusion.

\section{Calculations and data analysis}

The mean values for the hemodynamic variables were assessed during a 10 second period, 40 seconds before occlusion (control period) and a 10 second period at the end of occlusion. Mean umbilical arterial PI was calculated for 5 consecutive heart cycles which occurred during these intervals of 10 seconds. Placental vascular resistance was defined as the difference in fetal arterial inflow pressure and venous umbilical outflow pressure divided by the umbilical venous blood flow. Statistical analysis was performed for each variable on the pooled values from each animal by comparing the control values before occlusion with the values at the end of occlusion by means of Wilcoxon's matched-pairs signed-ranks test. A p-value of less than 0.05 was taken to represent statistical significance. Mean values are reported with the standard errors $( \pm S E M)$.

\section{Results}

\section{A. Maternal vena cava occlusion with intact fetal autonomic nervous system}

The mean values \pm SEM of the measured variables before and. at the end of the maternal vena cava occlusion in group I, are summarized in Table $I$. The mean fetal heart rate during the control period was $183 \pm 7.8$ beats per minute. The fetal heart rate decreased to $142 \pm 8.6 \mathrm{beats} / \mathrm{min}$ at the end of the one minute occlusion $(p<0.05)$. Fetal arterial blood pressure was $41.3 \pm 5.2 \mathrm{mmHg}$ before occlusion and did not change during occlusion ( $45.1 \pm 2.6 \mathrm{mmHg}$ ). Umbilical venous pressure did not change during occlusion $(16.1 \pm 2.8 \mathrm{mmHg})$ as compared to 
Table I. Fetal hemodynamic wariables in relation to occherion of the waternal wena cava

\begin{tabular}{lcc}
\hline Mean \pm SEM (n=6) & Control & Occlusion \\
\hline Fetal heart rate (beats per minute) & $183 \pm 7.8$ & $142 \pm 8.6 *$ \\
Placental perfusion pressure (mmHg) & $30.3 \pm 4.5$ & $29.0 \pm 3.4$ \\
Umbilical blood flow (mL/nin) & $286 \pm 28.4$ & $233 \pm 43.8 *$ \\
Placental vascular resistance (mmHgml-1.min) & $0.113 \pm 0.021$ & $0.151 \pm 0.033^{*}$ \\
Pulsatility index umbilical artery & $1.05 \pm 0.05$ & $1.85 \pm 0.4$ \\
\hline
\end{tabular}

$* p<0.05$ compared with control value (Wilcoton's matched pairs signed-ranks test)

control value $(11.0 \pm 8.8 \mathrm{mmHg})$. Fetal placental perfusion pressure (fetal femoral arterial pressure minus umbilical venous pressure) was $30.3 \pm 4.5 \mathrm{mmHg}$ before occlusion and did not change during occlusion $(29.0 \pm 3.4 \mathrm{mmHg})$. Umbilical blood flow decreased from $286 \pm 28.4 \mathrm{ml} / \mathrm{min}$ before to $233 \pm$ $43.8 \mathrm{ml} / \mathrm{min}$ during occlusion $(\mathrm{p}<0.05$ ). Placental vascular resistance increased from $0.113 \pm 0.021 \mathrm{mmHg} \cdot \mathrm{ml}^{-1}$. min during control period to $0.151 \pm 0.033 \mathrm{mmHg} \cdot \mathrm{ml}^{-1} \cdot \mathrm{min}$ at the end of occlusion $(\mathrm{p}<0.05)$. Umbilical artery PI increased from $1.05 \pm$ 0.05 to $1.85 \pm 0.4$ during the occlusion $(\mathrm{p}<0.05)$.

\section{B. Maternal vena cava occlusion after fetal parasympathetic blockade}

Table II summarizes the mean values \pm SEM of the measured fetal hemodynamic variables before and at the end of the maternal vena cava occlusion after cholinergic blockade with atropine in group II. Fetal heart rate did not change during maternal vena cava occlusion $(207 \pm 10.4 \mathrm{beats} / \mathrm{min})$ as com-

Table II. Fetal hemodynamic wariables in relation to occlusion of the maternat vena cava after atropine administration to the fetus

\begin{tabular}{lcc}
\hline Mean \pm SEM ( $=6)$ & Control & Occlusion \\
\hline Fetal heart rate (beats per minute) & $206 \pm 10.1$ & $207 \pm 10.4$ \\
Placental perfusion pressure (mmHg) & $25.9 \pm 4.9$ & $28.6 \pm 4.4$ \\
Umbilical blood flow (ml/min) & $288 \pm 32.3$ & $255 \pm 37.8 *$ \\
Placental vascular resistance (mmHg.ml- $1 . \mathrm{min})$ & $0.091 \pm 0.014$ & $0.121 \pm 0.021 *$ \\
Pulsatility index umbilical artery & $0.98 \pm 0.1$ & $1.12 \pm 0.12 *$ \\
\hline
\end{tabular}

* $p<0.05$ compared with control value (Wilcoxon's matched pairs signed-ranks test) 
pared to control ( $206 \pm 10.1$ beats/min). Placental vascular resistance increased from $0.091 \pm 0.014 \mathrm{mmHg} \cdot \mathrm{ml}^{-1} \cdot \mathrm{min}$ during control to $0.121 \pm 0.021 \mathrm{mmHg} \cdot \mathrm{ml}^{-1} \cdot \mathrm{min}$ at the end of occlusion ( $p<0.05$ ). The Pulsatility Index of the umbilical artery also increased from $0.98 \pm 0.1$ during control to $1.12 \pm 0.12$ at the end of occlusion $(\mathrm{p}<0.05)$.

Umbilical blood flow decreased from $288 \pm 32.3 \mathrm{ml} / \mathrm{min}$ before to $255 \pm 37.8 \mathrm{ml} / \mathrm{min}$ during occlusion $(\mathrm{p}<0.05)$. Fetal arterial blood pressure was $38.1 \pm 5.5 \mathrm{mmHg}$ before occlusion and remained unchanged $(38.2 \pm 7.2 \mathrm{mmHg}$ ) during occlusion. Umbilical venous pressure did not change during occlusion as compared to control value $(9.7 \pm 11.3 \mathrm{mmHg}$ and $12.2 \pm 9.8$ $\mathrm{mmHg}$ respectively). Fetal placental perfusion pressure showed no change during occlusion.

\section{The influence of atropine administration on the fetal hemodynamic variables}

Statistical analysis of the differences in fetal heart rate, placental perfusion pressure, umbilical blood flow, placental vascular resistance and umbilical artery Pulsatility Index between the control values of the two groups did not show a significant effect of atropine administration on these parameters.

\section{Discussion}

Occlusion of the maternal vena cava was carried out to raise placental vascular resistance to flow and to observe the effect of the increase in resistance on umbilical arterial flow velocity waveforms. Obstruction of maternal placental outflow resulted in an increase in placental vascular resistance.

Vena cava occlusion furthermore resulted in a decrease in fetal heart rate, which can be baro- and/or chemoreceptor mediated. However, no significant effect on fetal blood pressures was observed. Infrarenal vena cava occlusion causes a $30 \%$ fall in maternal cardiac output (16) and a decrease in uterine blood flow of approximately $40 \%(16,17)$. The magnitude of the uterine blood flow decrease in the present study was not measured but expected to be approximately $40 \%$, which is great enough to interfere with adequate oxygen supply to the fetus (18). Stimulation of fetal chemoreceptors could therefore explain the fall in FHR. The present data can 
however not be conclusive with regard to the mechanism of the fetal heart rate decrease. In cases of longer lasting reductions in uterine blood flow of a greater magnitude resulting in severe fetal hypoxemia, an increase in placental resistance is observed $(19,20)$. To what extent fetal hypoxemia occurred during the vena cava occlusion in the present study is not known, but an influence on placental vascular resistance by fetal hypoxemia is not expected, as we have recently shown that a moderate fall in fetal pO2 from 26.0 to $18.3 \mathrm{mmHg}$ caused by shortlasting (60-90 sec.) total occlusion of arteriall uterine blood flow did not result in a change in placental vascular resistance (21).

Maternal placental outflow obstruction was associated with a rise in placental vascular resistance, without a change in perfusion pressure, and an increase in the PI of the umbilical artery. As the PI (22) is influenced by bradycardia, we repeated the measurements after fetal parasympathetic blockade with atropine. The observed rise in umbilical artery PI from $0.98 \pm 0.1$ during the control period to $1.12 \pm 0.12$ $(\mathrm{p}<0.05)$ during vena cava occlusion was associated with a decrease in umbilical blood flow without a change in perfusion pressure and heart rate and thus with a rise in placental vascular resistance.

The PI of the umbilical artery flow velocity waveform is the total oscillatory energy in the flow velocity waveform divided by the energy of the mean forward flow velocity over the cardiac cycle (3). The degree of pulse wave damping (PI) is supposed to be lower or higher with respect to a decrease or increase in placental vascular resistance $(1,5,6,10,11)$. Instead of resistance which is applicable only to steady flow, it would be more correct to correlate impedance, which is the heart rate independent ratio between pulsatile pressure and pulsatile flow, to the pulsatille flow velocity waveform. Calculation of impedance, however, requires a cumbersome method of resolving the waveforms into their harmonic components. Impedance and resistance are related to each other in such a way that relatively great increases in impedance are accompanied by increases in callculated resistance.

The observed association between placental vascular resistance and the PI of the umbilical artery during maternal placental outflow obstruction in these experiments is in agreement with results in the human during different maternal positions, which might decrease inferior vena cava flow $(13,14)$. 
We conclude that the relationship between placental vascular resistance and the PI of the umbilical artery flow velocity waveform, observed over an experimentally induced heart rate independent range of placental vascular resistance values by parasympathetic blockade, supports the hypothesis that, in the fetal sheep, placental vascular resistance is one of the determinants of the PI of the umbilical artery. This animal model provided one of the first physiological basis to explain the high umbilical artery PI seen in clinical conditions, such as intrauterine growth-retardation which was believed to be due to a high placental vascular resistance.

\section{References}

1. Schulman H, Fleischer A, Stern W, Farmakides G, Jagani N, Blattner $P$. Umbilical velocity wave ratios in human pregnancy. Am J Obstet Gynecol 1984;148:985-90.

2. van Vugt JMG, Ruissen CJ, Hoogland HJ, de Haan J. A prospective study of the umbilical artery waveform in appropriate-for-date and growth-retarded fetuses. Gynecol Obstet Invest 1987;23:217-25.

3. Grosling RG, Dunbar G, King DH, Newman DL, Side CD, Woodcock JP, Fitzgerald DE, Keates JS, MacMillan D. The quantitative analysis of occlusive peripheral arterial disease by a non- intrusive ultrasonic technique. Angiology 1971;22:52-5.

4. Ruissen CJ, van Vugt JMG, Hoogland HJ, Hoeks APG, de Haan J. Technical aspects of fetal Doppler measurements. Gynecol Obstet Invest 1987;24:1-13.

5. Trudinger BJ, Giles WB, Cook CM, Bombardieri J, Collins L. Fetal umbilical artery flow velocity waveforms and placental resistance: clinical significance. Br J Obstet Gynaecol 1985;92:23-30.

6. Giles WB, Trudinger BJ, Baird PJ. Fetal umbilical artery flow velocity waveforms and placental resistance: pathological correlation. $\mathrm{Br} J$ Obstet Gynaecol 1985;92:31-8.

7. Dawes GS. The umbilical circulation. In: Fetal and neonatal physiology. Chicago: Year Book Medical Publishers, 1968 pp. 66-78.

8. Newnham JP, Kelly RW, Roberts RV, Macintyre M, Speijers J, Johnson T, Reid SE. Fetal and maternal Doppler flow velocity waveforms in normal sheep pregnancy. Placenta 1987;8:467-76.

9. Erskine RLA, Ritchie JWK. Umbilical artery blood flow characteristics in normal and growth-retarded fetuses. Br J Obstet Gynaecol 1985; 92:605-10. 


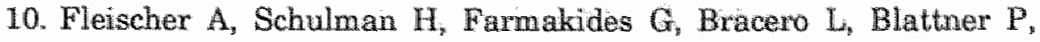
Randolph G. Umbilical artery welocity wavelorms and intratuterine growth retardation. Am J Obstet Gynecol 1985;151:502-5.

11. Trudinger BJ, Stevens $D_{*}$ Comnelly A, Hales JRS, Alexander $\mathrm{C}_{3}$ Bradley $\mathbb{L}$, Fawcett $A$, Thompson RS. Umbilical artery flow velocity waveforms and placental resistance: The effects of embolization of the umbilical circulation. Am J Obstet Gynecol 1987;157:1443-48.

12. van Vugt JMG, Hasaart THM, Ruissen JC, Hoogland HJ, Hoeks APG, de Haan J. The Pulsatility Index and its relationship to placental vascular resistance during partial umbilical venous occlusion: a study in fetal lambs. Gynecol Obstet Invest 1988;26:1-7.

13. Kauppila A, Koskinen M, Puolakka J, Tuimala R, Kuikka J. Decreased intervillous and unchanged myometrial blood flow in supine recumbency. Obstet Gynecol 1980;55;203-5.

14. Marx GF, Patel S, Berman JA, Farmakides G, Schulman H. Umbilical blood flow velocity waveforms in different maternal positions and with epidural analgesia. Obstet Gynecol 1986;68:61-4.

15. Soma LR, White RJ, Kane PB. Surgical preparation of a chronic maternal fetal model in pregnant sheep: A technique for the measuren ment of middle uterine blood flow, umbilical blood flow, and fetal sampling in the awake sheep. Journal of Surgical Research 1971; 11:85-94.

16. Lotgering FK, Wallenburg HCS. Hemodynamic effects of caval and uterine venous occlusion in pregnant sheep. Am J Obstet Gynecol 1986;155:1164-70.

17. Kuenzel W, Kastendieck E, Boehme U, Feige A. Uterine hemodynamics and fetal response to vena caval occlusion in sheep. J Perinat Med. $1975 ; 3: 260-8$.

18. Boyle JW, Lotgering FK, Longo LD. Acute embolization of the uteroplacental circulation: Uterine blood flow and placental $\mathrm{CO}$ diffusing capacily. J Dew Physiol 1984;6:377-86.

19. Cohn NE, Jackson BT, Piasecki GJ, Cohen WR, Novy MJ. Fetal cardiowascular responses to asphyxia induced by decreased uterine perfusion. J Dev Physiol 1985;7:289-97.

20. Yaffe H, Parer JT, Block BS, Llanos AJ. Cardiorespiratory responses to graded reductions of uterine bloodflow in the sheep fetus. J Dev Physiol 1987:5:325-36.

21. van Huisseling $\mathrm{H}$, Hasaart THM, Ruissen $\mathrm{CJ}$, Muijsers GJJM, de Haan J. Umbilical artery flow welocity wave forms during acute hypoxemia and the relationship with hemodynamic changes in the fetal lamb. Am J Obstet Gynecol 1989;161:1061 4. 
22. Mulders LGM, Muijsers GJM, Jongsma HW, Nijhuis JG, Hein PR. The umbilical artery blood flow welocity waveform in relation to fetal breathing movements, fetal heart rate and fetal behavioural states in normall pregnancy at 37 to 39 weeks. Early Hum Dev 1986;14:283-93. 


\section{Fetal hypertension induced by norepinephrine infusion and umbilical artery flow velocity waveforms in fetal sheep}

Hans van Huisseling, Tom H.M. Hasaart, Guido J.J.M. Muijsers and Jelte de Haan.

Submitted for publication

\section{Abstract}

This study was designed to examine the effects of fetal hypertension on the umbilical artery Pulsatility Index (PIumb). Fetal arterial blood pressure and umbilical venous pressure were measured in 8 sheep, 3 to 5 days after surgery. Umbilical blood flow was measured with an electromagnetic flow meter around the common umbilical vein. Umbilical artery flow velocity waveforms were obtained either by an indwelling $5 \mathrm{MHz}$ pulsed Doppler device or transcutaneously by a $4 \mathrm{MHz}$ continuous wave Doppler device. Fetal blood pressure was raised by intravenous infusion of 10 micrograms norepinephrine (NE) per minute during 5 minutes. NE-infusion resulted in elevated arterial and umbilical venous pressures, accompanied by a bradycardia during the first 3 minutes. Umbilical blood flow, calcullated placental vascular resistance (PVR) and Plumb did not change. After atropine administration, the NE induced elevated arterial and umbilical venous pressures were accompanied by a tachycardia, increased umbilical blood flow and no change in PVR and Plumb. It is concluded that fetal arterial hypertension provoked by NE-infusion has no effect on PVR, umbilical blood flow and PIumb. $\mathrm{NE}$-infusion furthermore raises umbilical venous pressure. 


\section{Introduction}

Since the introduction of Doppler ultrasound in the study of the fetal circulation by Fitzgerald and Drumm (1) more than a decade ago, an overwhelming number of papers has been published concerning umbilical artery flow velocity waveforms. Initial reports showed promising results concerning the capability of umbilical artery velocimetry to detect intrauterine growth restriction and predict fetuses with poor perinatal outcome $(2,3,4,5)$. Later studies questioned the validity of umbilical waveform analysis with regard to the detection of intra uterine growth restriction and/or compromised fetuses $(6,7,8,9$,$) . In case of an abnormal umbilical artery waveform, it$ is suggested that the fetus may be seriously ill. On the other hand, a seriously ill fetus may have a normal umbilical artery waveform (7). Abnormal waveforms can be seen in growth retarded fetuses already several weeks before the occurrence of fetal heart rate decelerations as a sign of fetal hypoxia (2). In contrast we have shown in fetal sheep that moderate and severe fetal hypoxia can exist without any effect on umbilical artery waveform indices $(10,11,12,13)$. Analysis of the umbilical artery waveform, therefore, does not seem to give adequate information to what extent fetal reserve capacity and compensatory mechanisms are mobilised. This view is supported by a recent paper of Block et al. (14), in which study the observed distribution of regional blood flows in fetal sheep was not different during imposed acute hypoxemia in fetuses with normal placentas compared to fetuses in which intra uterine growth restriction was created by umbilical embolisation. Hypoxic stress results in a release of catecholamines, mainly norepinephrine (NE), which has a predominant alphaadrenergic receptor stimulating effect. Through alpha-receptor stimulation fetal cardiac output redistribution occurs, which is essential for an adequate supply of oxygen to high priority organs as brain and heart during hypoxemia $(15,16)$. Norepinephrine infusion causes an increase of systolic and diastolic arterial pressure in the fetal circulation $(17,18)$ with secondary effects on fetal heart rate and/or umbilical blood flow (19). The influence of fetal hypertension on the umbilical artery velocity waveform is not known. The aim of the present study was to investigate the effect of an increased fetal arterial blood pressure on the umbilical artery flow velocity waveform. Fetal blood pressure was raised by intravenous infusion 
of norepinephrine. The umbilical artery flow velocity waveform was described by the Pulsatility Index, according to Gosling et al. (20).

\section{Material and methods}

\section{Surgery}

The experiments were carried out in 8 ewes of the Dutch Texel breed, between 113 and 124 days gestation (term 147 days). Surgical instrumentation was carried out under aseptic conditions and general anesthesia and involved insertion of a catheter in the distal aorta via a femoral artery, a catheter in a femoral vein for drug infusion, a catheter in a major umbilical vein via a cotyledonary vein, placement of an electromagnetic flowmeter around the intra-abdominal common umbilical vein and placement of an inflatable balloon occluder around the umbilical cord at the site of the abdominal insertion for in vivo zero blood flow calibration. A $5 \mathrm{MHz}$ pulsed Doppler device was placed around one of the two umbilical arteries. Anesthetic technique and surgical instrumentation has extensively been described previously $(10,21)$. The surgical and experimental procedures were approved by the local Animal Medical Ethics Committee.

\section{Measurements}

Blood flow in the common umbilical vein was measured with a Skalar transflow 601 flowmeter system (Skalar, Delft, Holland). Fetal arterial blood pressure and umbilical venous pressure were determined with the zero point at the level of the ewe's spine. Fetal heart rate was calculated from the pulse of the arterial blood pressure wave. All signals were led to amplifiers (Hewlett Packard 8800 series, Hewlett Packard, Andover, Massachusetts, USA), displayed on a monitor and an eight-channel strip chart recorder, stored on magnetic tape, digitized and analyzed with a computer. Umbilical artery waveforms were obtained by the $5 \mathrm{MHz}$ pulsed Doppler probe around one umbilical artery in four animals. Due to malfunctioning of the $5 \mathrm{MHz}$ indwelling Doppler probe, umbilical artery velocity waveforms were obtained by a $4 \mathrm{MHz}$ continuous wave Doppler device (Delalande Electronique, Courbevoie, France) in the other four animals. The ultrasound beam was insonated from the abdominal skin of the standing ewe after visualisation of the umbilical cord by ultrasonography (Scan- 
ner 400 , Sanyo, Japan). The origin of the received signals was verified by comparison with fetal heart rate, derived from the arterial pressure waveform, and by presence of oppositely directed venous blood flow velocities within the Doppler sample volume. The Doppler frequency shift signals were stored in quadrature on analog tape, synchronously with the other signals for off-line analysis. After transformation of the Doppler shift signals by a spectrum analyzer (Doptek Ltd., Chicester, England), PI values were obtained by drawing the maximum envelope curves of the frequency-shift spectra with a handguided lightpen. In the group of fetuses in which the continuous wave Doppler device was used, it was not always possible to obtain representative umbilical artery velocity waveforms at every point of time. Nevertheless velocity waveforms were obtained in all animals at 4 and 5 minutes of infusion.

\section{Experiments}

The animals were allowed to recover for three to five days after surgery. After establishing baseline conditions during one hour, norepinephrine was infused by an infusionpump (Vicker Ltd., no.IP3H, Basingstroke, England) at a rate of 10 micrograms per minute during 5 minutes in 8 fetal sheep with intact autonomic nervous system (group 1). To eliminate the baroreceptor effect of the NE induced hypertension on the fetal heart rate, cholinergic blockade was established by atropine at a dose of $1 \mathrm{mg} / \mathrm{kg}$ estimated fetal weight (group II). Each animal was used in two protocols, one without atropine and one after atropine administration on different days after randomization. Ten minutes before and ten minutes after the experiments an arterial blood sample was drawn for analysis of fetal $\mathrm{pO}_{2}, \mathrm{pCO}_{2}$ and $\mathrm{pH}$, measured at 39 degrees Celsius.

\section{Calculations and data analysis}

The mean values for the hemodynamic variables were assessed during a 10 second period one minute before the start of infusion (control period) and during a 10 second period every one minute following the start of the infusion and a 10 second period 10 minutes after the start of the infusion. Mean umbilical artery PI was calculated over 5 consecutive heart cycles which occurred during these periods of $\mathbb{1 0}$ seconds. Placental vascular resistance was defined as the difference between fetal arterial pressure in the distal aorta and venous umbilical pressure divided by umbilical venous blood flow. 
Statistical analysis was performed for each variable on the pooled values from each animal by comparing the control values before infusion with the values during and after the infusion by means of a paired Student $t$-test with Bonferroni correction for repeated comparisons (22). In those cases in which umbilical artery velocity waveforms, at the various points of time, could not be obtained in all 8 animals, comparisons were made between the reduced number of values during the infusion period and their respective control values. A p-value of less than 0.05 , after Bonferroni correction, was taken to represent statistical significance. The values of the fetal arterial acid-base balance are compared before and after NE-infusion with a paired Student t-test. Mean vallues are reported with the standard errors ( \pm SEM).

\section{Results}

\section{A. Intact autonomic nervous system (group I)}

Table I and figure 1 show the effects of $\mathrm{NE}$-infusion on the fetal cardiovascular variables. NE-infusion causes an increase in mean arterial blood pressure (FBP). The increase in arterial pressure is accompanied by a bradycardia which lasts during the first three minutes of infusion. Fetal bradycardia has disappeared at 4 and 5 minutes during infusion and 5 minutes after infusion. Umbilical venous pressure (UVP) significantly increases at 2, 3 and 4 minutes during infusion. Placental perfusion pressure (FBP-UVP) is not significantly elevated during NE-infusion. Umbilical blood flow does not change either. Placental vascular resistance (PVR) does not significantly change during and after infusion compared to baseline values. Umbilical artery Pulsatility Index tends to decrease at 4 and 5 minutes of infusion $(n=8)$, but this change is insignificant with Bonferroni correction. At 1 minute of infusion the umbilical artery flow velocity waveforms of 6 animals could be obtained. The mean umbilical artery Pulsatility Index at 1 minute of infusion has not significantly changed compared to the mean value at control of the same 6 animals. The umbilical artery Pulsatility Indices could be obtained in respectively 4 , 3 and 5 animals, at 2 and 3 minutes of infusion and after infusion. The mean values at these points of time do not differ 

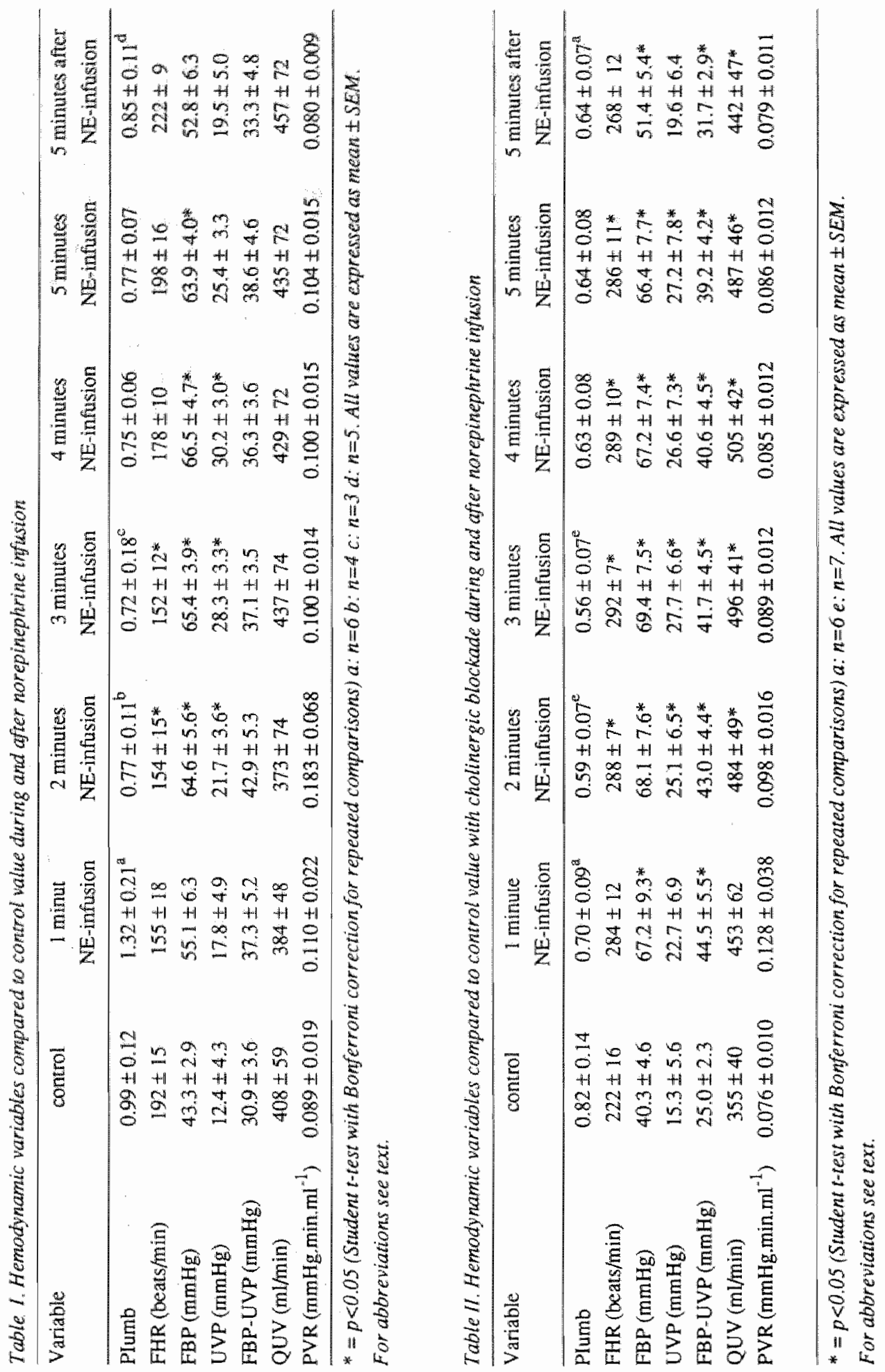


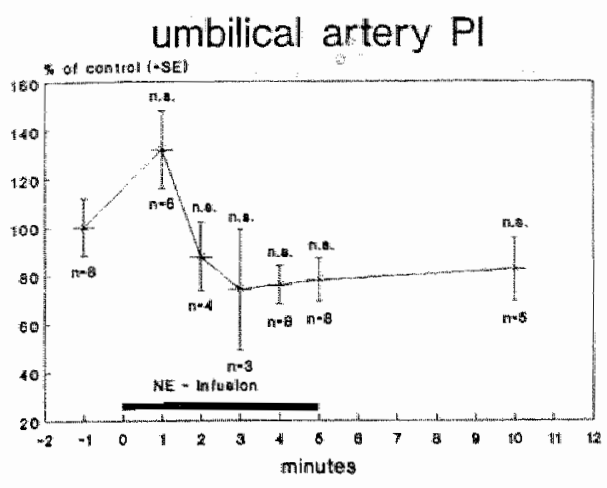

fetal arterial blood pressure

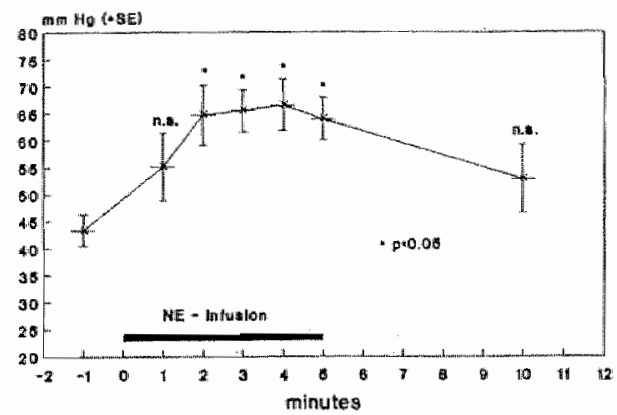

fetal heart rate

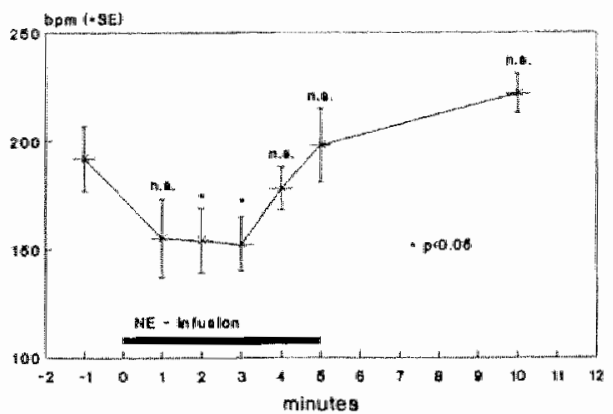

placental vascular resistance

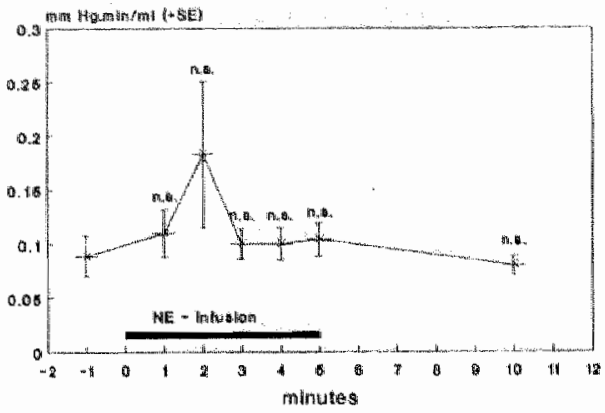

umbilical venous pressure

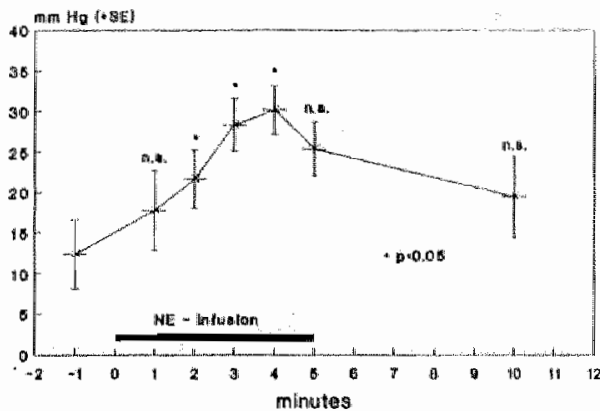

umbilical blood flow

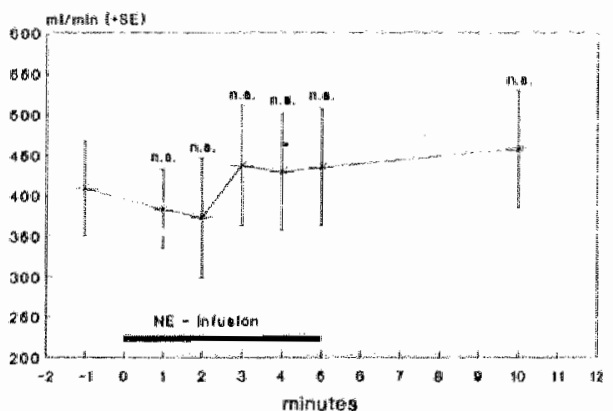

Figure 1. Cardiowascular variables and umbilical artery PI before, during and after 5 minutes of norepinephrine infusion. The vallues of the umbilical artery Pulsatility Index are expressed as percentage change of control. 


\section{umbilical artery $\mathrm{Pl}$}

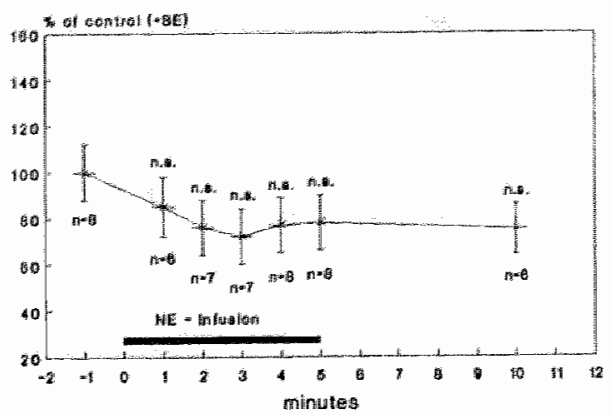

fetal arteriall blood pressure

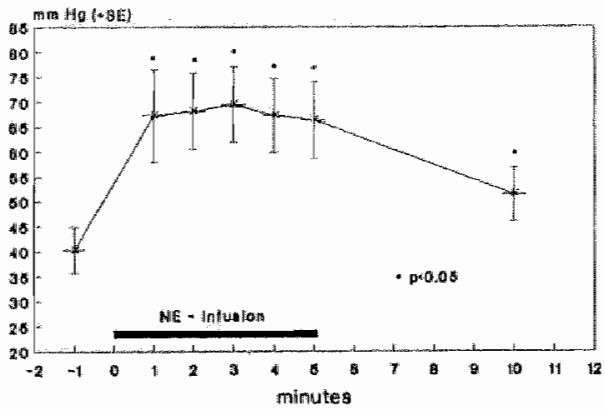

fetal heart rate

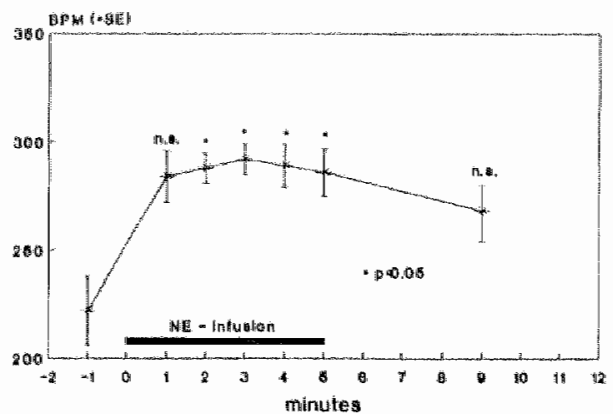

placental vascular resistance

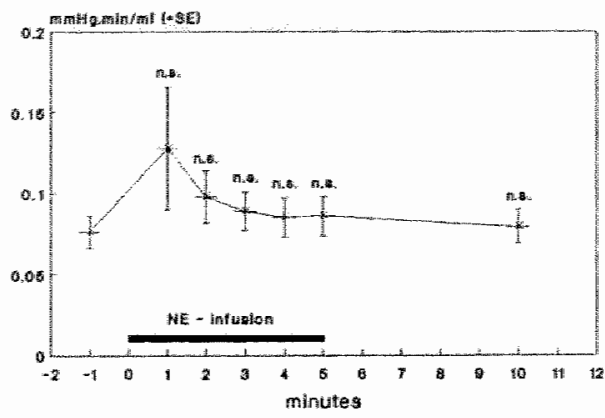

umbilical venous pressure

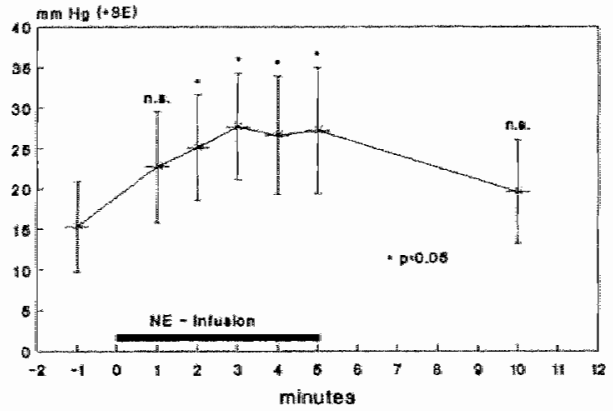

umbilical blood flow

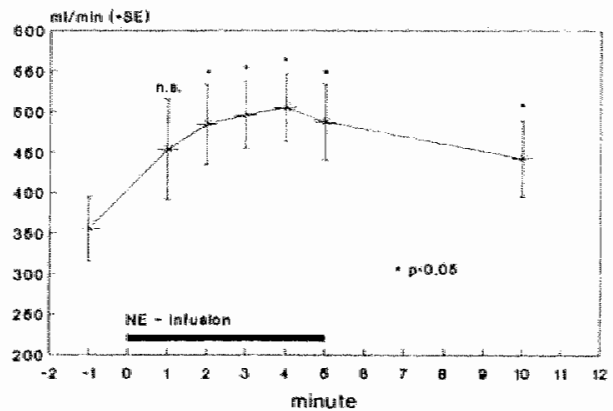

Figure 2. Cardiovascular variables and umbilical artery PI after cholinergic blockade by atropine before, during and after 5 minutes of norepinephrine infusion. The values of the umbilical artery Pulsatility Index are expressed as percentage change of control. 
from their respective control values. The small number of observations however, do not allow reliable statistical analysis.

\section{B. After parasympathetic blockade with atropine (group II)}

Table II and figure 2 show the results of $\mathrm{NE}$-infusion after cholinergic blockade by atropine. NE-infusion causes a more pronounced increase in mean arterial pressure compared to the experiments without cholinergic blockade. Fetal heart rate however, significantly increases during NE-infusion. Umbilical venous pressure increases significantly during NE-infusion and returns to baseline values 5 minutes after infusion. Placental perfusion pressure also significantly increases during and after infusion. A significant rise in umbilical blood flow occurs during infusion and is still present at 5 minutes after infusion. Placental vascular resistance does not change during and after infusion. The umbilical artery Pulsatility Index tends to decrease during the infusion, but the change is not significant. The number of observations of umbilical artery Pulsatility Indices at 1,2 and 3 minutes of infusion and 5 minutes after infusion are obtained in $6,7,7$ and 6 fetuses respectively.

No significant changes in fetal acid-base balance are seen after NE-infusion. Fetal arterial pH is $7.35 \pm 0.01$ before and $7.31 \pm 0.01$ after $\mathrm{NE}$-infusion, while $\mathrm{pCO}_{2}$ is respectively 5.72 \pm 0.30 and $5.73 \pm 0.29 \mathrm{kPa}$ and $\mathrm{pO}_{2}$ is $1.89 \pm 0.25$ before and $2.27 \pm 0.30 \mathrm{kPa}$ after $\mathrm{NE}$-infusion.

\section{Discussion}

The purpose of the present study was to investigate the effect of fetal hypertension on the umbilical artery flow velocity waveform expressed by the Pulsatility Index. We are not aware of any previous reports regarding the relationship between fetal blood pressure and the umbilical artery flow velocity waveform. NE-infusion causes arterial hypertension in the fetal circulation, which is in accordance with previous studies $(16,17,18,19,23,24,25,26)$. Data from the literature on the effects of norepinephrine on umbilical blood flow, fetal heart rate, placental perfusion pressure and placental vascular resistance are conflicting. Some authors report an increase in 
placental vascular resistance and a decrease in umbilical blood flow with bradycardia during alpha adrenergic stimulation $(17,27)$, whereas others find either no change in placental vascular resistance and an increase in umbilical blood flow $(23,25)$ with stable heart rate $(16,25,26)$, or no change in umbilical blood flow and an increase in placental vascular resistance (18). The differences in results may be explained by different experimental set-ups, for example whether NE is infused or given as a bolus, whether the animal preparations are chronic or acute, whether bradycardia or normocardia exists $(19,24)$. The differences may furthermore depend on the definition of placental vascular resistance and may be caused by the different doses of NE given. We used a dose of 10 micrograms NE per minute which exceeds the catecholamine levels seen in fetal stress, since it was our objective to induce fetal hypertension.

The increase in mean arterial pressure has a considerable effect on fetal heart rate in the fetuses with intact autonomic nervous system. Due to baroreflex activity fetal heart rate decreases during the first three minutes of infusion, but recovers at 4 minutes of infusion. To avoid the reflex bradycardia during fetal hypertension another series of NE-infusions was performed after cholinergic blockade with atropine (group II), as it is known that bradycardia increases the umbilical artery Pulsatility Index (10). Calculation of placental vascular resistance is furthermore questionable during bradycardia, because a concomitant decrease in umbilical blood flow during bradycardia cannot be attributed to an increase in vascular resistance $(19,24)$. The increase in fetal heart rate in group II during NE-infusion is explained by the prevailing betaadrenergic system, since parasympathetic vagal activity is blocked.

During NE -infusion a tendency of the umbilical artery PI to decrease was noted in group I as well as in group II. These changes were however not significant after the Bonferroni correction for repeated comparisons. In group I placental vascular resistance does not change, mainly because of the relatively small increase in perfusion pressure with rather stable umbilical blood flows. In group II placental perfusion pressure and umbilical blood flow both increase. No change in calculated placental vascular resistance occurs therefore. In contrast to group I the umbilical arterial-venous pressure difference is more pronounced after cholinergic blockade and 
parallels the increase in umbilical blood flow and fetal heart rate. The increase in umbilical blood flow in group III is very likely related to the increase in fetal heart rate (24).

NE-infusion causes furthermore a significant rise in umbilical venous pressure in both groups. The increase in umbilical venous pressure is more gradual than the increase in arterial pressure, which explains the increase in perfusion pressure during the first two minutes of infusion in group I. The later onset of the umbilical venous pressure increase is also reflected in the higher mean values of calculated placental vascular resistance during the first two minutes of infusion.

Norepinephrine constricts the systemic arterial vascular bed while the umbilical arteries are unaffected. It follows that in case of catecholamine release as during hypoxic stress, the fetus is capable of regulating placental perfusion pressure, not only by increasing arterial blood pressure, but also by increasing umbilical venous pressure to maintain umbilical blood flow and to avoid compromise of its gas exchange. This is illustrated by the fact that $\mathrm{pH}, \mathrm{pCO}_{2}$ and $\mathrm{pO}_{2}$ were not affected, which is in accordance with previous reports $(16,24)$. We infer that umbilical venous vasomotor tone may play an important role in regulating placental perfusion pressure and umbilical blood flow.

Inferior ven a cava pressure is not representative for umbilical venous pressure, since it is not affected by NE-infusion (26), as is the hepatic vasculature (27). Placental vascular resistance calculations using vena cava pressure may therefore increase the numerator and hence increase calculated placental vascular resistance $(17,18)$. In an acute experiment. Adamson et al. found no significant changes in resistance of the umbilical artery and intrinsic cotelydon vasculature during NE-infusion and no change in umbilical blood flow. They observed however a rise in umbilical venous resistance, from which they conclude that the umbilical vein was constricted during NE-infusion (26). Recently Paulick et al. observed a pressure drop in the umbilical vein from placenta to the portal sinus, which increased during hypoxemia, indicating increased resistance. This would distend and recruit vessels in the placenta and hence improve gas exchange (28).

It is concluded that:

1. Fetal hypertension caused by $\mathrm{NE}$-infusion has no effect on umbilical artery PI. 
2. Norepinephrine infusion does not alter placental vascular resistance.

3. Norepinephrine infusion does not alter umbilical blood flow.

4. Norepinephrine infusion increases umbilical venous pressure.

5. Norepinephrine infusion does not affect fetal acid-base balance.

We speculate that fetal hypertension has no effect on umbilical artery waveform indices in fetuses with normal placentation and that the fetus is capable of regulating placental perfusion pressure by altering systemic arterial pressure and umbilical venous tone.

\section{References}

1. Fitzgerald DE, Drumm JE. Non-invasive measurement of the fetal circulation using ultrasound; a new method. Br Med J 1977;2:1450-51.

2. Reuwer PJHM, Rietman GW, Sijmons EA et al. Intra-uterine growth retardation: Prediction of perinatal distress by Doppler ultrasound. Lancet 1987;ii:415-18.

3. Erskine RLA, Ritchie JWK. Umbilical artery blood flow characteristics in normal and growth-retarded fetuses. $\mathrm{Br} J$ Obstet Gynaecol 1985;92:605-10.

4. Giles WB, Trudinger BJ, Baird PJ. Fetal umbilical artery flow velocity waveforms and placental resistance: pathological correlation. $\mathrm{Br} \mathrm{J}$ Obstet Gynaecol 1985;92:31-8.

5. Fleischer A, Schulman H, Farmakides G, Bracero L, Blattner P, Randolph $G$. Umbilical artery velocity waveforms and intrauterine growth retardation. Am J Obstet Gynecol 1985;151:502-5.

6. Redman CWG. Examination of the placental circulation by Doppler ultrasound. Br Med J 1989;298:621-2.

7. Beattie RB, Dornan JC. Antenatal screening for intrauterine growth retardation with umbilical artery Doppler ultrasonography. Br Med J $1989 ; 298 ; 631-5$.

8. Neilson JP. Doppler ul trasound. Br J Obstet Gynaecol 1987;94:929-32.

9. Dempster J, Mires GJ, Patel N, Taylor DJ. Umbilical artery velocity waveforms: poor association with small-for-gestational-age babies. $\mathrm{Br}$ J Obstet Gynaecol 1989;96:692-6.

10. van Huisseling H, Hasaart THM, Ruissen CJ, Muijsers GJJM, de Hlaan J. Umbilical artery flow vellocity wave forms during acute hypoxemia and the relationship with hemodynamic changes in the fetal lamb. Am J Obstet Gynecol 1989;161:1061-4. 
11. Muijsers GJJM, Hasaart THM, Ruissen CJ van Huisseling H, Peeterts LiLH, de Haan J. The response of the umbilical and femoral artery pulsatility indices in fetal sheep to progressively reduced uteroplacental bloodflow. J Dev Physiol 1990 (in press).

12. van Huisseling H, Hasaart THM, Muijsers GJJM, de Haan J. Umbilical artery pulsatility index and placental vascular resistance during hypoxemia in fetal lambs [Abstract 315]. In: Proceedings of the 37th annual meeting of the Society for Gynecologic Investigation, St. Lours, Missouri, March 21-24, 1990:254.

13. Muijsers GJJM, Hasaart THM, van Hutsseling H, de Haan J. The response of the umbilical artery Pulsatility Index in fetal sheep to acute and prolonged hypoxemia and acidemia induced by embolization of the uterine circulation. J Dev Physiol 1990 (in press).

14. Block BS, Schlafer DH, Wentworth RA, Kreitzer LA, Nathanielsz PW. Intrauterine growt hetardation and the circulatory responses to acute hypoxemia in fetal sheep. Am J Obst Gymecol 1989;161:1576-9.

15. Jones CT, Robinson RO. Plasma catecholamines in fetal and adult sheep. J Physiol 1975;248:15-33.

16. Jones CT, Ritchie JWK. The cardiovaseular effects of circulating catecholamines in fetal sheep. J Physiol 1978;285:381-93.

17. Rankin JHG, Stock MK, Anderson DF. Fetal heart rate and umbilical blood flow. J Dev Physiol 1980;2:11 6.

18. Oakes GK, Ehrenkranz RA, Walker AM, McLaughlin MK, Brennan SC, Chez RA. Effect of alpha-adrenergic agonist and antagonist infusion on the umbilical and uterine circulations of pregnant sheep. Biol Neonate 1980;38:229-37.

19. Berman jr W, Goodlin RC, Heymann MA, Rudolph AM. Effect of pharmacologic agents on umbilical blood flow in fetal lambs in utera. Biol Neonate 1978;33:225-35.

20. Goshing $R G$, Dunbar $G$, King DH, et al. The quantitative analysis of occlusive peripheral arterial disease by a non-intrusive ultrasonic technique. Angrology 1971;22:52-5.

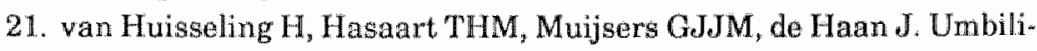
cal artery flow velocity waveforms and placental vascular resistance during placental outflow obstruction in fetal sheep. J Dev Physiol 1990 (in press).

22. Matthews DE, Farewell VT. Using and understanding medical statistics. Ed:Karger, Basel, New York, 1985.

23. Novy MJ, Piasecki G, dackson BT. The effect of PGT2 and PGF2al pha on the umbilical circulation. Prostaglandins 1974,5:543-55.

24. Rudolph AM. Factors affecting umbilical blood flow in the lamb in utero. In: Proceedings of the 5th European congress of Perinatal Medicine, Uppsala, Sweden, 1976:159-72. 
25. Lorijn RHW, Longo IDD. Norepinephrine elevation in the fetal lamb: oxygen consumption and cardiac output. Am J Physiol 1980;239:R11522.

26. Adamson SL, Morrow RJ, Bull SB, Langille BL. Vasomotor responses of the umbilical circulation in fetal sheep. Am I Physiol $1989 ; 256: 1056-62$

27. Barrett CT, Heymann MA, Rudolph AM. Alpha and beta adrenergic receptor activity in fetal sheep: Am J Obstet Gynecol 1972;112:111421.

28. Paulick RP, Meyers RL, Rudolph CD, Rudolph AM. Venous responses to hypoxemia in the fetal lamb [Abstract 311]. In: Proceedings of the 37 th annual meeting of the Society for Gymecologic Investigation, St.Louis, Missouri, March 21-24,1990:252. 


\title{
Umbilical artery pulsatility index and placental vascular resistance during acute hypoxemia in fetal lambs
}

Hans van Huisseling, Tom H.M. Hasaart, Guido J.J.M. Muijsers and Jelte de Haan.

Gynecologic and Obstetric Investigation (accepted for publication)

\begin{abstract}
The effect of hypoxemia on the Pulsatility Index (PI) of the umbilical artery flow velocity waveform and placental vascular resistance was studied. Fetal hypoxemia was induced by maternal breathing of a low oxygen gas mixture. Umbilical venous blood flow was measured with an electromagnetic flow meter. Placental vascular resistance (PVR) was defined as the ratio between perfusion pressure (mean arterial pressure minus umbilical venous pressure) and umbilical blood flow. Umbilical artery velocity waveforms were obtained by a 5 $\mathrm{MHz}$ pulsed Doppler device around one umbilical artery in 4 lambs and by a transcutaneous $4 \mathrm{MHz}$ continuous wave Doppler transducer in 3 lambs. Fetal arterial oxygen content was lowered from $2.28 \pm 0.18 \mathrm{mM}$ to $0.93 \pm 0.15 \mathrm{mM}$ ( $\mathrm{p}<0.05$ ), while $\mathrm{pCO}_{2}$ and $\mathrm{pH}$ remained unchanged. Control values of the hemodynamic variables were compared with values during deepest hypoxemia. Fetal heart rate, mean arterial and umbilical venous pressure, PVR and the umbilial artery PI did not significantly change, whereas umbilical blood flow increased from $436 \pm 64.7 \mathrm{ml} / \mathrm{min}$ to $491 \pm 65.9 \mathrm{ml} / \mathrm{min}(\mathrm{p}<0.05)$ during deepest hypoxemia. Individual regression analysis however, showed a significant inverse correlation between umbilical venous pressure and oxygen content, whereas PVR had a positive correlation with actual oxygen content. It is
\end{abstract}


concluded that, acute fetal hypoxemia slightly decreases PVR, but does not affect the umbilical artery PI in sheep. Decreasing fetal oxygenation is associated with an increase in pressure in the umbilical vein.

\section{Introduction}

With the introduction of umbilical artery Doppler velocimetry, a new tool is added to the methods for fetal surveillance. Flow velocity waveform indices are supposed to provide non-invasive information of fetal circulatory competence and would predict intra-uterine growth retardation and/or perinatal distress $[1,2]$. Others warn against decision making on basis of umbilical artery velocimetry, since this method has not proven its value in comparison with the conventional methods of fetal surveillance $[2,3,4,5]$. Reduced, zero or negative end-diastolic velocities of the umbilical artery flow velocity waveform are associated with increased placental vascular resistance $[6,7]$. Whether or not the pathological umbilical artery waveform is caused by placental disease or by the reaction of the fetus to placental disease, is not yet understood. Some authors report a correlation between the degree of fetal hypoxemia, measured in blood samples obtained by cordocentesis, and increased umbilical or aorta flow velocity indices $[8,9,10,11,12]$. The fetus is able to trigger a cascade of events as a reaction to a shortage of oxygen availability: bradycardia, hypertension, redistribution of blood flow in favor of the heart, brain and adrenals, mediated by chemo- and baroreceptor activity and catecholamine release $[13,14,15,16,17]$. In the chronically instrumented fetal lamb hypoxemia can be induced by various methods: Obstruction of umbilical circulation, obstruction of the uterine circulation, breathing of the ewe of a hypoxic gas mixture and embolisation of the placental microvasculature on the fetal side as well as on the maternal side. In earlier studies we showed that acute and also progressive reduction of uteroplacental blood flow, mechanically as well as by uterine embolisation in absence of bradycardia did not change the umbilical artery Pulsatility Index $[18,19]$.

We designed this study to evaluate the effect of fetal hypoxemia, induced by administration of a low-oxygen gas mixture to the ewe, on placental vascular resistance and umbilical artery Pulsatility Index. 


\section{Materials and Methods}

\section{Surgery}

The experiments were carried out in 7 ewes of the Dutch Texel breed, between 116 and 125 days of gestation (term 147 days). Anesthetic technique and surgical instrumentation has been extensively described previously $[7,18]$. Briefly: surgery was carried out under aseptic conditions and general anesthesia and involved insertion of catheters in the distal aorta via a femoral artery, a catheter in a major umbilical vein via a cotyledonarian vein, placement of an electromagnetic flowmeter around the common umbilical vein and an inflatable balloon occluder around the umbilical cord at the site of the abdominal insertion for in vivo zero blood flow calibration. A 5 $\mathrm{MHz}$ pulsed Doppler probe was placed around one of the two umbilical arteries. The guidelines for the use and care of the animals approved by the local Animal Medical Ethics Committee were followed.

\section{Measurements}

Blood flow in the common umbilical vein was measured with a Skalar transflow 601 flowmeter system (Skalar, Delft, Holland). Fetal arterial blood pressure and umbilical venous pressure were determined with the zero point at the level of the ewe's spine. Fetal heart rate was calculated from the pulse of the arterial blood pressure wave. All signals were led to amplifiers (Hewlett Packard 8800 series, Hewlett Packard, Andover, Massachusetts, USA), displayed on a monitor and an eight-channel strip chart recorder, stored on magnetic tape, digitized and analyzed with a personal computer. Umbilical artery waveforms were obtained by the $5 \mathrm{MHz}$ pulsed Doppler probe around one umbilical artery in four animals. Due to malfunctioning of the $5 \mathrm{MHz}$ indwelling Doppler probe, umbilical artery velocity waveforms were obtained by a $4 \mathrm{MHz}$ continuous wave Doppler device (Delalande Electronique, Courbevoie, France) in the other three animals. The ultrasound beam was insonated from the abdominal skin of the standing ewe after visualisation of the umbilical cord by ultrasonography (Scanner 400, Sanyo, Japan). The origin of the received signals was verified by comparison with fetal heart rate derived from the arterial pressure waveform and by presence of oppositely directed venous blood flow velocities within the Doppler ultrasound beam. The Doppler shift signals were stored in quadrature on analog tape, synchronously with the 
other signals for off-line analysis and transformed by a spectrum analyser (Doptek Ltd., Chicester, England). Pulsatility Index values were obtained by drawing the maximum envelope curves of the frequency-shift spectra with a handguided lightpen.

\section{Experiments}

The animals were allowed to recover for 1 to 3 days after surgery. A plastic bag was placed over the ewe's head and high flow room air was insufflated in the bag during 15 minutes in which baseline conditions were established, including fetal arterial blood samples for assessing fetal $\mathrm{pH}, \mathrm{pO}_{2}, \mathrm{pCO}_{2}$ at 39 degrees celsius (ABL, Radiometer, Copenhagen, Denmark) and fetal arterial hemoglobin concentration and oxygen saturation (OSM2 Hemoximeter, Radiometer, Copenhagen, Denmark) to calculate fetal arterial oxygen content. Subsequently the amount of $\mathrm{N}_{2}$ insufflation was increased to such a degree that the gas mixture in the bag contained $9 \% 12 \% \mathrm{O}_{2}$, in order to achieve a $50 \%$ reduction in fetal arterial oxygen saturation. Three percent $\mathrm{CO}_{2}$ was added to avoid hypocapnia due to maternal hyperventilation. This condition was maintained during 30 to 60 minutes. The percentage of oxygen, present in the bag, was continuously controlled by an oxygen meter (Oxycom 100D, Draegerwerk AG, Luebeck, FRG). Fetal arterial blood was sampled every five to ten minutes and appropriate adjustments in the gas mixture were made if necessary.

\section{Calculations and data analysis}

The mean values of the hemodynamic variables were assessed during a 10 second period, ten minutes before inducing hypoxemia (control period) and directly before or after a fetal. blood sample was taken. Mean umbilical arterial PI was calculated for 5 consecutive heart cycles which occurred during these periods of 10 seconds. Mean arterial pressure, umbilical venous pressure, fetal heart rate and umbilical blood flow were averaged over 10 second periods using a personal computer program. Placental vascular resistance was defined as the difference in fetal mean arterial pressure and umbilical venous pressure divided by the umbilical venous blood flow (Poisseulle equation).

For each individual fetus linear regression lines were calculated using all data of the cardiovascular variables and all data of fetal arterial oxygen content. The regression lines are depicted in the scatterplots of the cardiovascular variables 
versus oxygen content. The slopes of linear regression were tested by a two-tailed Student t-test and considered statistically significant when the interval of reliability exceeded 0.95 $(p<0.05)$. Furthermore, statistical analysis was performed for each variable on the pooled values from each animal by comparing the control values with the values during the period of lowest oxygen content by means of Wilcoxon's matched pairs signed rank test. A p-value of less than 0.05 was taken to represent statistical significance. Mean values are reported with the standard errors ( \pm SEM).

\section{Results}

Table 1 lists the results of the umbilical pulsatility index (PI) values with the hemodynamic variables, fetal arterial blood gasses and $\mathrm{pH}$ during the period of lowest $\mathrm{O} 2$ content compared with the values during the control period.

During maternal breathing of a low oxygen gas mixture fetal arterial oxygen content decreased from $2.28 \pm 0.18 \mathrm{mM}$ during control to $0.93 \pm 0.15$, which is the mean of the lowest levels measured. Fetal $\mathrm{pO}_{2}$ decreased from $1.99 \pm 0.41 \mathrm{kPa}$ to $1.28 \pm 0.34 \mathrm{kPa}$. Fetal arterial $\mathrm{pH}$ and $\mathrm{pCO}_{2}$ were not altered during the experiment. The decrease in oxygen content and $\mathrm{pO}_{2}$ was parallelled by a significant increase in umbilical

Table I. Hemodyamic variables during lowest oxygen content value compared to control walues

\begin{tabular}{lcc}
\hline Variable & control \pm SEM & hypoxemia \pm SEM \\
\hline Pl & $1.00 \pm 0.12$ & $1.06 \pm 0.13$ \\
Heart rate (beats/min) & $173 \pm 5.4$ & $167 \pm 12.7$ \\
FBP(mmHg) & $41.2 \pm 1.6$ & $42.3 \pm 2.4$ \\
UVP (mmHg) & $11.3 \pm 1.3$ & $13.0 \pm 1.6$ \\
QUV (ml/min) & $436 \pm 64.7$ & $491 \pm 65.9^{*}$ \\
PVR (mmig/ml/min) & $0.084 \pm 0.023$ & $0.074 \pm 0.020$ \\
PO2 (kPa) & $1.99 \pm 0.41$ & $1.28 \pm 0.34 *$ \\
pCO2 (kPa) & $4.70 \pm 0.49$ & $4.69 \pm 0.42$ \\
Oxygcn content (mM) & $2.28 \pm 0.18$ & $0.93 \pm 0.15 *$ \\
Fetal pH & $7.34 \pm 0.02$ & $7.33 \pm 0.03$ \\
\hline
\end{tabular}

* $=p<0.05$ Wilcoxon"s matched pairs signed ranks test Abbreviations are explained in the text 

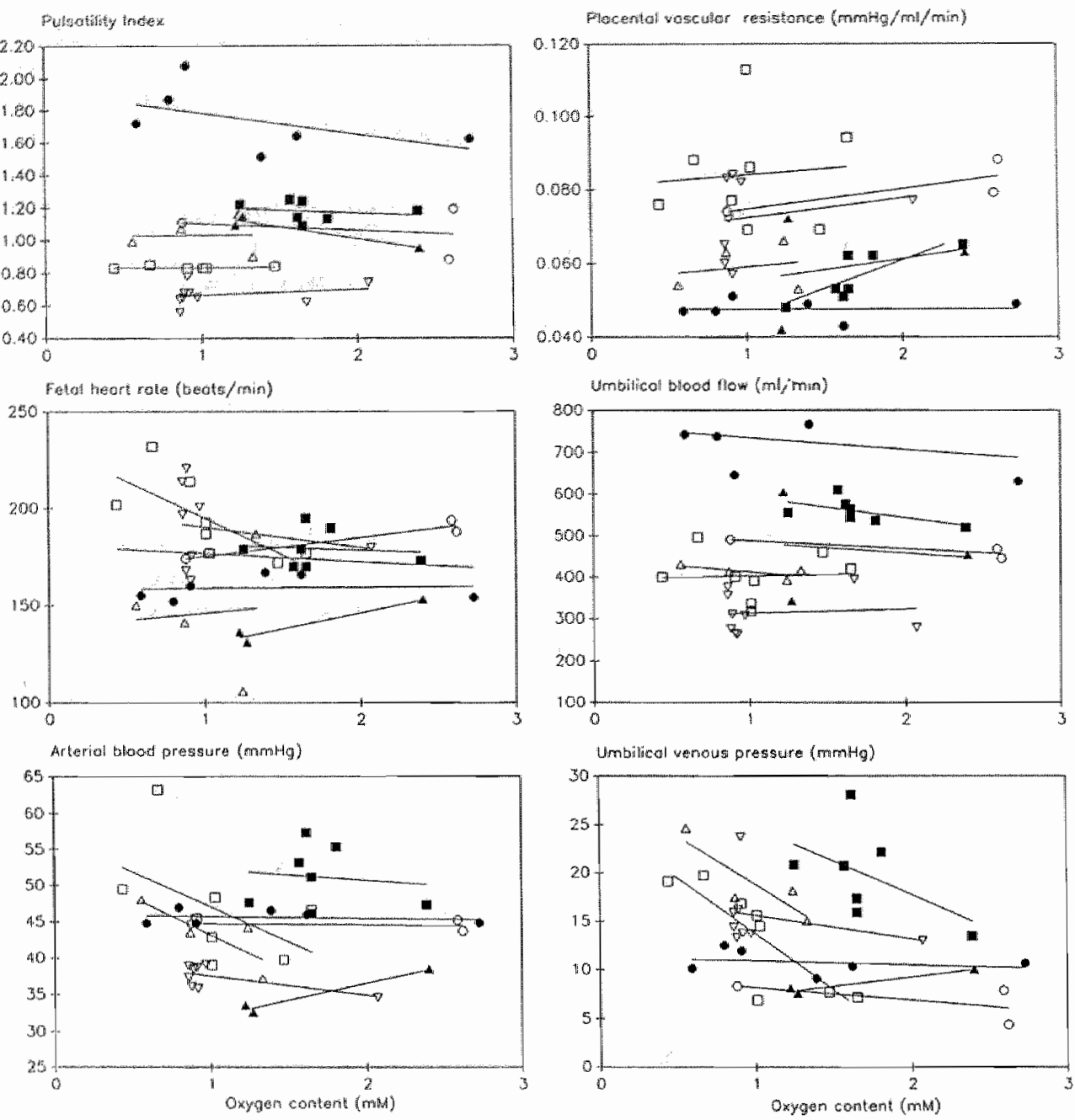

Figure 1. Individual regression lines of the cardiovascular variables versus oxygen content.

venous blood flow (QUV) from $436 \pm 64.7 \mathrm{ml} / \mathrm{min}$ to $491 \pm 65.9$ $\mathrm{ml} / \mathrm{min}(\mathrm{p}<0.05)$. Initially a decrease in fetal heart rate (FHR) was observed in 5 sheep, which returned to control values 10-20 minutes after the onset of the hypoxemia. Fetal arterial blood pressure and umbilical venous pressure increased slightly during the period of lowest oxygen content; these changes were however not significant compared to control. The PI did not change significantly: $1.00 \pm 0.12$ during control 
to $1.06 \pm 0.13$ during hypoxemia. Placental vascular resistance was $0.084 \pm 0.023 \mathrm{mmHg} \cdot \mathrm{min} / \mathrm{ml}$ during control and $0.074 \pm$ $0.020 \mathrm{mmHg} \cdot \mathrm{min} / \mathrm{ml}$ during the period of deepest hypoxemia.

The results of linear regression analysis between the cardiovascular variables and oxygen content are depicted in figure 1. The upper left panel in figure 1 illustrates the data points and regression lines of the Pulsatility Index versus fetal arterial oxygen content $\left(\left[\mathrm{O}_{2}\right]\right)$. The average linear correlation was $-0.046 \pm 0.026$ (not significant $=n . \mathrm{s}$.), with a range between -0.19 and 0.012 . The upper right panel shows the data of placental vascular resistance versus [O2]. A significant trend was observed, all fetuses showed a decrease in placental vascular resistance with decreasing [O2]. Mean linear correlation was $0.00556 \pm 0.00175(\mathrm{p}<0.05)$, range $0.000013-0.015$. Fetal heart rate (middle left panel) increased in 3 fetuses and decreased in 4 fetuses with decreasing [O2]. Mean linear correlation was $-2.49 \pm 6.85$ (n.s.), with a range of -38.15 to 16.72 . The middle right panel shows the relationship between um-

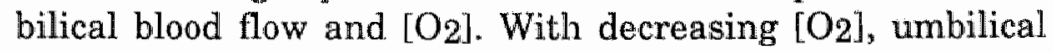
blood flow increased (mean linear correlation: $-19.51 \pm 7.99$ ( $<<0.05$ ), range -49.45 to 9.85 ). The lower left panel shows the linear regression lines and data for the individual animals of mean arterial blood pressure versus [O 2 ]. Mean linear correlation was $-3.09 \pm 2.00$ (n.s.), whille the individual correlation coefficients ranged between -10.41 and 4.60 . In 6 animals mean blood pressure showed an upward trend with decreasing $\left[\mathrm{O}_{2}\right]$, in 1 animal however blood pressure decreased. Umbilical venous pressure showed an inverse correlation with fetal arterial $\left[\mathrm{O}_{2}\right.$ ] (lower right panel). The average correlation was -4.77 $\pm 1.84(\mathrm{p}<0.05)$, range between -11.49 and 1.84 .

\section{Discussion}

The aim of the present study was to investigate the effects of acute maternal hypoxemia on the umbilical artery PI and placental vascular resistance. During the period of deepest. fetal hypoxemia no change occurred in placental vascular resistance and the umbilical artery $\mathrm{PI}$, whereas umbilical blood flow increased and fetal arterial blood pressure, umbilical venous pressure and fetal heart rate did not change. On the other hand, a significant negative linear correlation exists 
between fetal arterial oxygen content and umbilical venous pressure and a positive linear correlation between placental vascular resistance and fetal oxygen content.

Several studies report no change or an increase in umbilical blood flow and a slight increase in fetal blood pressure during hypoxemia $[13,15,20]$. In the present study we observed an increase in umbilical blood flow at the moment of deepest hypoxemia, which is in accordance with the studies of Bocking et al. and Block et al. [14,21]. Fetal arterial blood pressure did not change in the present study, although a, not significant, increasing trend in blood pressure with decreasing oxygenation was noted. The observed significant negative linear correlation between umbilical blood flow and oxygen content and the positive linear correlation between placental vascular resistance and oxygen content, reflect the phenomenon of blood flow redistribution in favor of the umbilical circulation occurring during fetal hypoxemia. The fetal bradycardia occurring at the start of the hypoxemic period in several lambs gradually disappeared and fetal heart rate was not different from control at deepest hypoxemia. A disturbing effect of heart rate on the Pulsatility Index [18] as well as on calculated placental resistance [20] can therefore be excluded.

An interesting finding is the significant negative linear correlation between umbilical venous pressure and oxygen content in the pooled data of all animals. Recently Paulick et al. made the same observation: umbilical venous pressure close to the placenta was markedly elevated during fetal hy. poxemia, while portal sinus and vena cava pressures only slightly increased [22]. They concluded that the major increase in resistance to umbilical venous return during hypoxemia resides in the umbilical veins [22]. The pressure drop in the course of the umbilical venous circulation explains the differences in outcome of placental wascular resistance calculation in different studies, as the umbilical venous pressure value depends on the site of measurement $[22,23]$. We conclude that acute hypoxemia induces no changes in the umbilical artery PI in the fetal lamb.

In human growth retarded fetuses a negative correlation has been reported between the mean blood velocity of the fetal aorta and the degree of fetal hypoxemia measured by means of cordocentesis $[8,11]$. Absence of end-diastolic frequencies in the umbilical artery are a sign of hypoxia and acidosis in human growth retarded fetuses according to Nicolaides et al. [9], although the linear correlation between umbilical artery 
PI and a complex "asphyxia index", based on umbilical venous blood gas analysis after cordocentesis, was very weak [12]. Moreover, Ferrazzi et al. found no significant correlation between umbilical venous oxygen content and the umbilical artery PI in 14 high risk pregnancies [24]. Weiner suggests that factors leading to an increase in the umbilical artery systolic/diastolic ratio are associated with a progressive impairment of placental gas exchange and that by the time diastolic flow is lost, hypoxemia is present [11]. On the other hand, Warren et al. reported a case with absent end-diastolic velocities and normal blood gasses, but with subsequent poor fetal outcome [25]. From these studies in human pregnancy one might conclude that a cause and effect relationship between fetal hypoxemia and elevated blood velocity indices is controversial. In a previous study we showed that severe hypoxemia, induced by uteroplacental flow obstruction, does not alter umbilical artery PI, but has a marked effect on the velocity waveform of the femoral artery in which reversed end diastolic velocities occurred [19]. Block et al, showed that growth retarded fetal sheep are able to meet basal metabolic oxygen requirements by restricting growth and respond in the same way to superimposed acute hypoxemia as normally grown fetal sheep until the placental reserve capacity is depleted [21]. Placental pathology may lead to impairment of fetal oxygen and nutrient uptake, upon which the fetus mobilizes its defence mechanisms. Placental abnormality may also result in end-diastolic blood velocity impairment, but one cannot conclude that hypoxemia and acidosis directly relate to elevated umbilical artery blood velocity indices. To what extent fetal blood velocity waveforms represent the degree of fetal reserve capacity at a given point in time, is not known at present.

We concur with Morrow et al. that normal umbilical artery blood velocity indices do not mean normoxemia [26].

It is concluded that, in the fetal sheep model, fetal hypoxemia induced by restricting the oxygen concentration in the ewe's inspired air, does not affect the umbilical artery PI. Decreasing fetal oxygenation is associated with an increase in pressure in the umbilical venous bed close to the placenta. The observed rise in umbilical blood flow during hypoxemia is parallelled by a tendency of placental vascular resistance to decrease. The flow velocity waveform of the umbilical artery does not reflect acute changes in fetal oxygenation. 


\section{References}

1 Reuwer P.THM, Rietman GW, Sijmons EA et al Intra-uterine growth retardation: Prediction of perinatall distress by Doppler ultrasound. Lancet $1987 ; \mathrm{ii}: 415 \% 8$.

2 Ergine RLA, Ritchie JWK. U mbilical artery blood flow characteristics in normal and growth-retarded fetuses. Br ob Obstet Gynaecol 1985; 92:605-110.

3 Redman CWG. Examination of the placental circulation by Doppler ultrasound. Br Med J 1989;298:621-2.

4 Beattie RB, Dornan JC. Antenatal screening for intrauterine growth retardation with umbilical artery Doppler ultrasonography. Br Med J 1989:298:631-5.

5 Neilson JP. Doppler ul trasound. Br J Obstet Gynaecol 1987;94:929-32.

6 Giles WB, Trudinger BJ, Baird PJ. Fetal umbilical artery flow velocity wave-forms and placental resistance: pathological correlation. $\mathrm{Br} \mathrm{J}$ Obstet Gynaecol 1985;92:31-8.

7 van Huisseling H, Hasaart THM, Muijsers GJJM, de Haan J. Umbilical artery flow velocity waveforms and placental vascular resistance during placental outflow obstruction in fetal sheep. J Dev Physiol 1990 (in press).

8 Soothill PW, Nicolaides KH, Bilardo CM, Campbell S. Relation of fetal hypoxia in growth retardation to mean blood velocity in the fetal aorta. Lancet $1986 ; \mathrm{ii}: 1118-9$.

9 Nicolaides KH, Bilardo CM, Soothill PW, Campbell S. Absence of end diastolic frequencies in umbilical artery; a sign of fetal hypoxia and acidosis. Br Med J 1988;297:1026-7.

10 Nicolaides KH, Bradley RJ, Soothill PW, Campbell S, Bilardo CM, Gibb D. Maternal oxygen therapy for intrauterine growth retardation. Lancet $1987 ; \mathrm{i}: 942-5$.

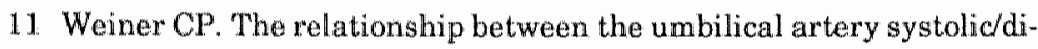
astolic ratio and umbilical blood gas measurements in specimens obtained by cordocentesis. Am J Obstet Gynecol 1990;162:1198-202.

12 Bilardo CM, Nicolaides KH, Campbell S. Doppler measurements of fetal and uteroplacental circulations: Relationship with umbilical venous blood gases measured at cordocentesis. Am J Obstet Gynecol $1990 ; 62: 115-20$.

13 Parer JT. The effects of acute matemal hypoxia on fetal oxygenation and the umbilical circulation in the sheep. Eur J Obstet Gynecol Reprod Biol 1980;10:125-36.

14 Bocking AD, Gagnon R, White SE, Homan J, Milne KM, Richardson BS. Circulatory responses to prolonged hypoxemia in fetal sheep. Am J Obstet Gynecol 1988;159:1418-24. 
15 Cohn HE, Piasecki GJ, Jackson BT. The role of autonomic nerwous control in the fetal cardiovascular response to hypoxemia; in Longo LD and Reneau DD (ed): Fetal and newbom cardiovascular physiology. New York and London, 1978, vol 2, pp 249-58.

16 Peeters LLH, Sheldon $\mathbb{R E}$, Jones Jr MD, Makowski EI, Meschia $\mathrm{G}$. Blood flow to fetal organs as a function of axterial oxygen content. Am J Obst Gynecol 1979;135:637-46.

17 Hanson MA. The importance of baro- and chemoreflexes in the control of the fetal cardiovascular system. J Dew Physiol 1988;10:491-511.

18 van Huisseling $\mathrm{H}$, Hasaart THM, Ruissen CJ, Mujisers GJJM, de Haan J. Umbilical artery flow velocity waveforms during acute hypoxemia and the relationship with hemodynamic changes in the fetal lamb. Am J Obstet Gynecol 1989;161:1061-4.

19 Muijsers GJJM, Hasaart THM, Ruissen CJ, van Huisseling $\mathrm{H}_{*}$ Peeters LLH, de Haan J. The response of the umbilical and femoral artery pulsatility indices in fetal sheep to progressively reduced uteroplacen. tall blood flow. d Dev Physiol 1990 (in press)

20 Rudolph AM. Factors affecting umbilical blood flow in the lamb in utero. Proceedings of the 5 th European congress of perinatal medicine, Uppsala, Sweden 1976:159-72.

21 Block BS, Schlafer DH, Wentworth RA, Kreitzer LA, Nathanielsz PW. Intrauterine grow th retardation and the circulatory responses to acute hypoxemia in fetal sheep. Am J Obst Gynecol 1989;161:1576-9.

22 Paulick RP, Meyers RL, Rudolph CD and Rudolph AM. Venous responses to hypoxemia in the fetal lamb. [Abstract no.311] In: Proceedings of the 37 th annual meeting of the Society of Gynecologic Investigation, St.Louis, Missouri, 1990.

23 Reuss ML, Parer JT, Harris JL, Krueger TR. Hemodynamic effects of alpha-adrenergic blockade during hypoxia in fetal sheep. Am J Obstet Gynecol 1982;142:410-5.

24 Ferrazzi E, Pardi G, Bauscaglia M, Marconi AM, Gementi B, Bellotti M, Makowski L, Battagilia FC. The correlation of biochemical monitoring versus umbilical how velocity measurements of the human fetus. Am J Obstet Gynecol 1988;159:1081-7.

25 Warren W, Ronkin S, Chayen B, Needleman L, Wapner RJ. Absence of end-diastolic umbilical artery blood flow predicts poor fetal outcome despite normal blood gases. Am J Obstet Gynecol 1989;160:197.

26 Morrow RJ, Adamson SL, Bull SB, Knox Ritchie JW. Acute hypoxemia does not affect the umbilical artery flow velocity waveform in fetal sheep. Obstet Gynecol 1990;75:590-3. 



\section{The acute response of the umbilical artery pulsatility index to changes in blood volume in fetal sheep}

Hans van Huisseling, Tom H.M. Hasaart, Guido J.J.M. Muijsers and Jelte de Haan

Submitted for publication

\section{Abstract}

This experimental study was designed to test the effects of acute changes in fetal circulating blood volume on the umbilical artery pulsatility index (PI). Six fetal sheep were provided with an electromagnetic flow meter for measurement of umbilical venous blood flow, with catheters for determination of arterial blood pressure and umbilical venous pressure, and with a $5 \mathrm{MHz}$ Doppler transducer around one umbilical artery for flow velocity waveform analysis. A catheter in the inferior vena cava was used to infuse $50 \mathrm{ml}$ of maternal blood (hypervolemia) into the fetal circulation or to withdraw $50 \mathrm{ml}$ of fetal blood (hypovolemia) after volume correction. Hypervolemia resulted in a rise in arterial pressure and umbilical venous pressure, without an effect on $P I_{\text {, umbilical blood flow or }}$ placental vascular resistance. Hypovolemia resulted in a de. crease in fetal heart rate, arterial pressure, umbilical venous pressure and umbilical blood flow. Calculated placental vascular resistance was not changed, whereas the PI increased by $42 \%$. We conclude that volume loading with $11-15 \%$ of fetal circulating volume does not affect the umbilical artery PI whereas acute reduction of fetal blood volume with the same amount is associated with an increase in the umbilical artery PI, without changes in calculated placental vascular resistance. 


\section{Introduction}

Absent or reversed end-diastolic flow velocities in the umbilical artery are associated with fetal and neonatal morbidity and mortality (1). Abnormal Doppler waveform indices in the umbilical artery are attributed to increased impedance to flow, possibly caused by pathological changes in the placental microvasculature (2). On the other hand, return of previously absent end-diastolic flow velocities in a compromised pregnancy has been observed, suggesting that pathological changes in the placenta are not the only cause for abnormal waveform indices (3). Since the flow velocity waveform is supposed to be the result of several interacting components, such as cardiac performance, vascular diameter and elasticity, blood viscosity and length of the vascular tree and downstream resistance, changes in either one of these components might influence the flow velocity waveform indices.

Changes in blood volume are known to affect cardiac output $(4,5,6,7,8)$. Especially volume depletion of the fetal circulation has been shown to reduce cardiac output and induce hypotension, whereas intravascular volume loading minimally affects cardiac output, but induces hypertension $(4,5,7)$. Clinical studies comparing Doppler flow velocity indices before and after intravascular transfusions for fetal hemolytic disease show either a decrease (9) or no change (10) in blood velocity indices.

In order to study the effect of acute changes in fetal blood volume on the umbilical artery pulsatility index, fetal hypervolemia and hypovolemia was induced by infusion or withdrawal of $50 \mathrm{ml}$ of blood in sheep.

\section{Materials and Methods}

\section{Surgery}

The experiments were carried out in 6 ewes of the Dutch Texel breed, between 117 and 125 days gestation (mean 1.22 days; term 147 days). Anaesthetic technique and surgical instrumentation has been previously described (11). Briefly: surgery was carried out under aseptic conditions and general anesthesia and involved insertion of catheters in the distal aorta via a femoral artery, a catheter in a major umbilical vein via a cotyledonarian vein, a catheter in the inferior vena cava via a femoral vein, placement of an electromagnetic flowmeter around the common umbilical vein and an inflatable balloon 
occluder around the umbilical cord at the site of the abdominal insertion for in wivo zero blood flow calibration. A $5 \mathrm{MHz}$ pulsed Doppler transducer was placed around one of the two umbilical arteries. The guidelines for the use and care of the animals approved by the local Animal Medical Ethics Committee were followed.

\section{Measurements}

Blood flow in the common umbilical vein was measured with a Skalar transflow 601 flowmeter system (Skalar, Delft, Holland). Fetal arterial blood pressure and umbilical venous pressure were determined with the zero point at the level of the ewe's spine. Fetal heart rate was calculated from the pulse of the arterial blood pressure wave. All signals were led to amplifiers (Hewlett Packard 8800 series, Hewlett Packard, Andover Massachusetts, USA), displayed on a monitor and an eight-channel strip chart recorder, stored on magnetic tape and digitized and analyzed with a personal computer. In four animals umbilical artery waveforms were obtained by the 5 $\mathrm{MHz}$ pulsed Doppler probe around one umbilical artery. Due to malfunctioning of the $5 \mathrm{MHz}$ indwelling Doppler probe, umbilical artery velocity waveforms were obtained by a $4 \mathrm{MHz}$ continuous wave Doppler device (Delalande Electronique, Courbevoie, France) in the other two animals. The ultrasound beam was insonated from the abdominal skin of the standing ewe after visualisation of the umbilical cord by ultrasonography (Scanner 400, Sanyo, Japan). The origin of the received signals was verified by comparison with fetal heart rate, derived from the arterial pressure waveform, and by presence of oppositely directed venous blood flow velocities within the Doppler sample volume. The Doppler shift signals were stored in quadrature on analog tape, synchronously with the other signals for off-line analysis, and transformed by a spectrum analyser (Doptek Ltd., Chicester, England). Pulsatility Index values were obtained by drawing the maximum envelope curves of the frequency-shift spectra with a handguided lightpen (12).

\section{Experiments}

The animals were allowed to recover for 2 to 5 days after surgery. Baseline conditions were established during at least 30 minutes, including fetal arterial blood samples for assessing fetal $\mathrm{pH}, \mathrm{pO}_{2}, \mathrm{pCO}_{2}$ at 39 degrees celsius (ABL, Radiometer, Copenhagen, Denmark), hematocrit, fetal arterial hemo- 
globin concentration and oxygen saturation (OSM2 Hemoximeter, Radiometer, Copenhagen, Denmark). Fetal hypervolemia was induced by infusion of $50 \mathrm{ml}$. freshly withdrawn maternal blood into the fetal inferior vena cava over a period of 5 minutes. After a period of 30 minutes blood volume was restored by withdrawing $50 \mathrm{ml}$ of fetal blood in 5 minutes. One hour after blood volume correction and after return to baseline heart rate, blood pressures and umbilical blood flow, hypovolemia was induced by withdrawing $50 \mathrm{ml}$. of fetal blood from the inferior vena cava catheter in 5 minutes. The blood was stored in a heparinised syringe and kept at 39 degrees for restitution to the fetus after the experiment. Before and after changes in blood volume were induced, blood samples were taken to determine fetal arterial blood gases, $\mathrm{pH}$, hemoglobin, hematocrit and oxygen content.

\section{Calculations and data analysis}

The mean values of the cardiovascular variables were assessed during a 10 second period before inducing changes in fetal blood volume (control period) and a 10 second period at two minutes after infusion or withdrawal of blood. Mean umbilical artery pulsatility index was calculated from 5 consecutive heart cycles which occurred during these periods of 10 seconds. Mean arterial pressure, umbilical venous pressure, fetal heart rate and umbilical blood flow were avaraged over 10 second periods using a personal computer program. Placental vascular resistance was defined as the difference in fetal mean arterial pressure and umbilical venous pressure divided by umbilical venous blood flow (Poisseuille equation).

Statistical analysis was performed for each variable on the pooled values from each animal by comparing the control values with the values shortly after the changes in blood volume by means of Wilcoxon's matched pairs signed ranks test. The values of fetal blood gases, $\mathrm{pH}$, base excess, hematocrit, hemoglobin and oxygen content were compared with the values preceeding the induced change in blood volume. A p-value of less than 0.05 was taken to represent statistical significance. Mean values are reported with the standard errors $( \pm \mathrm{SEM})$. 


\section{Results}

The effects of the acute blood volume changes on the cardiovascular variables under investigation were short lasting and had in general disappeared within 30 minutes. These findings are in accordance with the observations of Brace (13).

The results of the values of the arterial blood gas tensions, $\mathrm{pH}$, base excess, hemoglobin, hematocrit and oxygen content are shown in table I. There were no significant changes in $\mathrm{pO}_{2}$, $\mathrm{pCO}_{2}, \mathrm{pH}$, base excess, hematocrit and oxygen content between hypervolemia and control, between normovolemia after volume correction and hypervolemia, and between hypovolemia and the preceeding normovolemic state. A slight increase was seen in hemoglobin from control to hypervolemia and a decrease between hypovolemia and normovolemia.

Table I. Fetal blood variables during control and after changes in blood volume.

Values are compared with the preceeding value.

\begin{tabular}{|c|c|c|c|c|}
\hline Variable & Control & Hypenvolemia & Volumecorrection & Hypovolemia \\
\hline $\mathrm{pH}$ & $7.36 \pm 0.02$ & $7.37 \pm 0.01$ & $7.36 \pm 0.01$ & $7.35 \pm 0.01$ \\
\hline $\mathrm{pCO}_{2}(\mathrm{mmHg})$ & $38.5 \pm 2.7$ & $38.5 \pm 2.2$ & $39.8 \pm 3.5$ & $39.7 \pm 2.6$ \\
\hline $\mathrm{pO}_{2}(\mathrm{mmHg})$ & $13.1 \pm 2.0$ & $12.0 \pm 1.7$ & $11.7 \pm 1.7$ & $11.1 \pm 1.0$ \\
\hline Base excess & $-3.2 \pm 1.7$ & $-2.0 \pm 1.2$ & $-3.2 \pm 1.3$ & $-3.1 \pm 1.3$ \\
\hline Hemaglobin ( $\mathrm{mmol} / \mathrm{l})$ & $6.6 \pm 0.5$ & $7.0 \pm 0.3^{*}$ & $7.2 \pm 0.4$ & $6.4 \pm 0.5^{*}$ \\
\hline Hematocrit (\%) & $38.5 \pm 2.6$ & $39.8 \pm 2.8$ & $39.3 \pm 2.0$ & $37.5 \pm 2.8$ \\
\hline $\mathrm{O}_{2}$ content $(\mathrm{mM})$ & $2.76 \pm 0.33$ & $2.37 \pm 0.36$ & $2.48 \pm 0.36$ & $2.08 \pm 0.28$ \\
\hline
\end{tabular}

* $=p<0.05$ (Wilcoxon matched pairs signed ranks test) Values are expressed as mean $\pm S E M$.

\section{A. Hypervolemia}

The cardiovascular data during the control period and during the 10 second period shortly after infusion of $50 \mathrm{ml}$. maternal blood are shown in table II and illustrated as percentage change of control in figure 1. The umbilical artery PI was not significantly different from control. Fetal heart rate (FHR) decreased slightly but insignificantly after infusion of the maternal blood. Fetal blood pressure (FBP) was increased after the blood infusion with $29 \%$ to $43.4 \pm 3.0 \mathrm{mmHg}$ (p<0.05) and umbilical venous pressure (UVP) was increased with more than $100 \%$ to $9.1 \pm 2.4 \mathrm{mmHg}(\mathrm{p}<0.05)$. Placental perfu- 
Table II. Results of cardiovascular variables compared with control after intravenous infusion of $50 \mathrm{cc}$ maternal blood.

\begin{tabular}{lcc}
\hline Variable & Control & Hypervolemia \\
\hline PI & $1.03 \pm 0.11$ & $1.11 \pm 0.16$ \\
FHR (beats/min) & $174 \pm 8$ & $163 \pm 5$ \\
FBP (mmHg) & $33.6 \pm 3.4$ & $43.4 \pm 3.0^{*}$ \\
UVP (mmHg) & $4.4 \pm 4.0$ & $9.1 \pm 2.4^{*}$ \\
FBP UVP (mmHg) & $30.8 \pm 1.4$ & $32.4 \pm 3.7$ \\
QUV (ml/min) & $440 \pm 54$ & $514 \pm 72$ \\
PVR (mmHg.min/ml) & $0.072 \pm 0.010$ & $0.080 \pm 0.023$ \\
\hline
\end{tabular}

$*=0<0.05$ (Wilcoxon matched pairs signed ranks test) Abbreviations are explained in the text. Values are expressed as mean \pm SEM.

\section{hypervolemia}

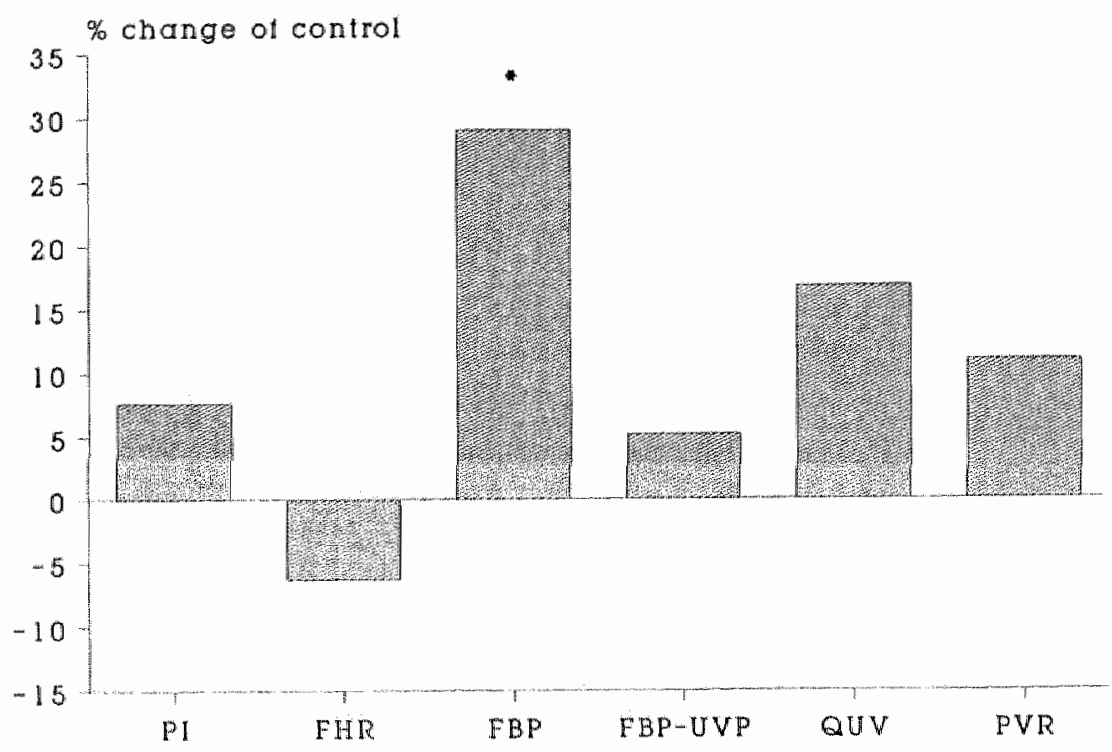

Figure 1. Acute changes of the cardiovascular variables after infusion of $50 \mathrm{ml}$ of maternal blood into the fetal circulation expressed as percent change of control. The change in umbilical wenous pressure is not depicted because of the magnitude of the change. Hypervolemia causes an increase in fetal arterial pressure and umbilical venous pressure (not depicted), with no significant change in umbilical blood flow, placental vascular resistance and pulsatility index. ${ }^{*}=p<0.05$ (Wilcoxon's matched pairs signed ranks test) 


\section{hypovolemia}

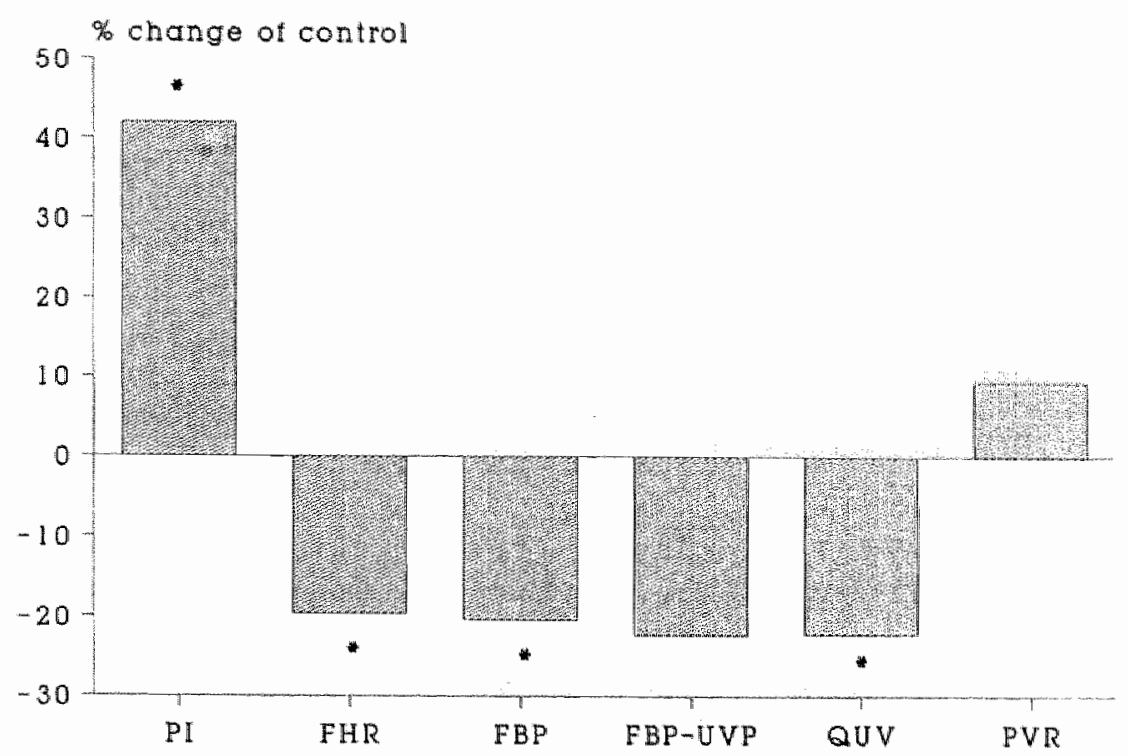

Figure 2. Acute changes of the cardiovascular variables after withdrawal of $50 \mathrm{ml}$. of fetal blood expressed as percent change of control. The change in umbilical venous pressure is not depicted because of the magnitude of the change. Hemorrhage causes arterial hypotension, a decrease in umbilical venous pressure (not depicted), and a decrease in umbilical blood flow with a marked rise in umbilical artery Pulsatility Index. ${ }^{*}=p<0.05$ (Wilcoxon's matched pairs signed ranks test)

sion pressure (FBP-UVP) did not differ significantly from control. Umbilical blood flow (QUV) showed a small but, insignificant rise of $17 \%$ during hypervolemia. No significant change in calculated placental vascular resistance (PVR) was observed after blood infusion.

\section{B. Hypovolemia}

Impressive changes occurred during hypovolemia after withdrawal of $50 \mathrm{ml}$. of fetal blood. The results are shown in table III and illustrated in figure 2 as percent change of control. The umbilical artery Pulsatility Index increased with $42 \%$ to $1.42 \pm 0.19$ ( $\mathrm{p}<0.05$ ). In one fetus nearly zero end-diastolic flow velocities were observed during hypovolemia. Fetal 
Table III. Results of cardiovascular wathables compared with control after reduction of blood wolume by withdrawal of $50 \mathrm{ml}$ fetal blood.

\begin{tabular}{lcc}
\hline Variable & Control & Hypovolemia \\
\hline PI & $1.00 \pm 0.12$ & $1.42 \pm 0.19^{*}$ \\
FHR (beats/min) & $183 \pm 7$ & $147 \pm 14^{*}$ \\
FBP (mmHg) & $30.8 \pm 5.8$ & $24.5 \pm 5.5^{*}$ \\
UVP (mmHg) & $4.0 \pm 3.3$ & $0.9 \pm 3.8^{*}$ \\
FBP-UVP (mmHg) & $30.4 \pm 3.8$ & $23.6 \pm 2.0$ \\
QUV (ml/min) & $482 \pm 65$ & $375 \pm 70^{*}$ \\
PVR (mmHg.min/ml) & $0.073 \pm 0.016$ & $0.080 \pm 0.019$ \\
\hline
\end{tabular}

$*=p<0.05$ (Wilcoxon marched pairs signed ranks test) Abbreviations are explained in the text, Values are expressed as mean \pm SEM.
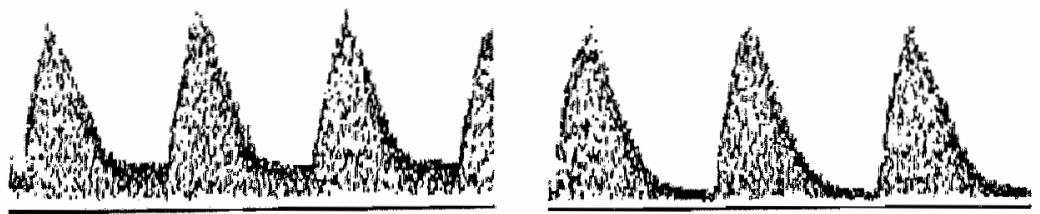

Figure 3. Example of of umbilical artery flow velocity waveforms during control (left panel) and shortly after hemorrhage (right panel). A reduction of end-diastolic flow vellocities is observed after hemorrhage with no major change in fetal heart rate.

heart rate was decreased with $20 \%$ to $147 \pm 14$ beats $/ \mathrm{min}$. Fetal hypotension occurred with a decrease of $20 \%$ to $24.5 \pm$ $5.5 \mathrm{mmHg}(\mathrm{p}<0.05)$ and umbilical venous pressure dropped with $75 \%$ to $0.9 \pm 3.8 \mathrm{mmHg}(\mathrm{p}<0.05)$. The $22 \%$ decrease in placental perfusion pressure to $23.6 \pm 2.0 \mathrm{mmHg}$, was not significant. Umbilical blood flow fell significantly with $22 \%$ to $375 \pm 70 \mathrm{ml} / \mathrm{min}$ during hypovolemia $(\mathrm{p}<0.05)$. Placental vascular resistance was not changed after blood withdrawal.

\section{Discussion}

The purpose of the present study was to investigate the effect of blood transfusion and blood withdrawal on the umbilical artery pulsatility index and placental vascular resistance as calculated by the Poisseuille equation. Creasy et al. determined fetal placental blood volume to be $135 \mathrm{ml} . / \mathrm{kg}$. fetal 
weight (14). The mean weight of the fetuses at autopsy was 2.9 $\pm 0.4 \mathrm{~kg}$. Therefore it was estimated that we infused or removed 11-15\% of feto-placental blood volume.

Impressive changes were observed in response to hemorrhage (figure 2). The existence of a reduction in cardiac output is concluded from the fall in fetal heart rate and umbilical blood flow together with a drop in fetal arterial and venous blood pressures. Several factors may be responsible for the observed $42 \%$ increase in umbilical artery PI. Firstly, it is known that bradycardia increases the umbilical artery PI (11), but the $20 \%$ decrease in fetal heart rate does not completely account for the $42 \%$ increase in umbilical artery PI. This is furthermore illustrated by the nearly zero end-diastolic flow velocities observed in one of the fetuses, during slightly reduced heart rate (figure 3). Secondly, changes in downstream resistance affect the blood flow velocity waveform by reducing end-diastolic velocities. Hemorrhage increases fetal levels of catecholamines (15), angiotensin II (16) and vasopressin (17), of which the latter two are known to induce vasoconstriction in the arterial umbilico-placental vascular bed $(18,19)$. Calculated total placental vascular resistance, however, did not change. This finding is in accordance with the study of Toubas et al.(8). Thirdly, underfilling of the vascular bed may influence diastolic blood velocities. Volume flow (Q) is represented by the formula blood velocity (v) times cross sectional vessel area $\left(\mathrm{Q}=\mathrm{v} \cdot \pi \mathrm{r}^{2}\right)$. The degree of extension of the vessel wall during systole and diastole is dependent on the transmural pressure gradient. Underfilling of the vascular bed leads to hypotension and a fall in umbilical blood flow. As a result, the degree of vessel wall extension during systole will be smaller, but was in the present experiments apparently large enough to maintain systolic velocities, as peak systolic velocity did not fall (fig 3). During diastole, however, collapse of the umbilical artery vessel wall does not occur. The cross sectional area of the vessel will be maintained at a certain intrinsic unstrained value (20). Diastolic blood flow velocities therefore will diminish on the basis of the aforementioned formula, as volume flow decreases due to hypotension while vessel diameter is maintained. A rapid loss of diastolic frequencies and a decrease in umbilical flow has been reported during fetal hypotension after nitroprusside infusion (21). Fetal hypoxemia did not contribute to the rise in PI as arterial oxygen content was not altered after acute hemorrhage. Moreover, we have shown in a previous study that even severe fetal 
hypoxemia does not affect the umbilical artery PI (22). No differences were observed in fetal hematocrit during the course of the experiment which could account for changes in the umbilical artery flow velocity waveform $(23,24)$. The increase in pulsatility index during hypovolemia is thus explained by the fall in end-diastolic velocities during hypotension. The $20 \%$ decrease in heart rate may have had an additional effect on the rise in umbilical artery PI.

Infusion of $50 \mathrm{ml}$. of maternal blood into the fetal circulation resulted in an increase in umbilical venous pressure and a $29 \%$ rise in fetal arterial pressure with an insignificant change in umbilical blood flow. These findings are in accordance with earlier studies by Gilbert et al. and Schröder et al $(4,5,7)$. Volume loading has no major effect on cardiac output, because the fetal heart works near the top of the Starling curve $(4,5)$. No changes were observed in placental vascular resistance and the umbilical artery pulsatility index after blood infusion.

Fetal blood transfusions under pathological, and compared to these experiments, different conditions as e.g. erythroblastosis foetalis in the human, have been reported to be associated with either no change or a decrease in umbilical artery blood velocity waveform indices $(9,10)$.

We conclude that fetal hypotension induced by a $11-15 \%$ reduction of fetal blood volume causes an increase in the umbilical artery pulsatility index, which is not associated with increased placental vascular resistance. An 11-15\% increase in fetal blood volume, resulting in a $29 \%$ rise in arterial blood pressure does not affect the umbilical artery PI or placental vascular resistance.

This study provides evidence that increased umbilical artery blood velocity indices are not necessarily related to placental vascular pathology, but may be a sign of fetal hypotension.

\section{References}

1 Woo JSK, Liang ST, Lo RLS. Significance of an absent or reversed end diastolic flow in Doppler umbilical artery waveforms. J Ultrasound Med 1987;6:291-7.

2 Giles WB, Trudinger BJ, Baird PJ. Fetal umbillical artery flow velocity waveforms and placental resistance: pathological correlation. $\mathrm{Br} J$ Obstet Gynaecol 1985;92:31-8. 
3 Hanrety KP, Whitte MJ, Rubin PC. Feappearance of end diastolic velocity in a pregnancy complicated by severe pregnancy induced hypertension. Am J Obstet Gynecol 1988; 158:11234.

4. Gilbert RD. Control of fetal cardiac output during changes in blood volume. Am J Physiol 1980;238H80-6.

5. Gibert RD. Effects of afterload and baroreceptors on cardiac function in fetal sheep. of Dev Physiol 1982,4:299-309.

6 Faber JJ, Gault CF, Green TJ, Thornburg KL. Fetal blood volume and fetal placental blood flow in lambs. Proc Soc Exp Biol Mod 1973; $142: 340-4$.

7 Schröder $\mathrm{H}$, Gilbert $\mathrm{RD}$, Power GG. Urimary and hemodynamic responses to blood volume changes in fetal sheep. J Dev Physiol 1984; $6: 131-41$.

8 Toubas PL, Silverman NH, Heymann MA, Rudolph AM. Cardiovascular effects of acute hemorrhage in fetal lambs. Am J Physiol 1981; 240:H45-8.

9 Weiner CP, Anderson TL. The acute effect of cordocentesis with or without fetal curarization and of intravascular transfusion upon umbilical artery waveform indices. Obstet Gynecol 1989;73:219-24.

10 Copel JA, Grannum PA, Belanger K, Green JJ, Hobbins JC. Pulsed Doppler flow-velocity waveforms before and after intrauterine intravascular transfusion for severe erythroblastosis fetalis. Am J Obstet Gynecol 1988;158:768-74.

11 van Huisseling H. Hasaart THM, Ruissen. CJ, Muijsers GJJM, de Haan J. Umbilical artery flow velocity wave forms during acute hypoxemia and the relationship with hemodynamic changes in the fetal lamb. Am J Obstet Gynecol 1989;161:1061-4.

12 Ruissen $C J$, van Vugt JMG, Hoogland HJ, Hoeks APG, de Haan J. Technical aspects of fetal Doppler measurements. Gynec Obstet. Invest $1987: 24: 1-13$

13 Brace RA. Ovine fetal cardiovascular responses to packed red blood cell transfusions. Am J Obstet Gynecol 1989;161:1367-4.

14 Creasy $\mathbb{R K}$, Drost M, Green MV, Morris JA. Determination of fetal, placental, and neonatal blood volumes in the sheep. Circ Res 1970; 27:487-94.

15 Jones CM, Rose JC, Randall IKT, Hargrave BY. Catecholamine responses in fetal lambs subjected to hemorrhage. Am J Obstet Gynecol 1985; 151:475-8.

16 Robillard JE, Gomez RA, Meernik JG, Kuehl WD, VanOrden D. Role of angiotensin II on the adrenal and vascular responses to he morrhage during development in fetal lambs. Circ Res 1982;50:645-50.

17 Drummond WH, Rudolph AM, Keil LC, Gluckman PD, MacDonald AA, Heymann MA. Arginine vasopressin and prolactin after hemorthage in the fetal lamb. Am J Physiol 1980;238:E214-9. 
18 Irion $\mathrm{GL}$, Mack CE, Clark KE. Fetal hemodynamic and fetoplacental vascular response to exogenous arginine vasopressin. Am J Obstet Gynecol 1990;162:1115-20.

19 Iwamoto HS, Rudolph AM. Effects of angiotensin II on the blood flow and its distribution in fetal lambs. Circ Res 1981;48:183-9.

20 Milnor WR. Properties of the vascular wall In Hemodynamics. Baltimore, USA: Williams and Wilkins, 1982, pp 56-91.

21 CopelJA, Schlafer D, Wenthworth R, Figueroa JP, Hobbins JC, Nathanielsz PW. Effects of acute fetal and maternal hypotension on umbilical artery Doppler waveforms and fetal acid-base status. [Abstract no.310/ In: Proceedings 37 th Annual Meeting of the Society for Gymecolocical Investigation, St. Louis, Missouri, 1990, p 251.

22 Muijsers GuJM, Hasaart THM, van Huisseling $H$, de Haan J. The response of the umbilical artery Pulsatility Index in fetal sheep to acute and prolonged hypoxemia and acidemia induced by embolization of the uterine circulation. J Dev Physiol 1990 (in press).

23 Steel SA, Pearce JMF, Nash G, Christopher B, Dormandy J, Bland JM. Correlation between Doppler flow velocity waveforms and cord blood viscosity. $\mathrm{Br} J$ Obstet Gynaecol 1989;96:1168-72.

24 Rightmire DA, Nicolaides KH, Rodeck CH, Campbell S. Fetal blood velocities in $\mathrm{Rh}$ isoimmunization: relationship to gestational age and to fetal hematocrit. Obstet Gynecol 1986;68:233-6. 


\section{Umbilicoplacental vasculatory}

responses to norepinephrine and angiotensin II in relation to blood velocity waveforms in the placental circulation in fetal sheep

Hans van Huisseling, Guido J.J.M. Muijsers and Tom H.M. Hasaart

Submitted for publication

\section{Abstract}

The effects of 5 microgram angiotensin II (AII) and 10 microgram norepinephrine (NE) bolus injections on the vascular resistances and pulsatility indices at two sites of the umbilicoplacental circulation were assessed in 8 anesthesized fetal sheep in utero. Catheters were advanced in the distal aorta, a cotyledonary artery, a cotyledonary vein and the inferior vena cava. An electromagnetic flowmeter, as well as a $20 \mathrm{MHz}$ Doppler transducer were attached to the common umbilical artery. Another Doppler transducer was placed on a cotyledonary artery. Following $\mathrm{NE}$ a $178 \%$ increase in umbilical venous resistance and a $225 \%$ rise in umbilical venous pressure was observed, with no effect on umbilical blood flow, umbilical artery resistance and umbilical pulsatility index (PIumb), cotyledonary vascular resistance and cotyledonary artery pulsatility index (PIcot). In contrast, AII induced a 5 -fold increase in umbilical artery resistance with a $36 \%$ fall in umbilical blood flow, whereas smaller and insignificant increases in the resistances of the umbilical venous circulation and the cotyledonary vasculature were measured. The vasoconstrictive effect of AII on the umbilical artery appears to be associated 
with an increase in the umbilical artery PI, but induces inconsistent changes in the cotyledonary artery PI. Constriction of the umbilical vein after $\mathrm{NE}$, does not affect umbilical blood flow, umbilical artery and cotyledonary vascular resistance and does not appear to influence umbilical and cotyledonary artery PI.

\section{Introduction}

The umbilical artery flow velocity waveform displays a frequency pattern with relatively high diastolic velocities, which is indicative for low impedance distal to the site of measurement (1). Reduced, zero or even reversed end-diastolic velocities are attributed to increased impedance and associated with severe fetal and neonatal mortality and morbidity (2). Increased impedance of the placental vascular bed is possibly associated with pathological changes in the placenta in cases of intrauterine growth retardation (3). Increasing attention, however, is drawn to the fact that umbilical artery flow velocimetry is capable of predicting adverse perinatal outcome, rather than to predict intrauterine growth retardation $(4,5)$. A wide range of sensitivities and specificities are reported regarding the prediction of perinatal distress and/or intra-uterine growth retardation with umbilical artery velocimetry. This indicates that introduction of umbilical artery velocimetry into clinical practice is still questionable, until large controlled randomised clinical trials have been performed. Furthermore, a paucity of experimental data exists, with regard to the physiological and pathophysiological basis of the umbilical artery flow velocity waveform. One of the determinators of the shape of the flow velocity waveform is downstream vascular resistance. Adamson et al. showed that angiotensin II and norepinephrine play an important role in controlling umbilical vasomotor tone and are capable to change placental perfusion by vasoconstriction at different sites of the umbilicoplacental circulation (6). Both hormone levels are increased during fetal stress as e.g. hypoxemia or hemorrhage $(7,8,9)$. Angiotensin II has a vasoconstrictive effect on the arterial umbilical circulation, whereas norepinephrine exerts its action on the venous side of the umbilical circulation $(6,10,11)$. According to Tulenko the most potent vasoconstrictive effect of angiotensin II is exerted in the small arteries supplying the chorionic villi (12). The objective of the 
present study was to assess the effect of resistance changes in different umbilicoplacental vascular beds on proximal and distal umbilical artery blood velocity waveforms. To this end we placed Doppler transducers at two sites of the umbilical artery, i.e. the common umbilical artery and a cotyledonary artery. Resistances were changed by administration of norepinephrine and angiotensin II.

\section{Materials and Methods}

\section{Surgery}

Surgical instrumentation was carried out in 8 ewes of the Dutch Texel breed, between 112 days and 127 days of gestation (term 147 days). Anesthesia was induced with pentobarbital and maintained with 5\% halothane in 2:1 mixture of nitrous oxide and oxygen. The abdomen was opened through a paramedian incision. The fetal lambs were approached by hysterotomy in the uterine wall lying over the fetal pelvis. For another experimental protocol a $20 \mathrm{MHz}$ pulsed Doppler transducer was placed on the fetal abdominal aorta, just below the diaphragm. A precalibrated electromagnetic flow transducer (Skalar, Delft, The Netherlands) was placed retroperitoneally around the common part of the umbilical arteries, together with a $20 \mathrm{MHz}$ pulsed Doppler transducer $(545 \mathrm{C}-4$ Directional Pulsed Doppler Flowmeter, University of Iowa, Iowa City, USA). Fetal instrumentation involved furthermore the insertion of a polyvinyl catheter (outer diameter $1.6 \mathrm{~mm}$, inner diameter $0.8 \mathrm{~mm}$ ) in the femoral artery, advanced up into the distal aorta just above the offspring of the umbilical arteries, for registration of fetal arterial pressure, which is representative of umbilical arterial pressure (13). A catheter was inserted into the inferior vena cava via a femoral vein. Subsequently the fetus was replaced in the uterus and a catheter was inserted into a major umbilical vein through a cotyledonary vein for the measurement of umbilical venous pressure and another catheter was advanced through a cotyledonary artery in a major branch of one umbilical artery. A second $20 \mathrm{MHz}$ pulsed Doppler was placed on a major branch of the umbilical artery, just before branching into cotyledonary arteries. The uterus was closed in one layer and the maternal abdominal wall was approximated with surgical clamps. The catheters, Doppler and flowprobe wires were ex- 
teriorized through the incision. "The guidelines for the care and use of the animals approved by the local institution were followed.

\section{Measurements}

The experiments were conducted one hour after surgery, with the ewe in right lateral tilt position and maintained anesthesia. Blood flow in the common umbilical artery (QUA) was measured with a Skalar transflow 601 flowmeter system (Skalar, Delft, The Netherlands). Fetal arterial blood pressure, umbilical arterial and venous pressures and inferior vena cava pressure were determined with the zero point at the level of the abdominal incision. Fetal heart rate was derived from the pulse generated by the arterial pressure signal. All signals were led to amplifiers (Hewlett Packard 8800 series, Hewlett Packard Company, Andover, Massachusetts, USA), displayed on a monitor and an eight-channel strip chart recorder, stored on magnetic tape, digitized and analyzed using a personal computer program. The mean values of the arterial and venous blood pressures and umbilical blood flow were calculated over 10 second periods. The Doppler shift signals, obtained by the two indwelling $20 \mathrm{MHz}$ pulsed Doppler transducers, were stored in quadrature on analog tape, synchronously with the electromagnetic flow measurements, fetal arterial and venous pressures, umbilical arterial and venous pressures and fetal heart rate for off-line analysis. The Doppler shift signals were transformed by a spectrum analyser (Doptek, Chicester, England) and off-line analysis was performed by drawing the maximum envelope curves of the frequency-time spectra with a hand-guided lightpen (14).

\section{Experiments}

After establishing baseline values during one hour $1 \mathrm{ml}$. boluses of 5 micrograms angiotensin II or 10 micrograms norepinephrine were injected into the inferior vena cava after randomization. Each drug administration was followed by a $30 \mathrm{~min}$. recovery period. The mean values of the arterial and venous pressures and umbilical blood flow were assessed during the 10 second intervals at 30 seconds and at oneminute intervals for 7 minutes after intravenous injection of either norepinephrine or angiotensin II. The pulsatility index (PI) was used as a descriptive parameter for the proximal and distal umbilical artery flow velocity waveforms (15). The aver- 
age PI of five consecutive heart cycles was taken as the representative value during the aforementioned 10 second intervals.

\section{Calculations and data analysis}

Pressure differences were calculated between mean arterial pressure in the aorta ( $\mathrm{Pa}$.aor) and mean cotyledonary artery pressure ( $\mathrm{Pa} . \mathrm{cot})$, between mean cotyledonary artery pressure and mean cotyledonary venous pressure (Pv.cot), and between mean cotyledonary venous pressure and mean inferior vena cava pressure (Pv.cav). Umbilicoplacental vascular resistances were calculated using the Poisseuille equation for each subsequent traject of the umbilicoplacental circulation. This means that the vascular resistance value of the umbilical artery ( $\mathrm{R} 1$ ) is (Pa.aor-Pa.cot) divided by the umbilical blood flow (QUA), the resistance of the cotyledonary microvasculature (R2) is (Pa.cot-Pv.cot) divided by QUA, and the resistance of the umbilical vein (R3) is (Pr.cot-Pv.cav) divided by QUA. Baseline values were compared with maximum response values to norepinephrine or angiotensin II injection using Wilcoxon's matched pairs signed ranks test with Bonferroni correction for repeated comparisons (16).

\section{Results}

\section{Control values}

Since angiotensin II and norepinephrine were administered in random order, the results of the changes in cardiovascular variables were compared with control values, obtained prior to the injection of the drug. The results of the mean control values are listed in tables I and II. Baseline values before norepinephrine and angiotensin II injection were not significantly different from each other. Roughly, baseline pressure dropped with $35 \%$ from distal aorta to cotyledonary artery, with $57 \%$ from cotyledonary artery to cotyledonary vein, and with $36 \%$ from cotyledonary vein to inferior vena cava.

In 6 animals simultaneous baseline values of the common umbilical artery PI and cotyledonary artery PI could be obtained and compared. In 4 animals a higher value, and in 2 animals a lower value of the cotyledonary artery PI was observed, compared to common umbilical artery $\mathbb{P I}$. The mean of the common umbilical artery PI in these 6 animals was $1.01 \pm$ 
Table 1. Hewodynamic variables ( 1 SEM) conpared to control value (I SEM) at 1 and 2 minutes after an intravenous bolus of 10 microgran norepinephrine in 7 fetal sheep. The values of the PI's are obtained in 4 sheep.

\begin{tabular}{|c|c|c|c|}
\hline Variable & Control & Value all I minute & Value at 2 minutes \\
\hline Plumb $(n=4)$ & $0.98 \pm 0.06$ & $0.94 \pm 0.03$ & $0.97 \pm 0.08$ \\
\hline $\operatorname{PIcot}(n=4)$ & $1.56 \pm 0.40$ & $1.27 \pm 0.28$ & $1.29 \pm 0.28$ \\
\hline FHR (beats/min) & $167 \pm 8$ & $198+20$ & $182 \pm 15$ \\
\hline QUA (m)/min) & $333 \pm 69$ & $383 \pm 78$ & $354 \pm 73$ \\
\hline Pa.aor $(\mathrm{mmHg})$ & $40.2 \pm 1.3$ & $59.7 \pm 1.2^{*}$ & $56.3 \pm 2.2 *$ \\
\hline Pacol (mmilg) & $26.2 \pm 1.6$ & $45.5 \pm 2.0^{*}$ & $42.8 \pm 3.9^{*}$ \\
\hline PV.cot $(\mathrm{mmHg})$ & $9.7 \pm 0.6$ & $22.7 \pm 3.7^{*}$ & $23.5 \pm 3.8 *$ \\
\hline Pr.cav (mmllg) & $4.1 \pm 0.8$ & $6.2 \pm 1.1$ & $5.5 \pm 1.0$ \\
\hline Pa.aor-Pa cot (mmHg) & $13.9 \pm 1.9$ & $14.2 \pm 1.9$ & $13.4 \pm 2.9$ \\
\hline Pa.cot $P_{\mathrm{V}} \operatorname{col}(\mathrm{mmHg})$ & $16.5 \pm 1.5$ & $22.7 \pm 2.1^{*}$ & $19.3 \pm 2.3$ \\
\hline PV.col.PV.caw (mmHg) & $5.5 \pm 0.8$ & $16.5 \pm 3.5^{*}$ & $17.9 \pm 4.1 *$ \\
\hline $\mathrm{R} 1$ (mm $\mathrm{Hg} / \mathrm{ml} / \mathrm{min})$ & $0.051 \pm 0.0008$ & $0.046 \pm 0.010$ & $0.047 \pm 0.013$ \\
\hline $\mathrm{R} 2(\mathrm{~mm} \mathrm{Hg} / \mathrm{mul} / \mathrm{min})$ & $0.070 \pm 0.021$ & $0.070 \pm 0.011$ & $0.062 \pm 0.009$ \\
\hline $\mathrm{R} 3(\mathrm{~mm} \mathrm{H} \mathrm{g} / \mathrm{ml} / \mathrm{min})$ & $0.023 \pm 0.007$ & $0.056 \pm 0.015$ & $0.064 \pm 0.018 *$ \\
\hline
\end{tabular}

* = p 0.05 (Wilcoxon matched-pairs signed-ranks test with Bonferroni correction for repeated comparisons) Abbreviations are explained in the text.

Table II. Hemodynamic variables ( \pm SEM) compared to control value ( \pm SEM) at I and 3 mintutes after an intravenous bolus of 5 microgram angiotensin $I I$ in 8 fetal sheep. The values of the PIumb and the Plcot are obtained in 5 and 6 sheep respectively.

\begin{tabular}{|c|c|c|c|}
\hline Variable & Control & Vallue at 1 minute & Value at 3 minutes \\
\hline Plumb $(n=5)$ & $1.04 \pm 0.17$ & $0.95 \pm 0.14$ & $1.46 \pm 0.27$ \\
\hline PICot $(n=6)$ & $1.31 \pm 0.27$ & $1.70 \pm 0.60$ & $1.97 \pm 0.83$ \\
\hline FHR (beats/min) & $182 \pm 7$ & $196 \pm 7$ & $164 \pm 12$ \\
\hline QUA (ml/min) & $338 \pm 64$ & $305 \pm 75$ & $210 \pm 79 *$ \\
\hline Pa.nor (mmHg) & $41.0 \pm 1.5$ & $57.1 \pm 2.0^{*}$ & $49.4 \pm 1.2^{*}$ \\
\hline Pa.col (mmHg) & $26.1 \pm 1.7$ & $38.2 \pm 1.7^{*}$ & $24.4 \pm 2.0$ \\
\hline Pv.cot (mmHg) & $10.6 \pm 0.8$ & $13.1 \pm 0.8$ & $11.7 \pm 0.7$ \\
\hline Pv.cav: (mml-Hg) & $3.8 \pm 0.6$ & $6.6 \pm 1.1^{*}$ & $5.7 \pm 1.2$ \\
\hline Pa.aor-Pa.col (mmHg) & $14.9 \pm 2.4$ & $18.9 \pm 2.9$ & $25.0 \pm 2.5^{*}$ \\
\hline Pa.cot-Pr.col (mmHg) & $15.5 \pm 2.2$ & $25.0 \pm 1.6^{*}$ & $12.7 \pm 2.0$ \\
\hline Pv.col-Pw.caw (mmHg) & $6.7 \pm 0.5$ & $6.4 \pm 1.3$ & $6.0 \pm 1.4$ \\
\hline $\mathrm{R} /(\mathrm{mmH} / \mathrm{g} / \mathrm{ml} / \mathrm{min})$ & $0.052 \pm 0.008$ & $0.085 \pm 0.021$ & $0.268 \pm 0.119^{*}$ \\
\hline $\mathrm{R} 2(\mathrm{mmHg} / \mathrm{ml} / \mathrm{min})$ & $0.069 \pm 0.022$ & $0.134 \pm 0.033$ & $0.136 \pm 0.056$ \\
\hline $\mathrm{R} 3(\mathrm{mmHg} / \mathrm{ml} / \mathrm{min})$ & $0.027 \pm 0.007$ & $0.034 \pm 0.009$ & $0.090 \pm 0.042$ \\
\hline
\end{tabular}

* = p $<0.05$ (Wilcoxon matched-pairs signed-ranks rest with Bonferroni correction for repeated comparisons) Abbreviations are explained in the text. 

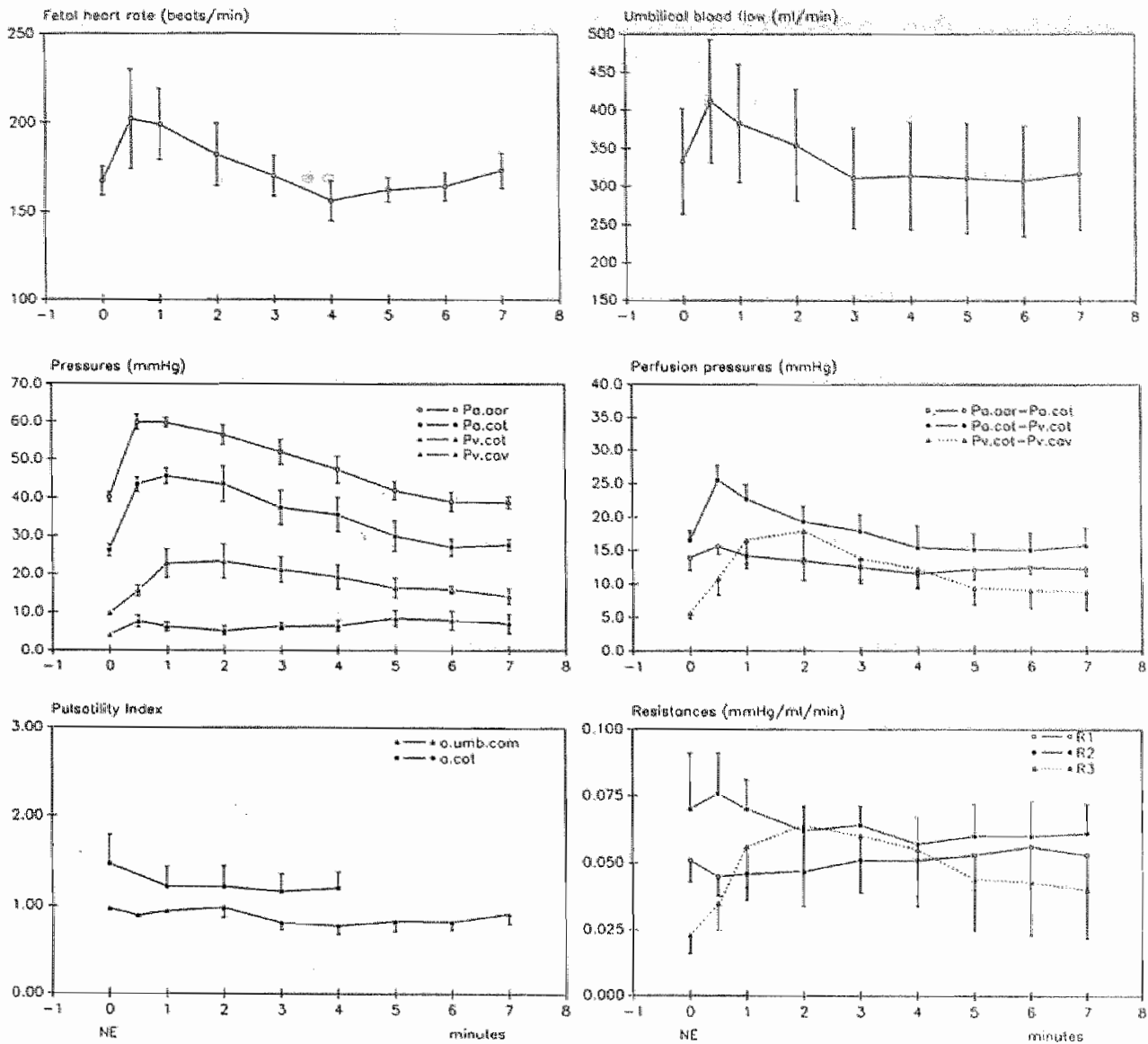

Figure 1 " The course of the variables under study after intravenous injection of 10 micrograms norepinephrine. Control vallues are depicted at 0 minutes. Erron bars represent standard error of the mean.

0.07 , whereas the mean of the cotyledonary artery PI was 1.34 \pm 0.40 . The difference between the two values was not significant (Student t-test).

\section{Norepinephrine administration (NE)}

The response of the cardiovascular variables and both umbilical artery pulsatility indices upon 10 micrograms norepinephrine bolus injection are listed in table I. Figure 1. depicts the reactions of the various variables to norepinephrine as a function of time. Norepinephrine was given in 7 fetal lambs and caused a marked pressor response. Mean aortic blood pressure 
increased with $48 \%$ to $59.7 \pm 1.2 \mathrm{mmHg}$ and cotyledonary artery pressure with $71 \%$ to $45.5 \pm 2.0 \mathrm{mmHg}$ at 1 minute after the NE bolus $(p<0.05)$. Cotyledonary venous pressure increased significantly with $142 \%$ to $23.5 \pm 3.8 \mathrm{mmHg}$ at peak response $(p<0.05)$; this maximum response was noted at $2 \mathrm{~min}$. after NE. After the peak response a slow decline in aortic pressure occurred, in parallel with the decline in cotyledonary artery pressure and cotyledonary venous pressure. Inferior vena cava pressure did not change (fig.1, left middle panel). The fetal heart rate (FHR) response to NE differed in the various animals: in 5 animals a slight tachycardia was observed directly after $\mathrm{NE}$, with return to baseline values at 3 min after NE. In 2 animals a mild bradycardia was noted following $\mathrm{NE}$. "The mean values did not significantly differ from control (fig. 1, left top panel). Umbilical blood flow (QUA) did not alter during the experiment (fig.1, right top panel). The pressure differences between mean aortic pressure and cotyledonary arterial pressure (umbilical artery perfusion pressure) were not different from control at 1 and $2 \mathrm{~min}$. after NE. Cotyledonary perfusion pressure (difference between cotyledonary arterial pressure and cotyledonary venous pressure) reached a short peak response immediately after $\mathrm{NE}$, but was not significantly different at $2 \mathrm{~min}$. after NE. On the other hand, umbilical venous perfusion pressure (difference between cotyledonary venous pressure and inferior vena cava pressure) significantly increased with $225 \%$ to $17.9 \pm 4.1$ $\mathrm{mmHg}(\mathrm{p}<0.05)$ at $2 \mathrm{~min}$. after $\mathrm{NE}$ (fig. 1 , right middle panel). This is also expressed in a significant increase in vascular resistance of the umbilical vein (R3) with $178 \%$ to $0.064 \pm$ $0.018 \mathrm{mmHg} / \mathrm{ml} / \mathrm{min}(\mathrm{p}<0.05)$ at $2 \mathrm{~min}$. after NE. Vascular resistances of the umbilical artery and cotyledonary microvasculature did not change (fig. 1, right lower panel).

Representative common umbilical artery waveforms as well as cotyledonary artery waveforms were obtained in 4 fetal lambs, because the Doppler transducers did not function properly in all lambs. These numbers do not allow statistical analysis. No change occurred in the mean values of the PI of the common umbilical artery, nor in the PI of the cotyledonary artery in 4 fetuses (fig.1, left lower panel).

\section{Angiotensin II (AII) administration}

The cardiovascular data during control and at 1 and $3 \mathrm{~min}$. after 5 microgram angiotensin II are listed in table II. Figure 2 illustrates the hemodynamic changes graphically as a func- 
tion of time. The mean values of the fetal heart rate after AII did not significantly differ from control (fig 2 , left upper panel). Umbilical blood flow was reduced with $36 \%$ at 3 minutes after the AII bollus $(p<0.05$ ) (fig. 2 , right upper panel and table III). Mean aortic pressure and cotyledonary artery pressule reached peak-value at 1 min. alter AII. Mean arterial pressure was increased with $39 \%$ to $57.1 \pm 2.0 \mathrm{mmHg}(\mathrm{p}<0.05)$ and cotyledonary artery pressure with $46 \%$ to $38.2 \pm 1.7$ $\mathrm{mmHg}(\mathrm{p}<0.05)$. A small rise in central venous pressure was noted at $1 \mathrm{~min}$. after AII $(\mathrm{p}<0.05)$, which did not differ from
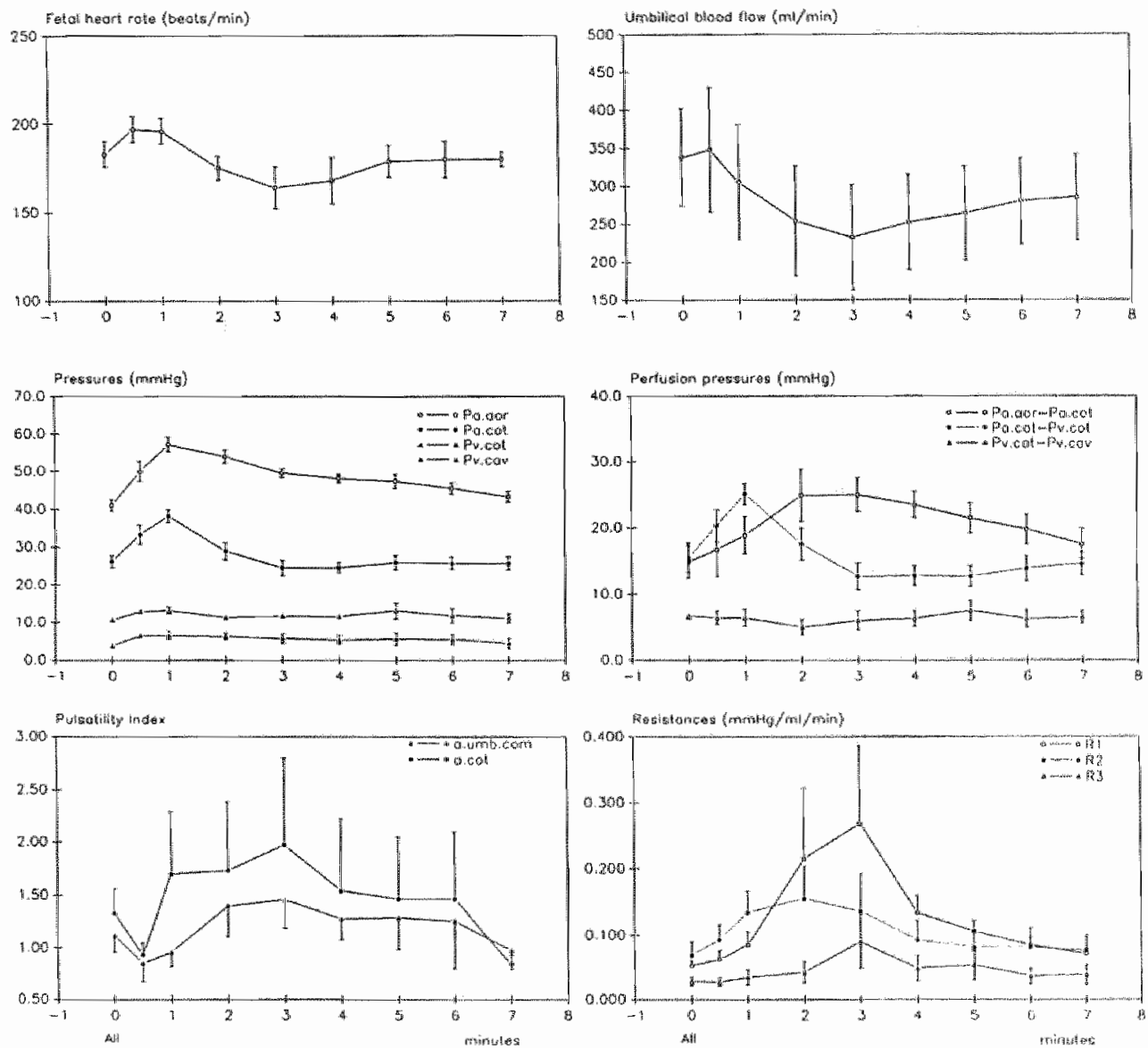

Figure 2. The course of the variables under study after intravenous injection of 5 micrograms angiotensin II. Control values are depicted at 0 minutes. Error bars represent standard error of the mean. 
control at $2 \mathrm{~min}$. Umbilical venous pressure did not change (fig.2, left middle panel); in contrast to the rise observed after NE. The difference between mean aortic pressure and cotyledonary artery pressure increased during the decline in both pressures after the peak response: umbilical arterial perfusion pressure (Pa.aor-Pa.cot) was significantly increased with $68 \%$ to $25.0 \pm 2.5 \mathrm{mmHg}(\mathrm{p}<0.05)$ at $3 \mathrm{~min}$. after AII (fig.2, right middle panel). Vascular resistance of the umbilical artery (R1) was therefore increased more than 5 -fold to $0.268 \pm 0.119$ $\mathrm{mmHg} / \mathrm{ml} / \mathrm{min}(\mathrm{p}<0.05$ ) (fig.2, right lower panel and table III). Cotyledonary perfusion pressure increased initially, but was not significantly changed at $3 \mathrm{~min}$. after AII (fig.2, right middle panel). The 2 -fold increase in cotyledonary resistance (R2) was not significant at $3 \mathrm{~min}$. (fig.2, right lower panel and table III). In contrast to the response after NE, no significant change was observed in umbilical venous perfusion pressure (Pv.cot-Pv.cav) (fig.2, right middle panel) and the vascular resistance of the umbilical vein (R3) (fig.2, right lower panel and table III).

After angiotensin II injection we were able to obtain representative waveforms of the common umbilical artery in 5 animals and of the cotyledonary artery in 7 animals although in 2 animals signals were not obtained continuously during the experiment (table III). The PI of the common umbilical artery (PIumb) increased in 4 animals with maximum values

Table III. Percentage change of control of Plumb, PIcot, QUA and resistances at 3 min. after 5 micrograms angiotensin ll bolus.

\begin{tabular}{lrrrrrr}
\hline & Plumb & Plcot & QUA & R1 & \multicolumn{1}{c}{$\mathrm{R} 2$} & \multicolumn{1}{c}{$\mathrm{R3}$} \\
\hline Animal 1 & $35 \% \uparrow$ & $600 \% \uparrow$ & $33 \% \downarrow$ & $165 \% \uparrow$ & $8 \% \uparrow$ & $44 \% \uparrow$ \\
Animal 2 & $32 \% \downarrow$ & $160 \% \uparrow$ & $67 \% \downarrow$ & $475 \% \uparrow$ & $138 \% \uparrow$ & $562 \% \uparrow$ \\
Animal 3 & $179 \% \uparrow$ & $32 \% \downarrow$ & $32 \% \downarrow$ & $273 \% \uparrow$ & $248 \% \uparrow$ & $100 \% \downarrow$ \\
Animal 4 & - & $27 \% \uparrow$ & $18 \% \uparrow$ & $51 \% \uparrow$ & $30 \% \downarrow$ & $81 \% \downarrow$ \\
Animal 5 & - & $40 \% \downarrow$ & $2 \% \downarrow$ & $14 \% \uparrow$ & $15 \% \uparrow$ & $18 \% \downarrow$ \\
Animal 6 & $35 \% \uparrow$ & - & $92 \% \downarrow$ & $3660 \% \uparrow$ & $169 \% \uparrow$ & $1365 \% \uparrow$ \\
Animal 7 & $16 \% \uparrow$ & $23 \% \downarrow$ & $24 \% \downarrow$ & $45 \% \uparrow$ & $4 \% \downarrow$ & $0 \%$ \\
Animal 8 & - & $30 \% \downarrow$ & $23 \% \downarrow$ & $62 \% \uparrow$ & $17 \% \uparrow$ & $16 \% \downarrow$ \\
\hline
\end{tabular}

The value of Plcot in anmal 2 is given at I min after All, since signals were lost afterwards. $R I=$ umbilical artery vascular resistance, $R 2=$ coryledonary vascular resistance, $R 3=$ umbilical venous vacular resistance. An increase is indicated with the arrow spwards and a decrease with the arrow downwards. 
at 2-3 minutes after AII, but decreased in 1 animal. The responses of the PI of the cotyledonary (PIcot) artery to angiotensin II were very inconsistent. The PI decreased slightly in 4 animals, but increased in the other 3 animals, to such a degree that in 2 cases negative end-diastolic flow velocities were observed.

\section{Discussion}

The results of the present study confirm that norepinephrine and angiotensin II exert their action on different sites of the umbilicoplacental circulation (6). Pressures were measured at 4 different sites of the umbilicoplacental circulation and hence the pressure differences and respective vascular resistances could be measured. Norepinephrine and angiotensin II both increased umbilical arterial pressure, but in contrast to angiotensin II, norepinephrine increased umbilical venous pressure as well. This suggests that norepinephrine actively constricts the umbilical vein or mediates a vasoconstriction of the umbilical vein. In cases of increased catecholamine release such as hypoxemia (17), this mechanism is likely to control umbilical blood flow, together with the redistribution of blood flow to high priority organs (18). An increase in umbilical venous pressure during hypoxemia was recently also demonstrated by Paulick et al. and our group $(10,19)$.

No changes were observed in the umbilical artery pulsatility index of the common umbilical artery and the cotyledonary artery after norepinephrine. Because of the limited number of representative blood velocity waveforms obtained after the NE bolus, conclusions regarding the pulsatility index in these vessels have to be drawn with caution.

Angiotensin II increased mean aortic pressure, but in contrast to norepinephrine, the pressor response in the cotyledonary artery did not parallel the pressure change in the aorta. The difference between the change of these pressures resulted in a marked increase in umbilical artery perfusion pressure. It follows from the concomitant drop in umbilical blood flow and the increase in umbilical artery resistance, that AII leads to vasoconstriction of the umbilical artery $(6,11,20)$. Since umbilical artery vascular resistance (R1) increased in all animals after angiotensin II, we expected also an increase of the umbilical and cotyledonary artery pulsatility index. This was however not a consistent finding (table III). After AII the 
umbilical artery vascular resistance increased in all animals, which was associated with a rise in umbilical artery PI in 4 of the 5 animals. The magnitude of the change in PI however, was not proportional to the changes in umbilical blood flow and/or changes in the vascular resistances. Furthermore, in animal 2 a $67 \%$ drop in umbilical blood flow and a marked rise in vascular resistances was accompanied by a $32 \%$ decrease in Plumb.

The rise in umbilical artery resistance and decrease in umbilical blood flow was not followed by a consistent rise in cotyledonary artery PI. A speculative explanation for this phenomenon could be a difference in release in the individual cotyledons of locally produced vasodilator prostaglandins, which have been shown to attenuate the angiotensin II response in perfused human cotyledons (21). Adamson et al. and Clark et al. observed no changes in the shape of the umbilical flow or velocity waveform and the $S / D$ ratio respectively in response to $\mathrm{AII}$, although their observations mainly were done on flow waveforms $(22,23)$.

In pre-eclampsia elevated levels of circulating angiotensin II are found in fetal umbilical wenous blood (24). It is also known that a relative deficiency exists of vasodilator prostaglandins in pre-eclampsia (25). One could speculate that a diminished attenuation of angiotensin II induced vasoconstriction by vasodilator prostaglandins in the cotyledonary small arteries can provoke reduced end-diastolic flow velocities of the umbilical artery. Improvement of this situation might be an explanation for the return of previously zero- or reversed end-diastolic flow velocities of the umbilical artery as observed by Hanretty et al. and Brar et al.(26,27). Moreover, aspirin therapy in patients with placental insufficiency and previous high systolic/diastolic ratios, seems to have a beneficial effect on umbilical artery flow velocity waveforms (28).

We conclude that angiotensin II induces vasoconstriction of the umbilical artery, resulting in decreased umbilical blood flow, which is associated with a rise in common umbilical artery PI. Increased umbilical artery resistance has no consistent effect on the cotyledonary artery pulsatility index. Norepinephrine exerts its vasoconstrictive effect on the umbilical vein and does not influence umbilical blood flow. The umbilical and cotyledonary artery pulsatility indices are not affected by an increase in umbilical venous resistance. 


\section{References}

1 McCallum WD, Williams CS, Napel S, Daigle RE. Fetall blood velocity waveforms. Am J Obstet Gynecol 1978;132:425 9.

2 Woo JSK, Liang ST, Lo RLS. Signficance of an absent or reversed diastolic flow in Doppler umbilical artery waveforms. I Ultrasound Med 1987;6:291-7.

3 Giles WB, Trudinger BJ, Baird PJ. Fetal umbilical artery flow velocity waveforms and placental resistance: pathological correlation. $\mathrm{Br} J$ Obstet Gynaecol 1985;92:31-8

4 van Vugt JMG, Ruissen CJ, Hoogland HJ, de Haan J. A prospective study of the umbilical artery waveform in appropriate-for-date and growth-retarded fetuses. Gynecol Obstet Invest 1987;23:217-25.

5 Dempster J, Mires GJ, Patel N, Taylor DJ. Umbilical artery velocity waveforms: poor association with small-for-gestational-age babies. $\mathrm{Br}$ J Obstet Gynaecol 1989;96:692-6.

6 Adamson SL, Morrow RJ, Bull SB, Langille BL. Vasomotor responses of the umbilical circulation in fetal sheep. Am J Physiol 1989;256: R1056-62.

7 Robillard JE, Weitzman RE, Burmeister L, Smith. Jr FG. Developmen tal aspects of the renal response to hypoxemia in the lamb fetus. Circ Res 1981;48:128-38.

8 Iwamoto HS, Rudolph AM. Role of renin-angiotensin system in response to hemorrhage in fetal sheep. Am J Physiol 1981;240:H848-54.

9 Robillard JE, Gomez RA, Meernik JG, Kuehl WD, VanOrden D. Role of angiotensin II on the adrenal and vascular responses to hemorrhage during development in fetal lambs. Circ Res 1982;50:645-50.

10 van Huisseling H, Hasaart THM, Mujjsers GJJM, de Haan J. Fetal hypertension induced by norepinephrine infusion and the umbilical artery velocity waveform in fetal sheep. Abstract 315] In: Proceedings of the 37 th annual meeting of the Sociaty for Gynecologic Investigation, St.Loüs, Missouri, march $21-25,1990$.

11 Berman $\mathrm{jr}$ W, Goodlin RC, Heymann MA, Rudolph AM. Effect of pharmacologic agents on umbilical blood flow in fetal lambs in utero. Biol Neonate 1978;33:225-35.

12 Tulenko TN. Regional sensitivity to vasoactiv polypeptides in the human umbilicoplacental vasculature. Am J Obstet Gynecol 1979; 135:629-36.

13 Dawes GS. The umbilical circulation. Am obstet Gynecol 1962; 84:1634-48.

14 Ruissen CJ, van Vugt JMG, Hoogland HJ, Hoeks $A P G$, de Haan J. Technical aspects of fetal Doppler measurements. Gymec Obstet Invest $1987 ; 24: 1-13$. 
15 Coshing $\mathrm{RG}$, Dunbar $\mathrm{G}$, King DH, et al. The quantitative analysis of occlusive peripheral arterial disease by a non-intrusive ultrasonic technique. Angiology 1971;22:52-5.

16 Wallenstein $\mathbf{S}$, Zucker $C L$, Fleiss JL. Some statistical methods useful in circulation research. Circ Res 1980;,47:1-9.

17 Jomes CT, Robinson RO. Plasma catecholamines in fetal and adult sheep. J Physiol 1975;248:15-33.

18 Peetergi LIH, Sheldon RE, Jones Jr MD, Makowski EI, Meschia G. Blood flow to fetal organs as a function of arterial oxygen content. Am J Obst Gynecol 1979;135:637-46.

19 Paulick RP, Meyers RL, Rudolph CD, Rudolph AM. Venous responses to hypoxemia in the fetal lamb. (Abstract no.311) in: Proceedings of the Society for Gynecologic Investigation, St. Louis, Missouri, March $21 \cdot 24,1990$.

20 Iwamoto HS, Rudolph AM. Effects of angriotensin II on the blood flow and its distribution in fetal lambs. Circ Res 1981;48:183-9.

21. Glance $\mathrm{DG}$, Elder $\mathrm{MG}_{\text {, }}$ Myatt $\mathrm{L}$. The actions of prostaglandins and their interactions with angiotensin II in the isolated perfused human placental cotyledon. Br J Obstet Gynaecol 1986;93:488-94.

22 Adamson SL, Morrow RJ, Langille BL, Bull SB, Ritchie JWK. Site-dependent effects of increases in placental vascular resistance on the umbilical artery velocity waveform in fetal sheep. Ultrasound Med Biol $1990 ; 16: 19-27$.

23 Clark KE, Mack C, Myatt L, Brockman D. Umbilical wascular effects of angiotensin II and norepinephrine: Release of prostaglandins and effect on systolic/diastolic ratios. [Abstract no. 137】 In: Proceedings of the 36th annual meeting of the Society for Gynecologic Investigation, San Diego, California, march 15-18,1989.

24 Broughton-Pipkin F, Symonds EM. Factors affecting angiotensin II concentrations in the human infant at birth. Clin Sci Mol Med 1977; $52: 449 \cdot 56$.

25 Mäkila VM, Jouppila P, Kirkinen P, Viinika L, Ylikorkala O. Relation between umbilical prostacyclin production and blood flow in the fetus. Lancet $1983 ; 7 ; 728-9$.

26 Hanretty $\mathrm{KP}$, Whittle $\mathrm{MJ}$, Rubin PC. Reappearance of end diastolic veloxity in a pregnancy complicated by severe pregnancy induced hypertension. Am J Obstet Gynecol 1988;158:1123-4.

27 Bra HS, Platt LD. Antepartum improvement of abnormal umbilical artery velocimetry: Does it occur? Am $\mathbb{J}$ Obstet Gynecol 1989;160:36-9.

28 Trudinger BJ, Cook CM, Thompson RS, Giles WB, Connelly A. Lowdose aspirin therapy improves fetal weight in umbilical placental insufficiency. Am J Obstet Gynecol 1988;159:681-5. 


\section{Summary and conclusions}

The non-invasive character of umbilical artery blood velocity waveform analysis enables the obstetrician to obtain information on the circulatory competence of the placenta. However, the initial high expectations of this method waned during the past decade. Critical studies have been published, showing no additional benefit of umbilical artery velocimetry in predicting intra-uterine growth retardation and/or fetal distress. It is assumed that an increased umbilical artery pulsatility index is associated with increased placental vascular resistance. Angle-independent indices, such as the pulsatility index (PI), are believed to express the vascular resistance downstream of the site of measurement. To what extent other hemodynamic factors contribute to changes in the umbilical artery blood velocity waveform, is poorly understood. The aim of the present study was to investigate the relationship between the umbilical artery pulsatility index and placental vascular resistance during various altered hemodynamic states in the ewe and fetal lamb. In chapter I a short introduction is given on the fetal circulation, with special reference to placental vascular resistance.

The relationship was evaluated, between the umbilical artery PI and fetal hemodynamic variables such as placental perfusion pressure, fetal heart rate, umbilical blood flow and placental vascular resistance. To this end, shortlasting changes in the fetal circulation were induced by means transient occlusions of the maternal common iliac artery, which induces acute fetal hypoxemia and a vagal-mediated fetal heart rate deceleration. The results are presented in chapter II. During the heart rate deceleration no change in placental vascular resistance was observed, whereas the umbilical artery PI significantly increased. After atropine fetal heart rate, placental vascular resistance and the umbilical artery PI did not change during occlusion. It was concluded that the observed change in umbilical artery PI during acute hypoxemia is associated with the change in fetal heart rate and is not related to placental vascular resistance in this experimental set-up. 
A prolonged cardiac cycle during slower heart rates results in a lower value of end diastolic velocities and therefore in an mcrease in pulsatility index.

Compression of the inferior vena cava in late human pregnancy has been reported to decrease intervillous blood flow and to be associated with elevated umbilical artery $S / D$ ratios.

In chapter III a study is presented in which the hypothesis was tested that compression of the maternal inferior vena cavat increases the umbilical artery PI on the basis of increased placental vascular resistance. To this end short-lasting occlusions of the maternal inferior vena cava were performed. Occlusion of the maternal vena cava resulted in a decrease in fetal heart rate, with a concomitant rise in placental vascular resistance and umbilical artery PI. In a previous study, discussed in chapter II, it has been noted that bradycardia increases the umbilical artery PI, therefore the experiments were repeated after parasympathetic blockade with atropine. After atropine, fetal heart rate did not change during occlusion while placental vascular resistance increased, as well as the umbilical artery PI. These results support the hypothesis that placental vascular resistance is one of the determinants ot the umbilical artery PI in fetal sheep.

Elevated fetal catecholamine levels have been shown to be present in cases of fetal stress, and are known to cause hypertension. Whether fetal hypertension influences the umbilical artery PI is not known. Whether norepinephrine increases placental vascular resistance is controversial. In chapter IV the results are presented of the effect of norepinephrine infusion on fetal hemodynamic variables and the umbilical artery PI. Norepinephrine infusion raised the mean arterial blood pressure in the fetal lamb and provoked a transient bradycardia. Placental perfusion pressure did not change during the norepinephrine infusion, since a significant rise in umbilical venous pressure was observed. Umbilical blood flow, placental vascular resistance, as well as the umbilical artery PI did not alter. After cholinergic blockade with atropine, the norepinephrine induced rise in arterial and umbilical venous pressures was accompanied by a tachycardia and a rise in umbilical blood flow, but no change in placental vascular resistance and umbilical artery PI. It was concluded that fetal hypertension, induced by norepinephrine infusion, does not affect placental vascular resistance, nor the umbilical artery PI. The observed 
rise in umbilical venous pressure during norepinephrine infusion may be functional in cases of fetal stress. Recently it was observed that during fetal hypoxemia, umbilical venous pressure close to the placenta was increased. The present study indicates that norepinephrine may mediate the umbilical venous response to hypoxemia.

In the literature negative correlations are reported between the degree of hypoxemia in the human fetus and increased umbilical blood velocity indices. Controversy exists whether hypoxemia may change placental vascular resistance. Chapter $\mathbf{V}$ deals with the effects of fetal hypoxemia, induced by maternal hypoxemia, on the umbilical artery PI and placental vascular resistance in the fetal lamb. When the fetal cardiovascular variables during deepest hypoxemia are compared with control values, a significant rise in umbilical blood flow was noticed, whilst placentall vascular resistance and umbilical artery PI showed no change. Linear regression analysis of the individual animals however, showed a significant inverse correlation of umbilical venous blood pressure, whereas placental vascular resistance had a positive correlation with actual arterial oxygen content. Since fetal hypoxemia is known to be associated with increased levels of catecholamines, these are very likely the cause of the increase in umbilical venous pressure, as we have shown in chapter IV. It is concluded that the blood velocity waveform of the umbilical artery does not reflect acute changes in fetal oxygenation.

Intravascular transfusion for fetal hemolytic disease has been reported to be associated with an increase or no change in umbilical artery blood velocity indices. Changes in blood volume have been shown to affect cardiac output. Fetal hemorrhage causes a decrease in cardiac output and hypotension. In chapter VI the results of the effects of acute changes in fetal circulating blood volume on the umbilical artery PI are presented. It was shown that an $11-15 \%$ increase in blood volume elevated arterial and umbilical venous pressure, with no effect on umbilical blood flow, placental vascular resistance or umbilical artery PI. The acute effect of an 11-15\% decrease in fetal circulating blood volume was a marked rise in the umbilical artery PI. A concomitant decrease in fetal heart rate, umbilical blood flow, arterial and umbilical venous pressure was observed, with no change in placental vascular resistance. The reason for the rise in umbilical artery $\mathrm{PI}$ is believed to be 
associated with the hypotension in addition to the decrease in fetal heart rate. In this study evidence is provided that increased umbilical artery blood velocity indices are not necessarily related to placental vascular pathology, but may be a sign of fetal hypotension.

Angiotensin II and norepinephrine have been reported to play an important role in controlling umbilical vasomotor tone by exerting their constrictive effects on the umbilical artery and vein respectively. The effects of resistance changes in different parts of the umbilical placental vascular bed on the proximal and distal umbilical artery PI were studied. Doppler transducers were placed on the common umbilical artery and a cotyledonary artery. Resistances were changed by intravenous bolus injections of angiotensin II and norepinephrine in the anesthesized fetal lamb. The results are presented in chapter VII. Norepinephrine injection resulted in a rise in umbilical venous resistance, with no changes in umbilical blood flow, umbilical artery resistance and PI, and cotyledonary resistance and cotyledonary artery PI. Angiotensin II injection provoked a 5-fold increase in umbilical artery resistance with a decrease in umbilical blood flow. The constriction of the umbilical artery by angiotensin II appears to be associated with an increase in umbilical artery PI, but resulted in inconsistent changes in the cotyledonary artery PI. Vasodilator prostaglandins have been shown to attenuate the angiotensin II response in perfused human cotelydons. It was suggested that a difference in release of these locally produced vasodilator prostaglandins may account for the observed inconsistent changes in the cotyledonary artery PI.

The results of the presented studies in the fetal sheep indicate that umbilical artery velocimetry has been prematurely introduced into clinical practice. No changes in the umbilical artery pulsatility index were observed during fetal hypoxemic stress, as shown in chapters II and V. During some experiments (chapters IV, V and VI) the baseline $\mathrm{pO}_{2}$ values were low, but as was shown in chapters II and V, even superimposed hypoxemia did not alter the umbilical artery PI. No changes in the umbilical artery PI were observed during fetal hypertensive states as with norepinephrine infusion (chapters IV and VII) and hypervolemia (chapter VI). Increased values of the umbilical artery PI were observed during bradycardia (chapter II), during maternal inferior vena cava obstruction 
(chapter III), after acute hemorrhage (chapter VI) and in some cases after angiotensin II injection (chapter VII). The relationship between elevated umbilical artery PI's and increased placental vascular resistance was shown in chapter III. Increased placental vascular resistance is however not necessarily associated with an elevated umbilical artery $\mathrm{PI}$, as shown in chapter VII. Moreover, elevated umbilical artery PIs were observed without any change in placental vascular resistance (chapters II and VI). 
$i$

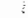




\section{Samenvatting en conclusies}

Golfvormanalyse van de bloedstroomsnelheden van de arteria umbilicalis door middel van de non-invasieve Doppler methode maakt het voor de obstetricus mogelijk gegevens te verkrijgen omtrent de circulatie van foetus en placenta.

De aanvankelijk hoge verwachtingen van deze methode zijn de laatste jaren wat afgenomen na kritische publicaties, die lieten zien dat analyse van de bloedstroomsnelheids-patronen van de arteria umbilicalis geen voordelen biedt in het voorspellen van intra-uteriene groeivertraging en/of foetale nood. Parameters zoals de pulsatility index (PI) en de S/D ratio, worden geacht uitdrukking te geven aan de vatweerstand distaal van het meetpunt. In vele publicaties wordt bij voorbaat aangenomen dat een verhoogde pulsatility index van de arteria umbilicalis gerelateerd is aan een verhoogde placentaire vaatweerstand. Dit is echter nooit bewezen, daar het meten van placentaire vaatweerstand bij de mens invasieve technieken vereist.

In welke mate andere foetale hemodynamische factoren bijdragen aan de veranderingen in de golfvorm van de bloedstroomsnelheden in de arteria umbilicalis, is nauwelijks onderzocht.

Het doel van dit onderzoek was de relatie te onderzoeken tussen de pulsatility index van de arteria umbilicalis en de placentaire vaatweerstand onder verschillende hemodynamische condities in het schaap en het foetale lam. Hoofdstuk I geeft een korte introductie over de foetale circulatie, met speciale aandacht voor placentaire vaatweerstand.

In hoofdstuk II wordt de relatie beschreven tussen de PI van de arteria umbilicalis en foetale hemodynamische variabelen zoals de placentaire perfusiedruk, de foetale hartfrekwentie, de umbilicale bloeddoorstroming en de placentaire vaatweerstand. Hiertoe werden kortdurende veranderingen in de foetale circulatie bewerkstelligd, door middel van afklemming van de bloedtoevoer naar de baarmoeder. Deze occlusies van de maternale arteria iliaca interna communis induceren een acute foetale hypoxemie met een deceleratie van de foetale hartfrekwentie als gevolg van activatie van de chemoreceptoren. Tijdens de daling van de hartfrekwentie 
werd geen verandering in de placentaire vaatweerstand gemeten, terwijl de PI van de arteria umbilicalis significant steeg. $\mathrm{Na}$ voorafgaande atropine toediening aan het lam werd geen verandering waargenomen in de foetale hartfrekwentie, placentaire vaatweerstand en de PI tijdens occlusie. De conclusie is dat de waargenomen verandering in de PI van de arteria umbilicalis tijdens acute hypoxemie veroorzaakt wordt door de verandering in de foetale hartfrekwentie en niet gerelateerd is a an placentaire vaatweerstand. De verlengde cardiale cyclus tijdens lage hartfrekwenties resulteert in een lagere waarde van de eind-diastolische snelheden van het bloed, met als gevolg een stijging van de PI.

Compressie van de vena cava inferior door de zwangere uterus in de mens zou een daling van de intervilleuze bloeddoorstroming veroorzaken en een stijging van de $S / D$ ratio van de arteria umbilicalis. In hoofdstuk III wordt de hypothese getest, dat compressie van de maternale vena cava inferior een verhoging van de PI van de arteria umbilicalis veroorzaakt, op basis van een verhoogde placentaire vaatweerstand. Occlusie van de maternale vena cava inferior veroorzaakte een daling in de foetale hartfrekwentie met een gelijktijdige stijging van de placentaire vaatweerstand en van de PI van de arteria umbilicalis. In de studie, gepresenteerd in hoofdstuk II werd gezien dat bradycardie een stijging van de PI veroorzaakt. Daarom werden het experiment herhaald na parasympathische blokkade door middel van atropine. $\mathrm{Na}$ atropine werd geen verandering in hartfrekwentie gezien tijdens de occlusie, terwijl de placentaire vaatweerstand en de PI toenamen. De conclusie is dat de placentaire vaatweerstand een van de factoren is, die de PI van de arteria umbilicalis bepaald in het foetale lam.

Foetale stress gaat gepaard met verhoogde foetale catecholamine spiegels, waarvan bekend is dat ze een bloeddrukstijging veroorzaken. Het is echter niet bekend of foetale hypertensie invloed heeft op de PI van de arteria umbilicalis.

Tevens bestaat geen eenduidigheid over het effect van norepinephrine op de placentaire vaatweerstand. In hoofdstuk IV worden de resultaten gepresenteerd van het effect van noradrenaline toediening op de foetale hemodynamische variabelen en de PI van de arteria umbilicalis. Noradrenaline toediening veroorzaakte een stijging van de gemiddelde arteriële bloeddruk in het foetale lam en een voorbijgaande brady- 
cardie. Er werd geen verandering gezien in de placentaire perfusiedruk tijdens noradrenaline toediening, vanwege een significante stijging van de umbilicale veneuze druk. De um. bilicale bloeddoorstroming, de placentaire vaatweerstand, evenals de PI van de arteria umbilicalis, veranderden niet. $\mathrm{Na}$ cholinerge blokkade met atropine, werd naast de door noradrenaline veroorzaakte stijging van de arteriële en umbilicale veneuze druk, een tachycardie gezien en een toename van de umbilicale bloeddoorstroming, echter geen verandering in placentaire vaatweerstand en PI van de arteria umbilicalis. De conclusie is dat de door noradrenaline geinduceerde foetale hypertensie geen effect heeft op de placentaire vaatweerstand en evenmin op de PI van de arteria umbilicalis. De waargenomen drukstijging in de vena umbilicalis tijdens noradrenaline toediening suggereert dat de foetus de placentaire vaatweerstand onder meer kan reguleren middels vasoconstrictie van de arteria umbilicalis.

In de literatuur zijn negatieve correlaties gemeld tussen de mate van hypoxemie in de humane foetus en verhoogde umbilicale bloedstroomsnelheids-indices. Of hypoxemie de placentaire vaatweerstand kan veranderen is vooralsnog niet duidelijk. Hoofdstuk $V$ gaat over het effect van langer durende foetale hypoxemie op de PI van de arteria umbilicalis en de placentaire vaatweerstand. De foetale hypoxemie werd veroorzaakt door de ooi een zuurstof-arm gasmengsel te laten ademen. Tijdens de periode van diepste hypoxemie bleken de placentaire vaatweerstand en de $P I$ van de arteria umbilicalis niet te veranderen. Analyse van de gemeten waarden in de individuele dieren liet een negatieve correlatie zien van de umbilicale veneuze druk met het arteriële zuurstofgehalte, terwijl de placentaire vaatweerstand een positieve correlatie toonde met het zuurstofgehalte. Catecholamines, waarvan bekend is dat deze vrijkomen tijdens foetale hypoxemie, zijn waarschijnlijk de oorzaak van de drukstijging in de vena umbilicalis, zoals aangetoond in hoofdstuk IV. De conclusie is dat acute veranderingen in foetale oxygenatie niet weerspiegeld worden in veranderingen van de PI van de arteria umbilicalis.

Tijdens intravasculaire transfusie bij actief rhesusantagonisme is vastgesteld dat de bloedstroomsnelheids-indices van de arteria umbilicalis toenamen of niet veranderden. 
Veranderingen in het foetale bloedvolume hebben invloed op het hartminuutvolume. In hoofdstuk VI worden de resultaten gepresenteerd van de effecten van acute veranderingen in het circulerend bloedvolume op de PI van de arteria umbilicalis. Er werd aangetoond dat een vergroting van het foetale bloedvolume, een verhoging teweegbrengt in de arteriele en veneuze umbilicale druk, zonder een effect op de umbilicale bloeddoorstroming, placentaire vaatweerstand of PI van de arteria umbilicalis. Acute afname van het foetale circulerende bloedvolume, resulteerde in een duidelijke stijging van de PI van de arteria umbilicalis. Tegelijkertijd wordt een daling gezien van de foetale hartfrekwentie, de umbilicale bloeddoorstroming en de arterielle en veneuze umbilicale druk, echter geen verandering in de placentaire vaat weerstand. De stijging van de PI wordt voornamelijk verklaard door de opgetreden hypotensie. Verhoogde bloedstroomsnelheids- indices van de arteria umbilicalis zijn dus niet noodzakelijkerwijs gerelateerd aan placentaire vasculaire pathologie, maar kunnen een teken zijn van hypotensie.

Van angiotensine II en noradrenaline is beschreven dat deze een belangrijke rol spelen bij het in stand houden van de tonus van de umbilicale vaten, door hun respectievelijke constrictieve effect op de arteria en vena umbilicalis. In hoofdstuk VII worden de effecten beschreven van veranderingen in weerstand van de verschillende vasculaire trajecten van het placentaire bed op de PI van de arteria umbilicalis, zowel proximaal als distaal. Hiervoor werden Doppler transducers geplaatst op de arteria umbilicalis communis en op een arteria cotyledonaria. De weerstandsveranderingen werden teweeggebracht door intraveneuze toediening van angiotensine II en noradrenaline aan het lam. Noradrenaline toediening resulteerde in een toename van de umbilicale veneuze weerstand. Geen veranderingen vonden plaats in de umbilicale bloeddoorstroming, de weerstand en PI van zowel de arteria umbilicalis als van de arteria cotyledonaria. De weerstand in de arteria umbilicalis werd verhoogd door angiotensine II, met als gevolg een daling van de umbilicale bloeddoorstroming. Dit ging gepaard met een verhoging van de PI van de arteria umbilicalis communis. De veranderingen in de PI van de arteria cotyledonaria waren niet eenduidig, hetgeen mogelijk verklaard kan worden door verschillen in afgifte van lokaal geproduceerde vasodilatoire prostaglandines. 
In de hoofdstukken II en $V$ werd aangetoond dat korter en langer durende foetale hypoxemie geen veranderingen teweegbrengt in de PI van de arteria umbilicalis. Bij enkele experimenten (hoofdstukken IV, V, VI) werden lage uitgangswaarden van de $\mathrm{pO} 2$ van het arteriële navelstrengbloed gemeten. Echter, de mate van hypoxemie heeft geen invloed op de PI (hoofdstukken II en V). Geen veranderingen van de PI van de arteria umbilicalis werden gezien tijdens foetale hypertensie door noradrenaline toediening (hoofdstukken IV en VII) en door hypervolemie (hoofdstuk VI). Verhoogde PI waarden van de arteria umbilicalis werden gezien tijdens bradycardie (hoofdstuk II), tijdens occlusie van de maternale vena cava inferior (hoofdstuk III), na acute verbloeding (hoofdstuk VI), en in enkele gevallen na angiotensine infusie (hoofdstuk VII). De relatie tussen verhoogde PI's van de arteria umbilicalis en toegenomen placentaire vaatweerstand werd aangetoond in hoofdstuk III. Verhoogde placentaire vaatweerstand hoeft echter niet altijd te betekenen dat de PI van de arteria umbilicalis toeneemt, zoals aangetoond werd in hoofdstuk VII. Bovendien kan een stijging van de PI van de arteria umbilicalis worden waargenomen zonder dat de placentaire vaatweerstand is veranderd (hoofdstukken II en VI). De resultaten van de gepresenteerde studies geven aan dat analyse van de bloedsnelheids-patronen van de arteria umbilicalis te vroeg in de klinische obstetrie is geintroduceerd. 


\section{Curriculum Vitae}

28-9-1952 Geboren te Axel

1971 Eindexamen HBS-b aan het Petrus Canisius College te Alkmaar

1971-1972 Studie wis- en natuurkunde aan de Universiteit van Amsterdam

1972-1980 Studie geneeskunde aan de Universiteit van Amsterdam

1980 Artsexamen

1980-1982 Wisselassistentschap St. Antoniusziekenhuis te Sneek (Hoofd afd. chirurgie: Dr C. van Driel)

1982-1985 Tropenarts te Fulacunda, regio Quinara, Guinee-Bissau

1985 Agnio afdeling heelkunde Academisch Ziekenhuis Maastricht (Hoofd: Prof.Dr J. Greep)

1985-1986 Arts-assistent Vroedvrouwenschool te Heerlen (Dr F.J.M.E. Roumen en Dr P.X.J.M. Bouckaert)

1986-1990 Opleiding tot gynaecoloog in het Academisch Ziekenhuis Maastricht (Opleider: Prof.Dr J. de Haan)

1990-heden Opleiding tot gynaecoloog in het De Wever Ziekenhuis te Heerlen (Opleider: Dr J.E.G.M. Stoot) 